\title{
Alternating Ring-Opening Metathesis Polymerization Provides Easy Access to Functional and Fully Degradable Polymers
}

Francis O Boadi, ${ }^{1}$ Jingling Zhang, ${ }^{2}$ Xiaoxi Yu, ${ }^{1}$ Surita R Bhatia, ${ }^{1}$ and Nicole S Sampson ${ }^{1, *}$

${ }^{1}$ Department of Chemistry, Stony Brook University, Stony Brook, NY 11794-3400

${ }^{2}$ Department of Materials Science and Chemical Engineering, Stony Brook University, Stony Brook, NY 11794-2275

*To whom correspondence should be addressed: nicole.sampson@stonybrook.edu

\section{Contents}

Figure $\mathbf{S 1}{ }^{1} \mathrm{H}$ and ${ }^{13} \mathrm{C}$ NMR of prop-2-enyl hept-6-enoate .................................................. 4

Figure $\mathbf{S 2}{ }^{1} \mathrm{H}$ and ${ }^{13} \mathrm{C}$ NMR of monomer $\mathbf{2 b}$.................................................................... 4

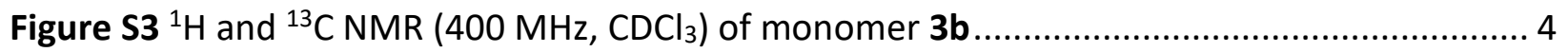

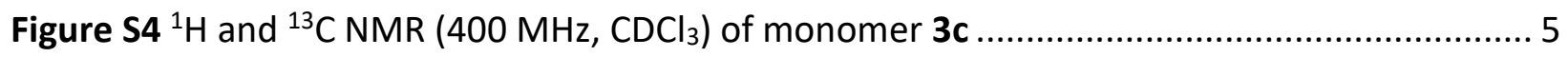

Figure S5 ${ }^{1} \mathrm{H}$ NMR of Monomer 2a before and after reacting with 0.1 equiv 5 for $24 \mathrm{~h}$.............. 5

Figure S6 Dioxepine 3a doesn't undergo ROMP but isomerizes to 3a' when treated with catalyst

5

Figure S7 Dioxepine 3c doesn't undergo ROMP but isomerizes to 3c' when treated with catalyst

5 7

Figure S8 Dioxepine 3b doesn't undergo ROMP and it rarely isomerizes to 3b' when treated with catalyst 5 8

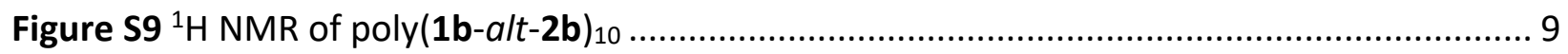

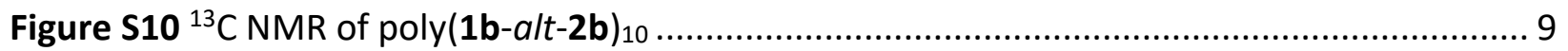

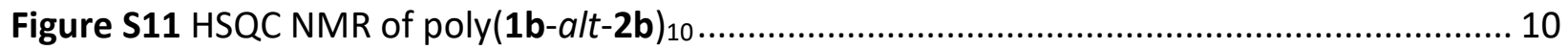

Figure S12 MALDI-TOF spectrum of poly(1a-alt-3a) ........................................................ 11

Figure S13 kinetics of incorporation of 3a in AROMP reaction with $1 \mathrm{a},(A){ }^{1} \mathrm{H} N M R,(B)$ a plot of unconsumed $\mathbf{3 b}$ vs. time. 12

Figure S14 kinetics of isomerization 3a to 3a', (A) ${ }^{1} \mathrm{H}$ NMR, (B) a plot of unconsumed $\mathbf{3 b}$ vs. time

Figure $\mathbf{S 1 5}{ }^{1} \mathrm{H}$ NMR kinetics of $\mathbf{3 b}$ treated with catalyst 5 (5 mol \%) in the presence of 1,4benzoquinone ( $26 \mathrm{~mol} \%),(A)$ without addition of 1,4-benzoquinone, (B) with addition of 1,4benzoquinone at various times.

Figure S16 ${ }^{1} \mathrm{H}$ NMR (left) and HSQC NMR (right) 1a-alt-3b copolymer, (A) prepared in the presence of 1,4-benzoquinone, (B) prepared without addition of benzoquinone ..................... 14

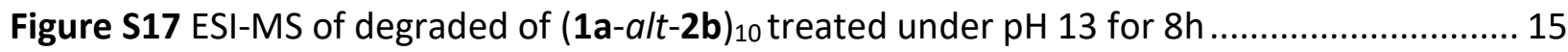


Figure S18 Selected region of ${ }^{1} \mathrm{H}$ NMR of poly(1a-alt-3a) $)_{20}$ treated with sodium phosphate buffer ( $\mathrm{pH} \mathrm{5)}$ at $37^{\circ} \mathrm{C}$. Hexylamine was added as a scavenging agent for formaldehyde if any is evolved from the polymer

Figure S19 ${ }^{1} \mathrm{H}$ NMR kinetics of the hydrolytic degradation of poly $(1 \mathbf{a}-a / t-3 \mathbf{b})_{20}$ at pH 5 and $37{ }^{\circ} \mathrm{C}$.

Figure S20 ESI-MS of hydrolytic mixture of (1a-alt-3b) 20 treated under $\mathrm{pH} 5$ for $30 \mathrm{~h}$. 18 Figure S21 ${ }^{1} \mathrm{H}$ NMR depicting block copolymer before and after hydrolysis, (I) poly(4)n, (II) diblock copolymer poly $(\mathbf{4})_{n}-b$-poly $(\mathbf{1 a - a l t - 3 a / b / c})_{m}$ before hydrolysis, (III) diblock copolymer poly $(4)_{n}-b$-poly $(\mathbf{1 a}-a / t-3 a / b / c)_{m}$ after treated with aqueous TFA, $\mathrm{pH} 1$, (III $\left.{ }^{\mathrm{a}}\right)$ diblock copolymer poly $(4)_{n}-b$-poly $(\mathbf{1 a}-a / t-3 a / b / c)_{m}$ after treated with sodium phosphate buffer , pH5...... 19 Figure S22 Discrete scanning calorimetry of acetal-based copolymers, poly(1a-alt-3) 50 . 3a (blue line), 3b (maroon line), 3c (red line), 6 (black line)................................................................ 20 Figure S23 Thermogravimetric analysis (TGA) of acetal-based and cyclohexene-based copolymers, 50mer. 3a (blue line), 3b (maroon line), 3c (red line), and $\mathbf{6}$ (black line). 21 Figure S24 Amplitude sweep of poly(1a-alt-3 $)_{50}$ and poly(1a-alt-6) $)_{50}$. solid dots, storage modulus $\left(G^{\prime}\right)$ : hollow dots, loss modulus $\left(G^{\prime \prime}\right)$. 22

Figure S25 Time sweep of poly $(\mathbf{1 a}-a / t-3)_{50}$ and poly $(\mathbf{1 a}-a / t-6)_{50}$. solid dots, storage modulus $\left(G^{\prime}\right)$ : hollow dots, loss modulus $\left(G^{\prime \prime}\right)$. 23

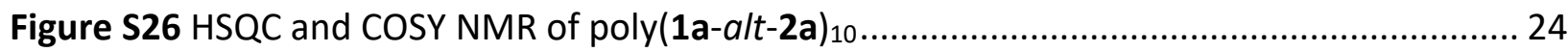

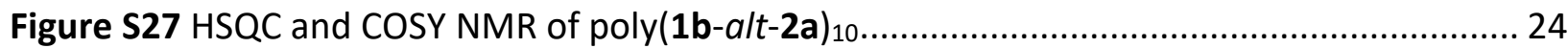

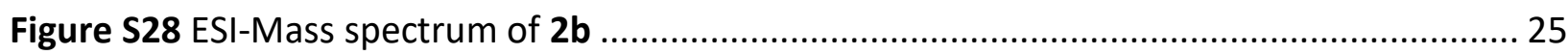

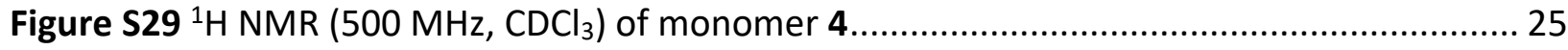

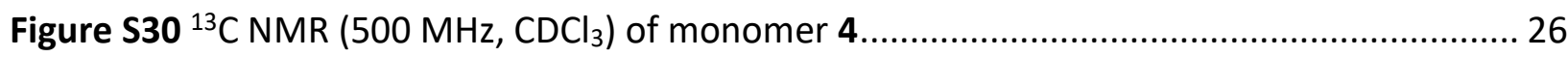

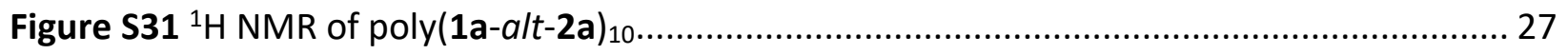

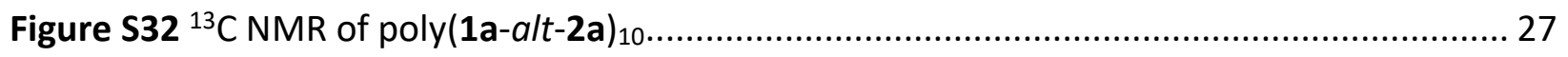

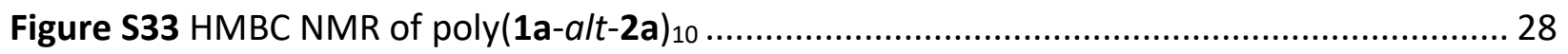

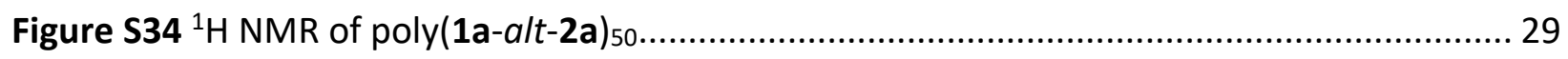

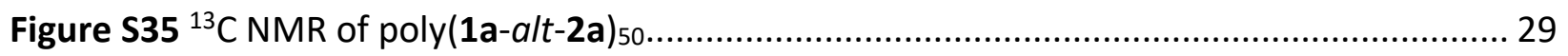

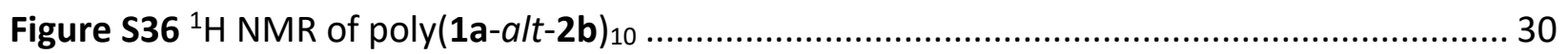

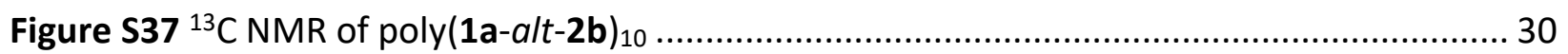

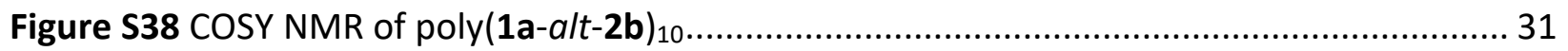

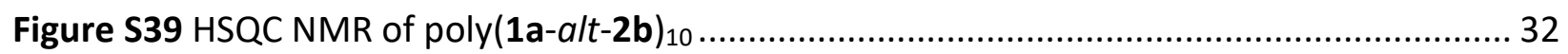

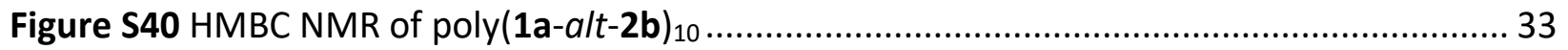

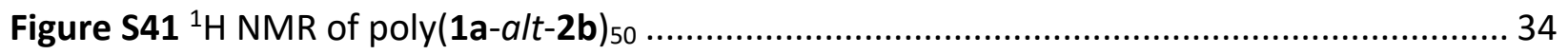

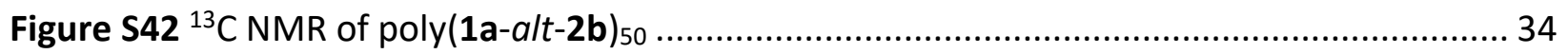

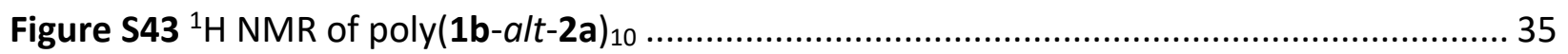

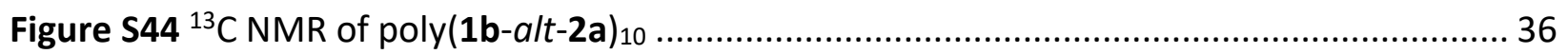

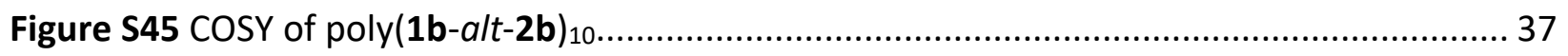

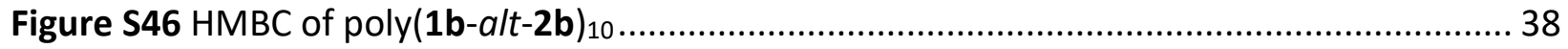

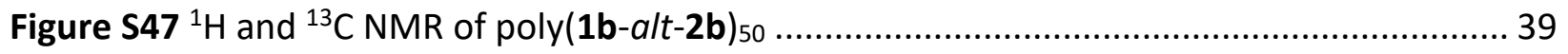

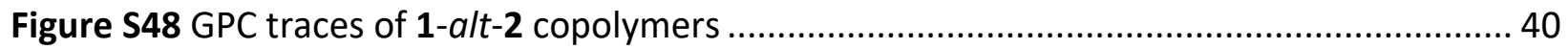


Figure S49 assigned ${ }^{1} \mathrm{H}-\mathrm{NMR}$ spectrum of 1a-alt-3a copolymer. Peak marked asterisked is artifact arising impurity in monomer $\mathbf{3 a}$. It is a singlet proton and does not arise from homoaddtion of $\mathbf{3 a}$.

Figure S50 ${ }^{13} \mathrm{C}$ NMR of 1a-alt-3a copolymer. Clearly, there 4 four major olefin carbons and 1 olefin isomer $\mathrm{C}^{\prime}$ ' 42

Figure S51 ${ }^{1} \mathrm{H}^{13} \mathrm{C}$ HSQC NMR of 1a-alt-3a copolymer ........................................................ 43

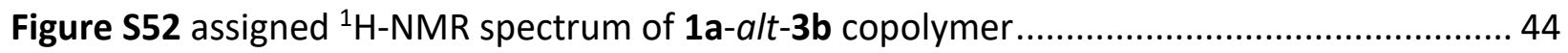

Figure S53 assigned ${ }^{1} \mathrm{H}-\mathrm{NMR}$ spectrum of 1a-alt-3c copolymer .............................................. 45

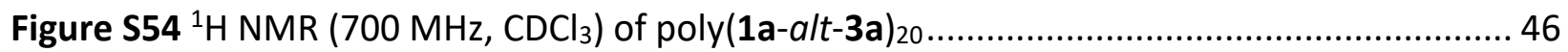

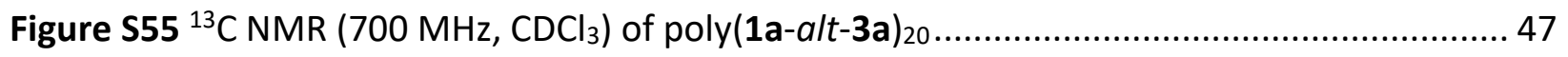

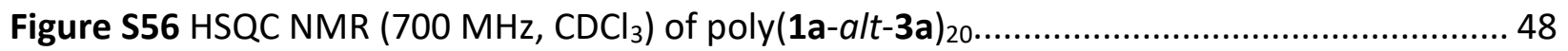

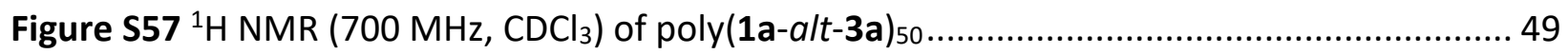

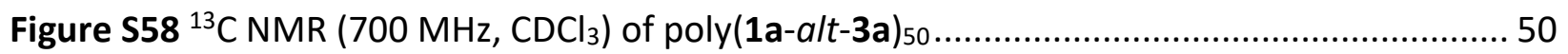

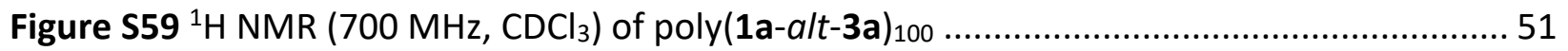

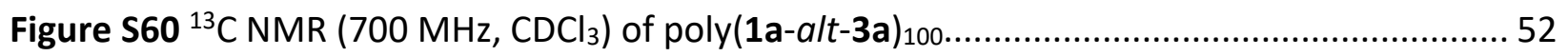

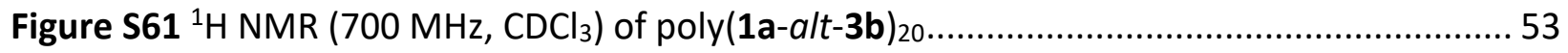

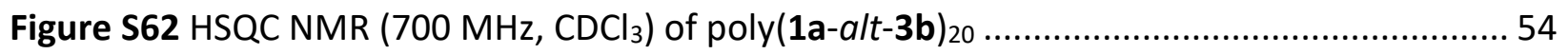

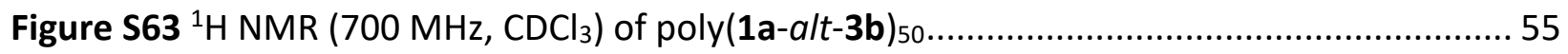

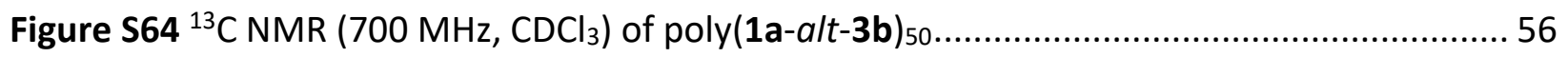

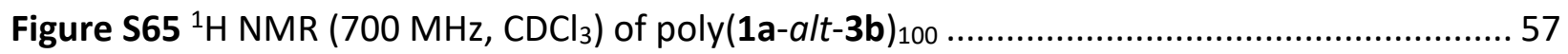

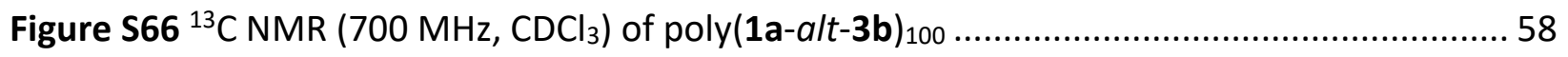

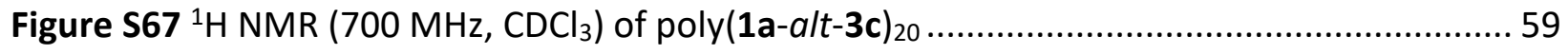

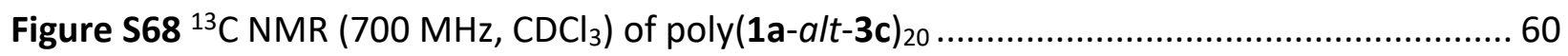

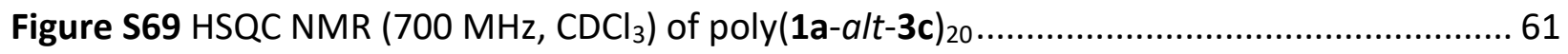

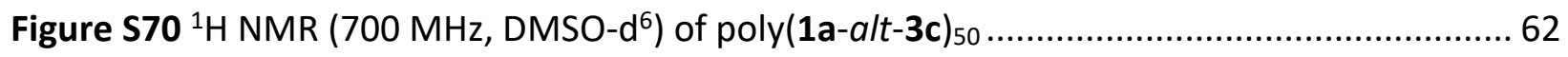

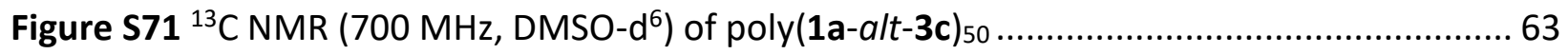

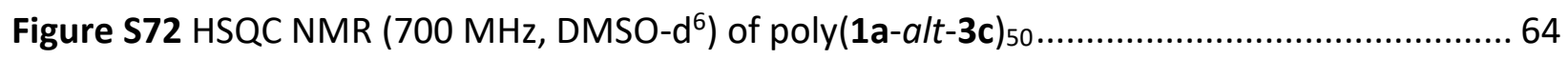

Figure S73 GPC traces of 1-alt-3 copolymers. ...). GPC was acquired on a Phenogel $5 \mu \mathrm{m} 10 \mathrm{E} 4 \mathrm{~A}$

LC column ( $300 \times 7.8 \mathrm{~mm}, 5-500 \mathrm{kDa} \mathrm{MW})$ with THF as eluent at a flow rate of $0.7 \mathrm{ml} / \mathrm{min}$ at 30 ${ }^{\circ} \mathrm{C}$. 
${ }^{1}$ H NMR<smiles>C=CCCCCC(=O)OCC=C</smiles>

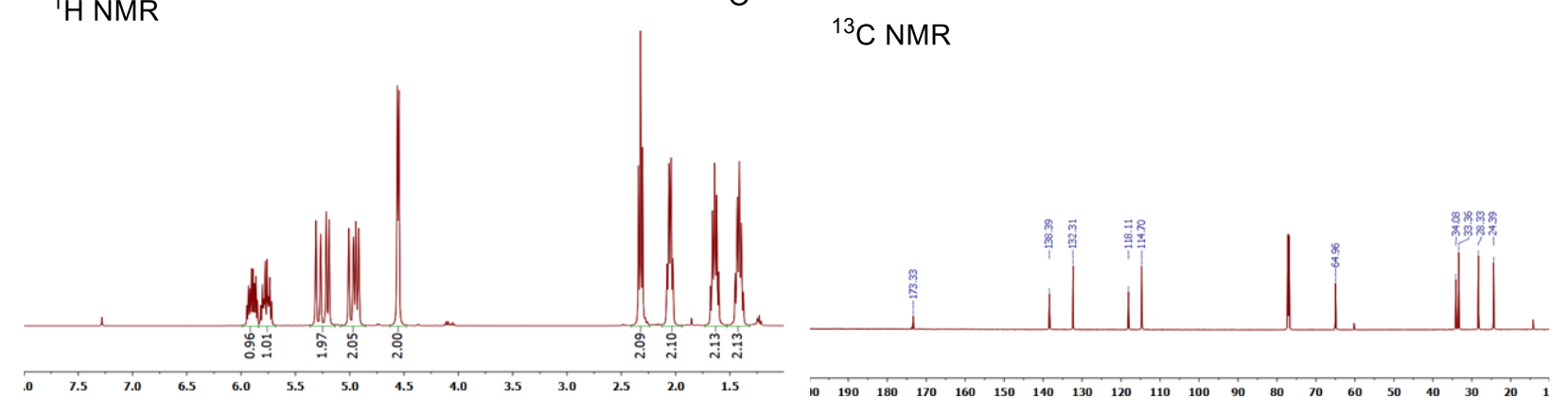

Figure $\mathrm{S} 1{ }^{1} \mathrm{H}$ and ${ }^{13} \mathrm{C}$ NMR of prop-2-enyl hept-6-enoate

${ }^{1} \mathrm{H}$ NMR<smiles></smiles>
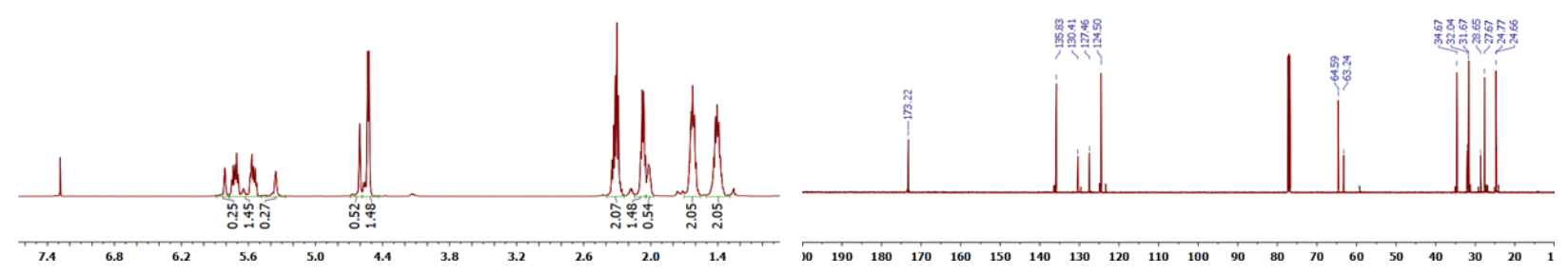

Figure $\mathbf{S} 2{ }^{1} \mathrm{H}$ and ${ }^{13} \mathrm{C}$ NMR of monomer $\mathbf{2 b}$

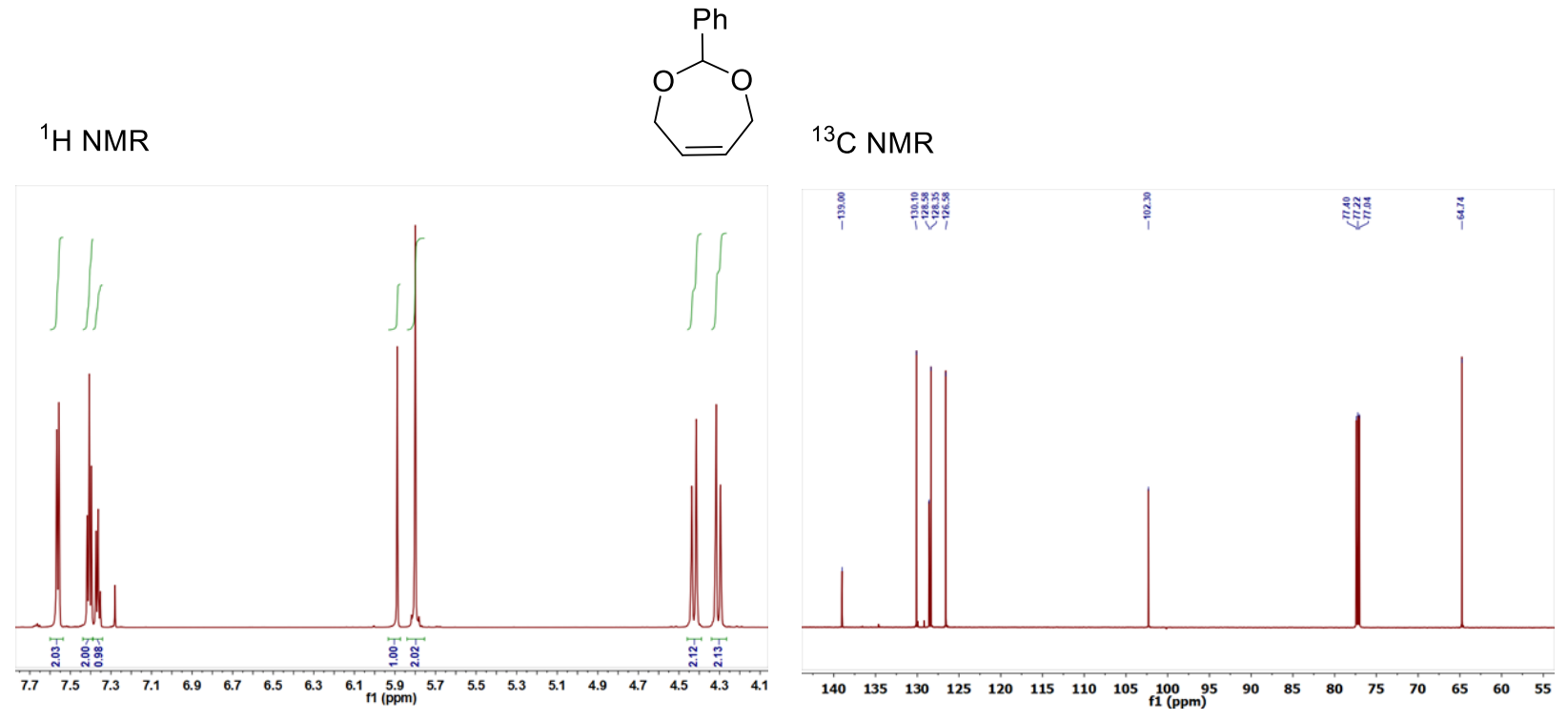

Figure $\mathbf{S 3}{ }^{1} \mathrm{H}$ and $\left.{ }^{13} \mathrm{C} \mathrm{NMR} \mathrm{(400} \mathrm{MHz,} \mathrm{CDCl}_{3}\right)$ of monomer $\mathbf{3 b}$ 


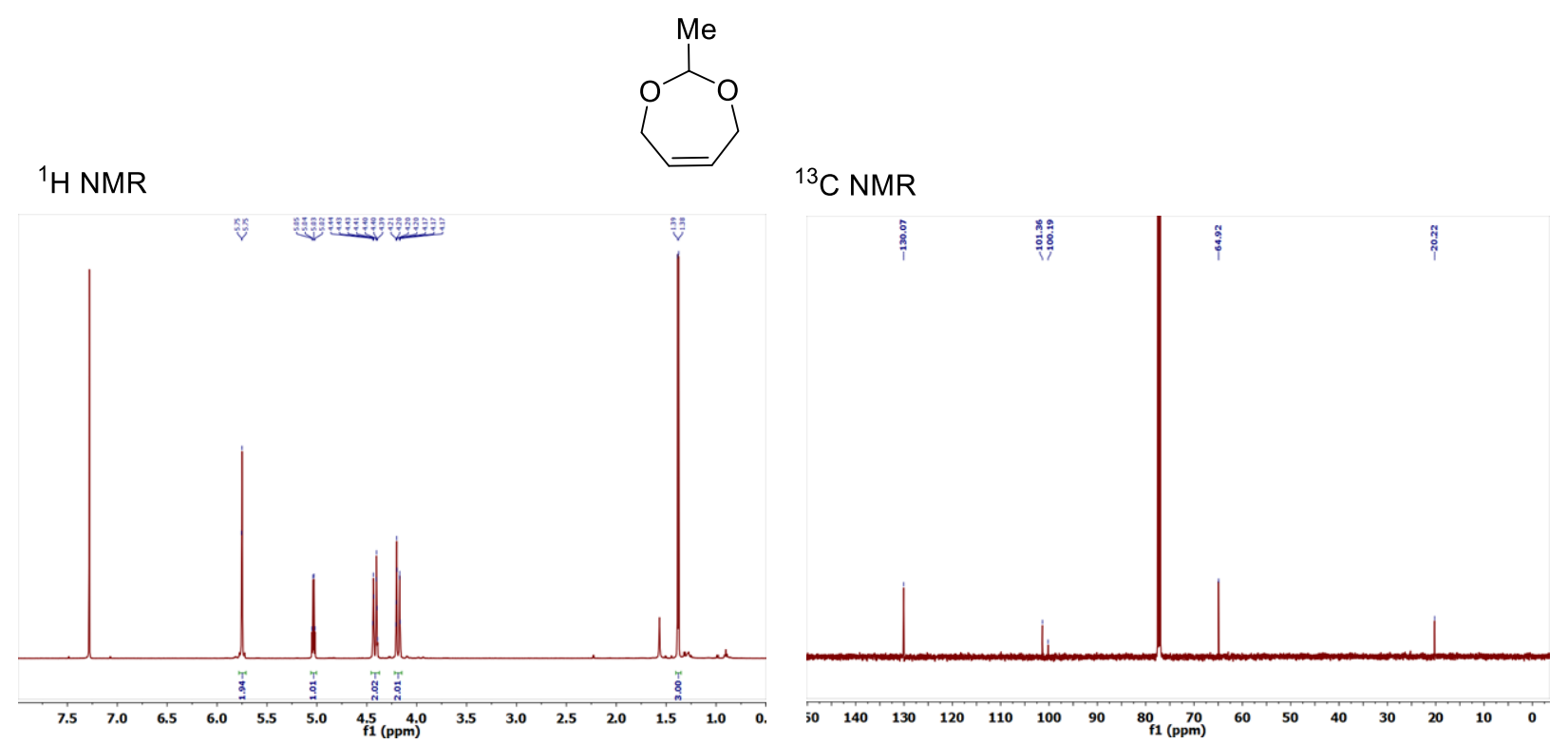

Figure S4 ${ }^{1} \mathrm{H}$ and ${ }^{13} \mathrm{C} \mathrm{NMR} \mathrm{(400} \mathrm{MHz,} \mathrm{CDCl}_{3}$ ) of monomer $3 \mathrm{C}$
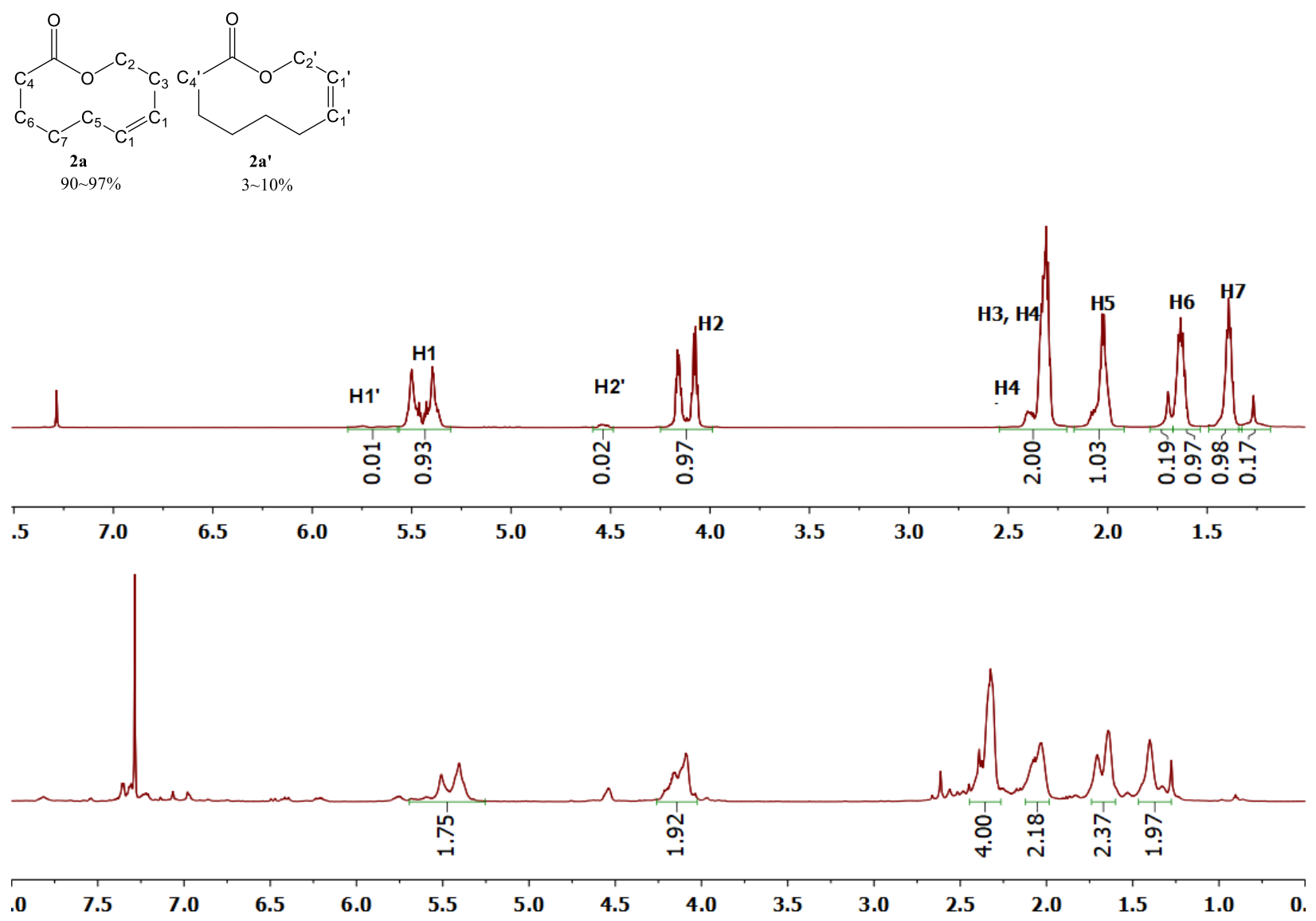

Figure S5 ${ }^{1} \mathrm{H}$ NMR of Monomer $2 \mathrm{a}$ before and after reacting with 0.1 equiv 5 for $24 \mathrm{~h}$ 


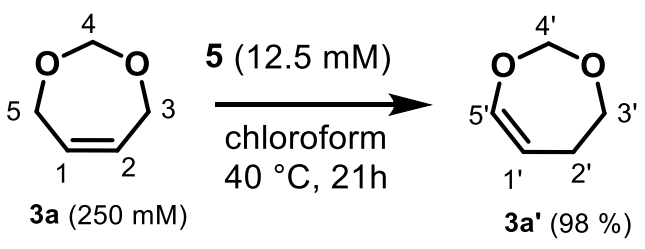

${ }^{1} \mathrm{H}-\mathrm{NMR} 3 \mathrm{a}$

${ }^{1} \mathrm{H}-\mathrm{NMR} 3 \mathrm{a}$ after treated with 5
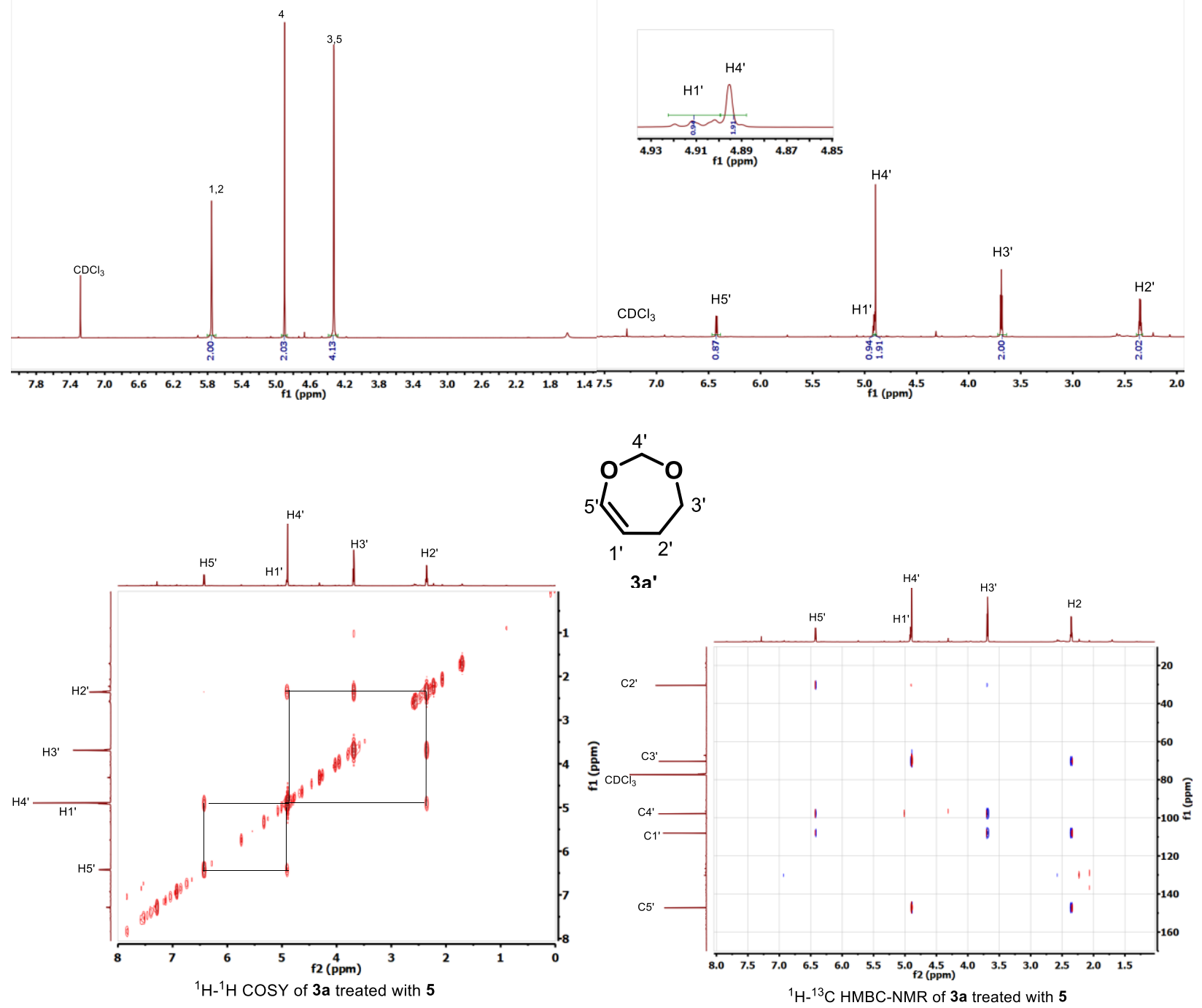

Figure S6 Dioxepine 3a doesn't undergo ROMP but isomerizes to 3a' when treated with catalyst 5 

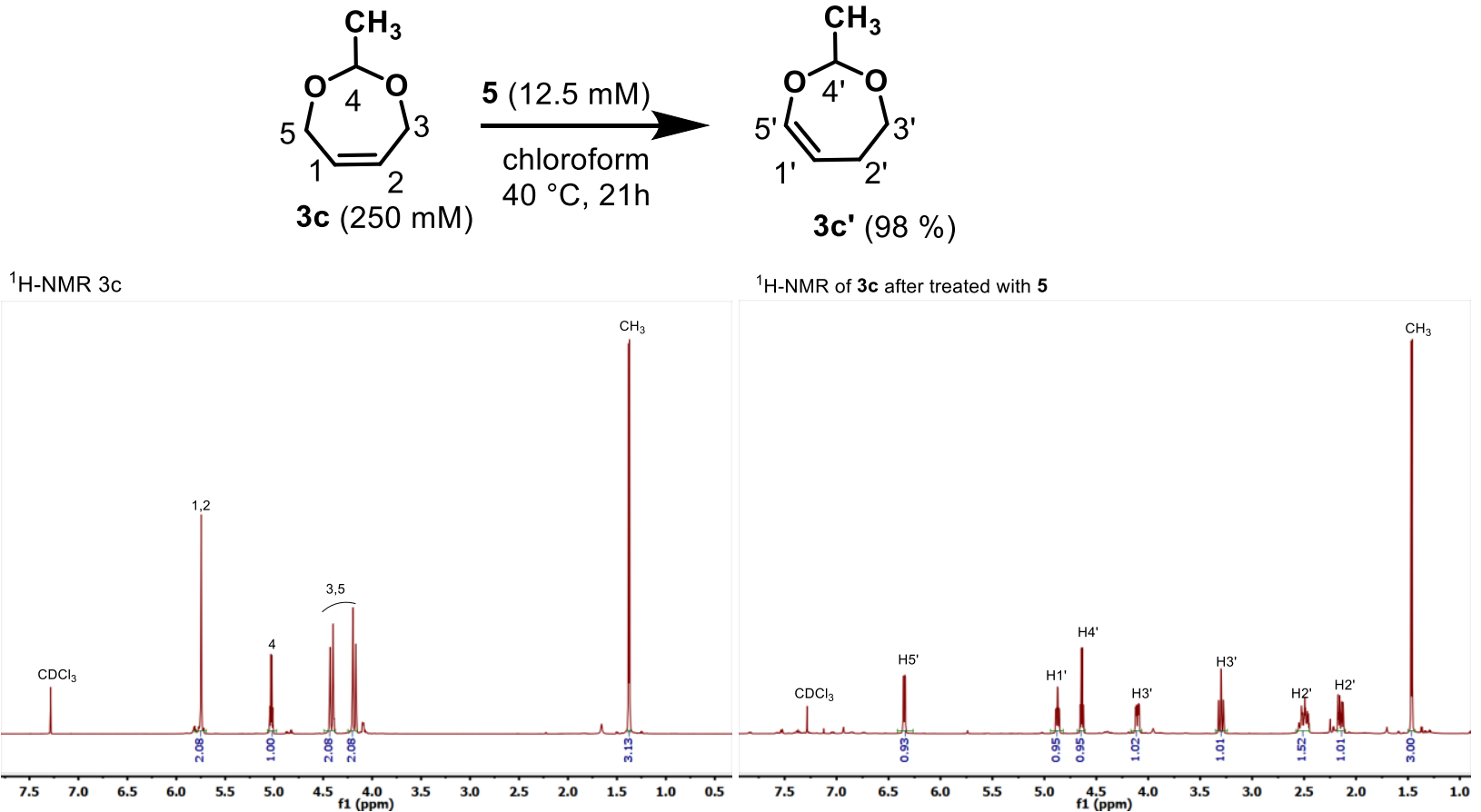

Figure S7 Dioxepine 3c doesn't undergo ROMP but isomerizes to $3 c^{\prime}$ when treated with catalyst 5 

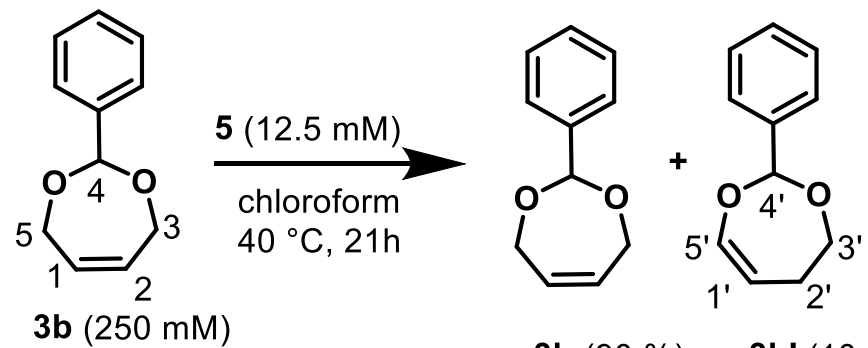

3b $(90 \%) \quad$ 3b' (10\%)

${ }^{1} \mathrm{H}-\mathrm{NMR}$ 3b

${ }^{1} \mathrm{H}-\mathrm{NMR}$ of $\mathbf{3 b}$ after treated with $\mathbf{5}$

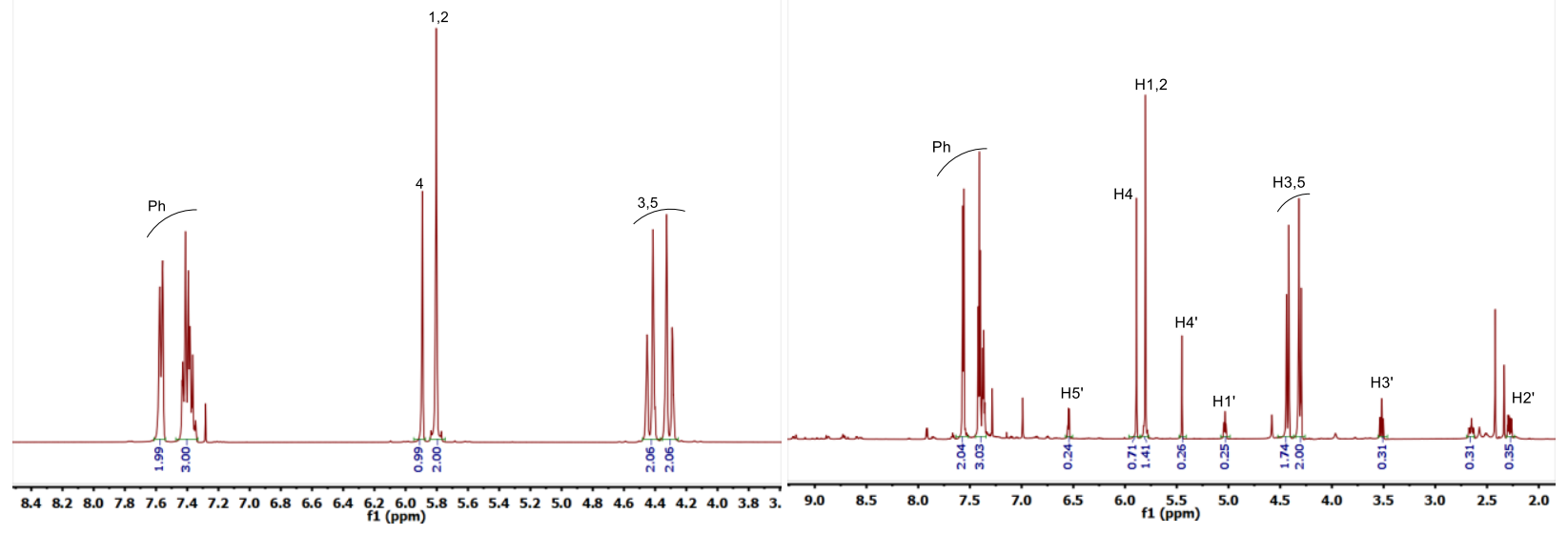

Figure S8 Dioxepine 3b doesn't undergo ROMP and it rarely isomerizes to 3b' when treated with catalyst 5 


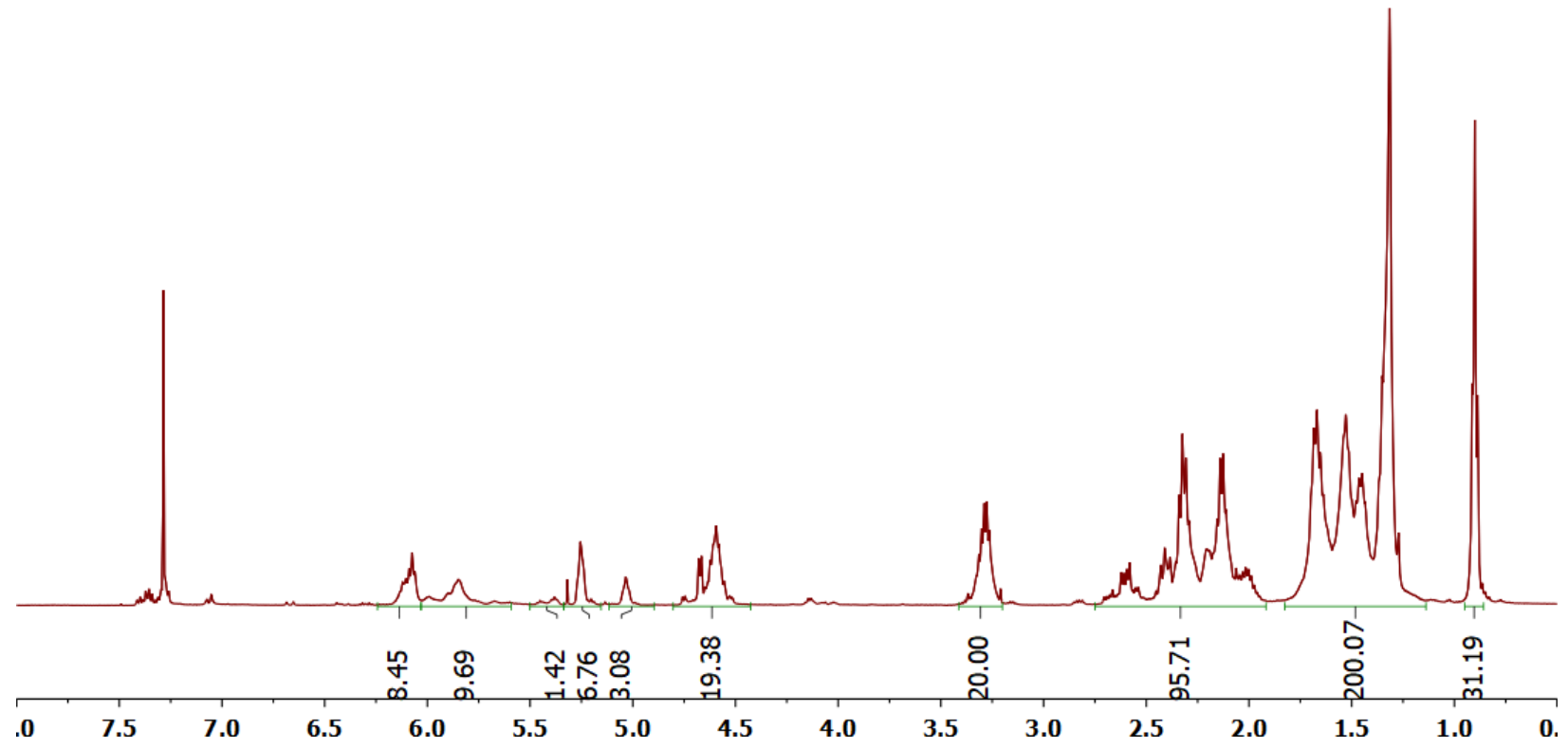

Figure S9 ${ }^{1} \mathrm{H}$ NMR of poly $(\mathbf{1 b}-a / t-\mathbf{2 b})_{10}$

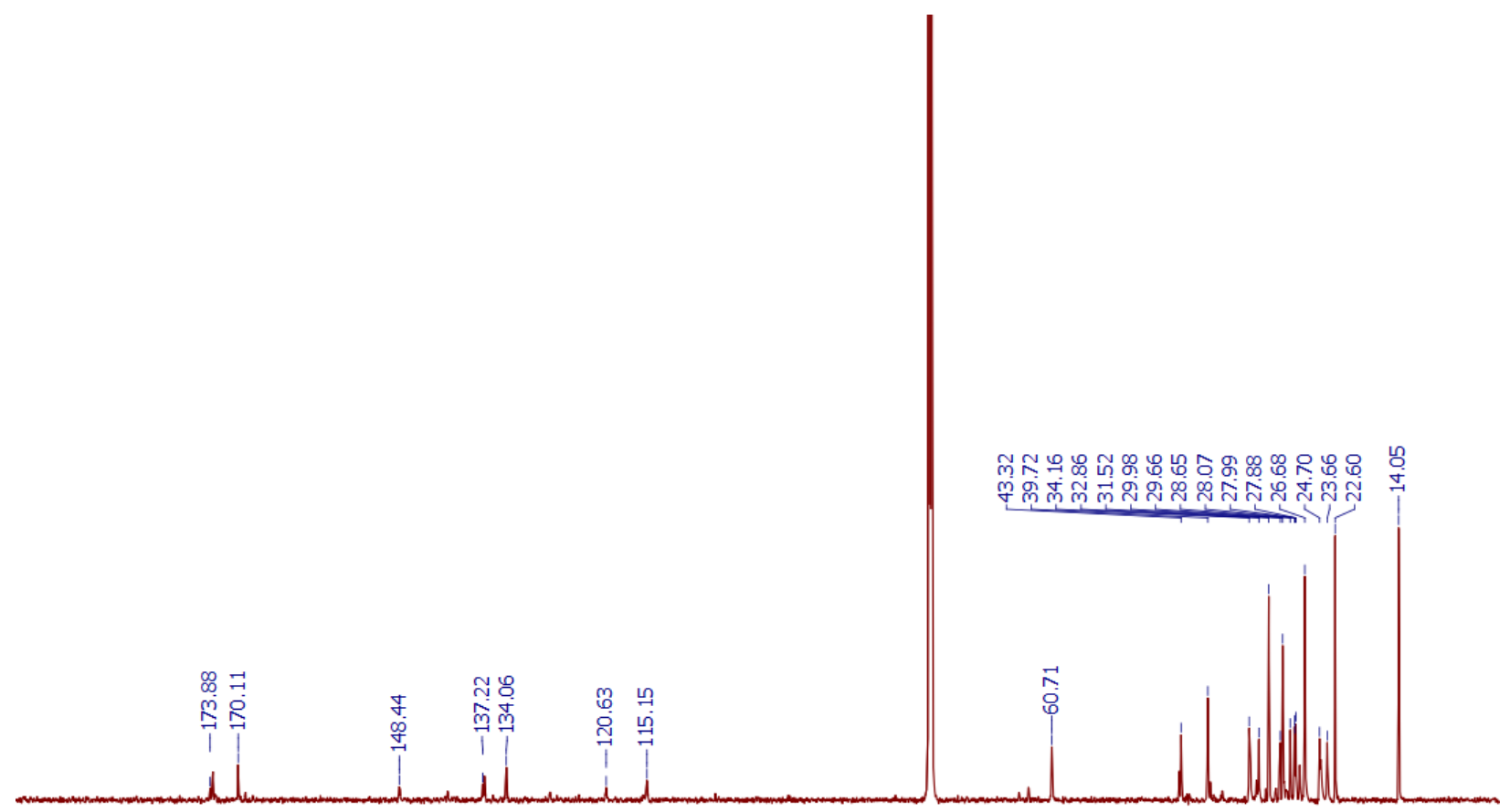

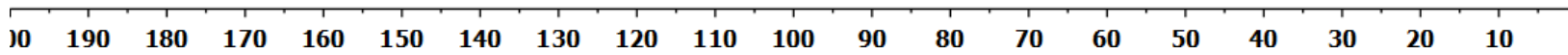

Figure $\mathbf{S 1 0}{ }^{13} \mathrm{C}$ NMR of poly $(\mathbf{1 b}-\text { alt-2b) })_{10}$ 


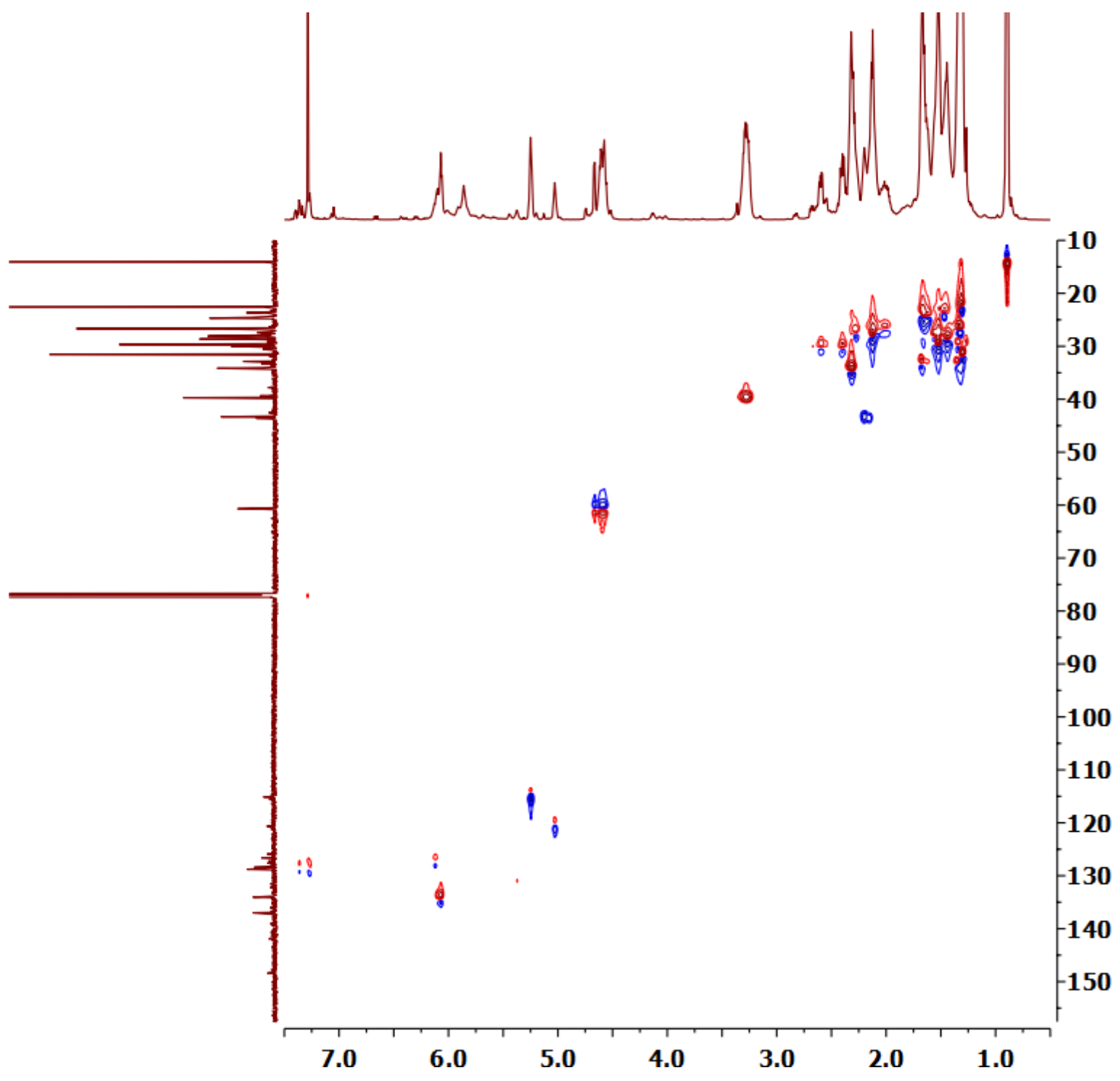

Figure S11 HSQC NMR of poly $(\mathbf{1} \mathbf{b}-\text { alt-2b })_{10}$ 


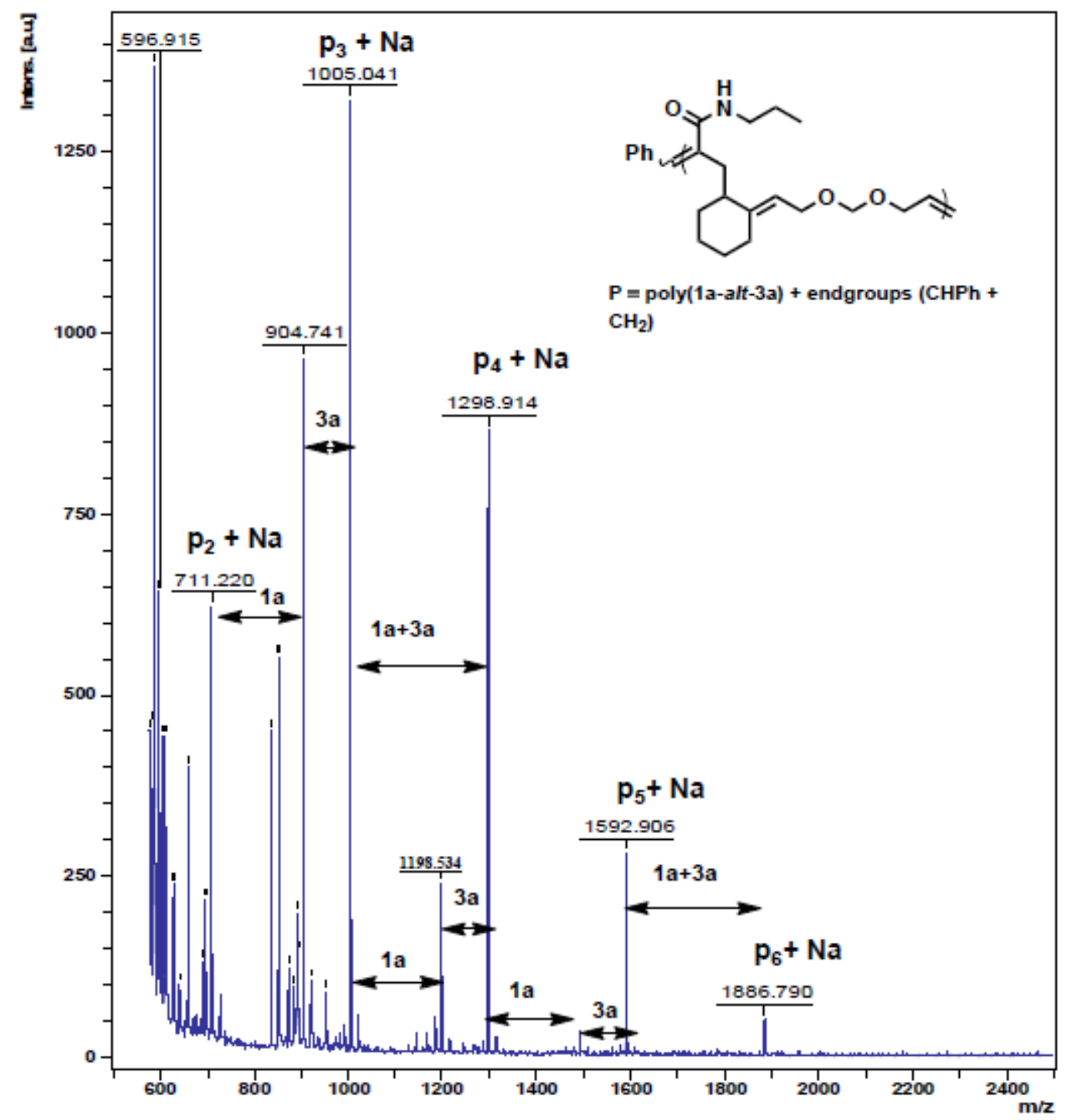

Figure S12 MALDI-TOF spectrum of poly(1a-alt-3a) 

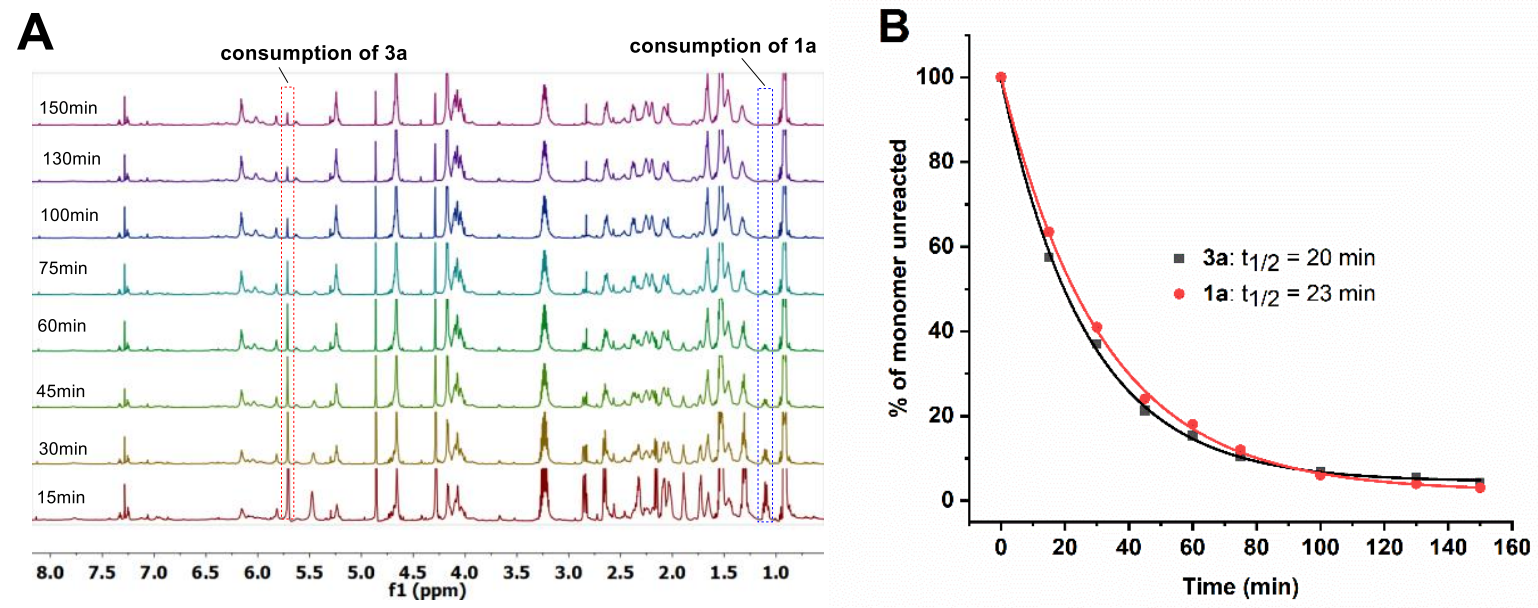

Figure S13 kinetics of incorporation of $3 \mathbf{a}$ in AROMP reaction with $1 \mathbf{1 a},(A)^{1} \mathrm{H} N M R$, (B) a plot of unconsumed $\mathbf{3 b}$ vs. time

A

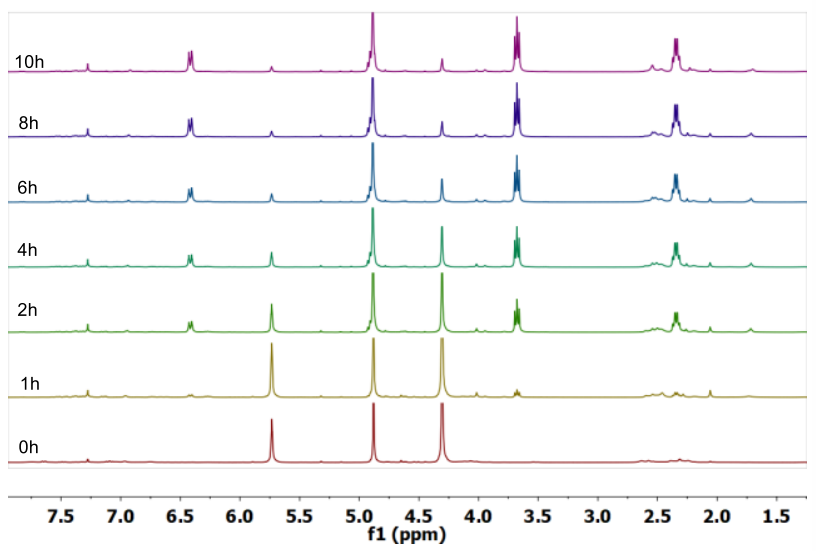

B

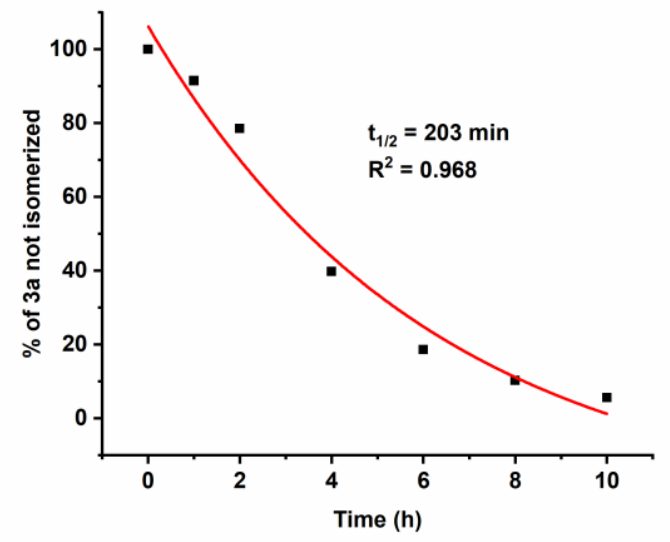

Figure S14 kinetics of isomerization 3a to $3 a^{\prime},(A){ }^{1} H$ NMR, (B) a plot of unconsumed $\mathbf{3 b}$ vs. time 


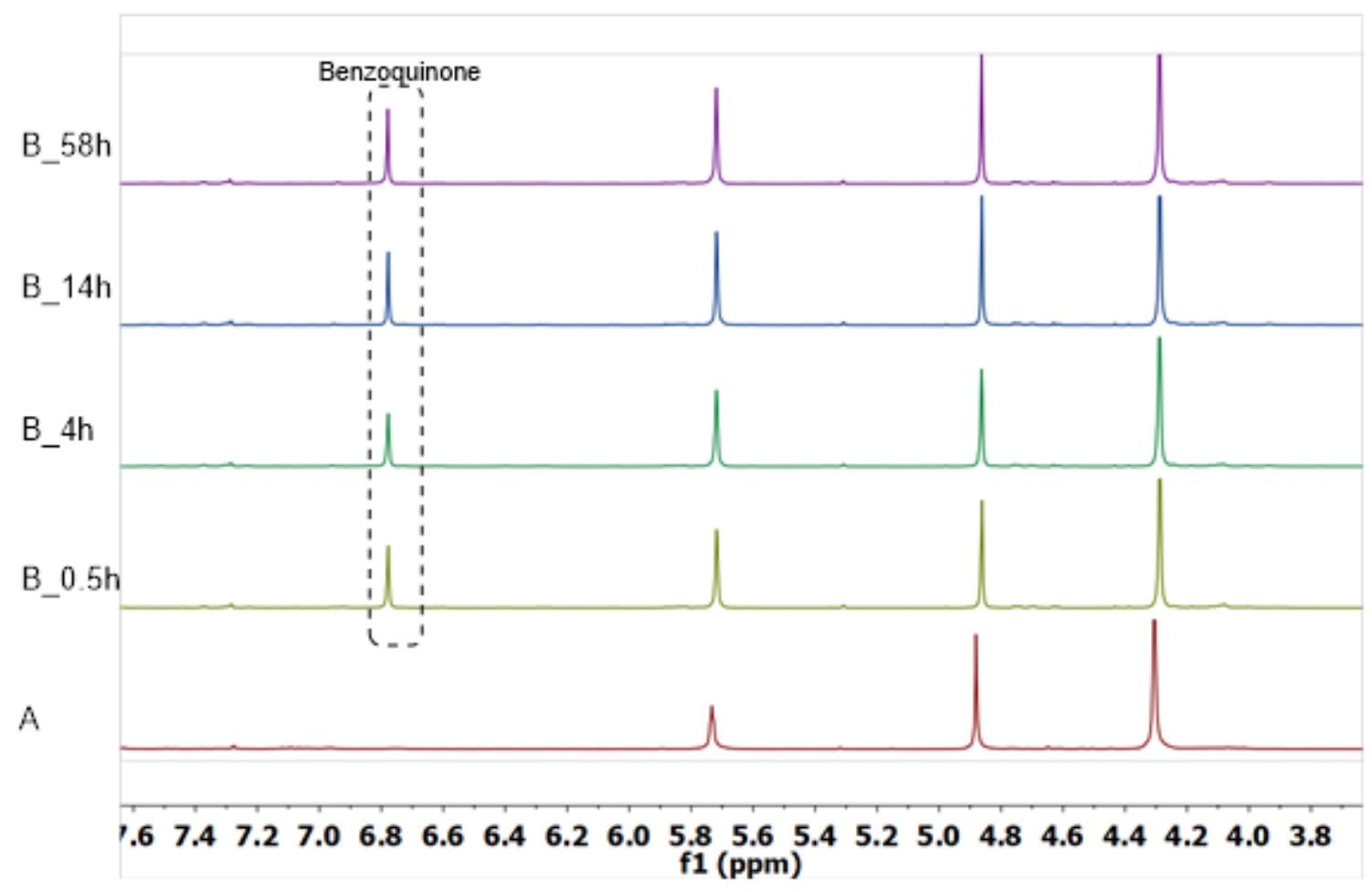

Figure $\mathbf{S 1 5}{ }^{1} \mathrm{H}$ NMR kinetics of $\mathbf{3 b}$ treated with catalyst $\mathbf{5}$ (5 mol \%) in the presence of 1,4benzoquinone (26 mol \%), (A) without addition of 1,4-benzoquinone, (B) with addition of 1,4benzoquinone at various times. 
A 1a-alt-3a in the presensece of 1,4-benzoquinone

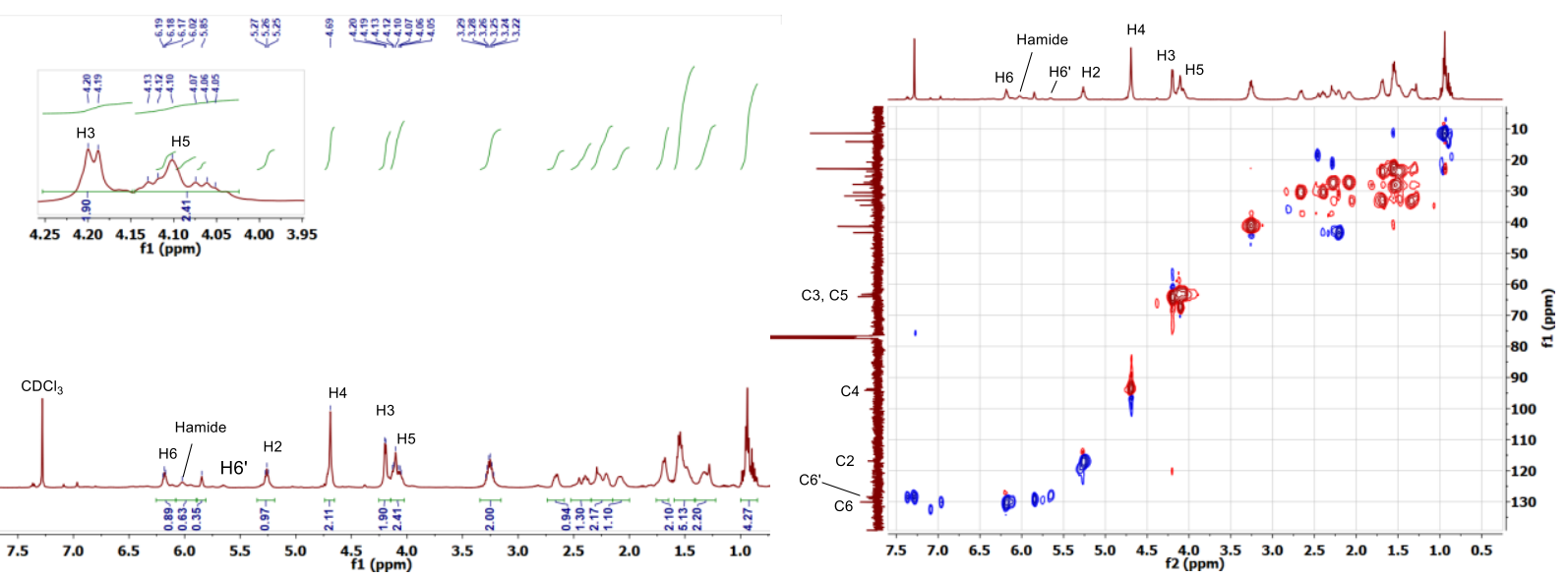

B 1a-alt-3a without addition of 1,4-benzoquinone
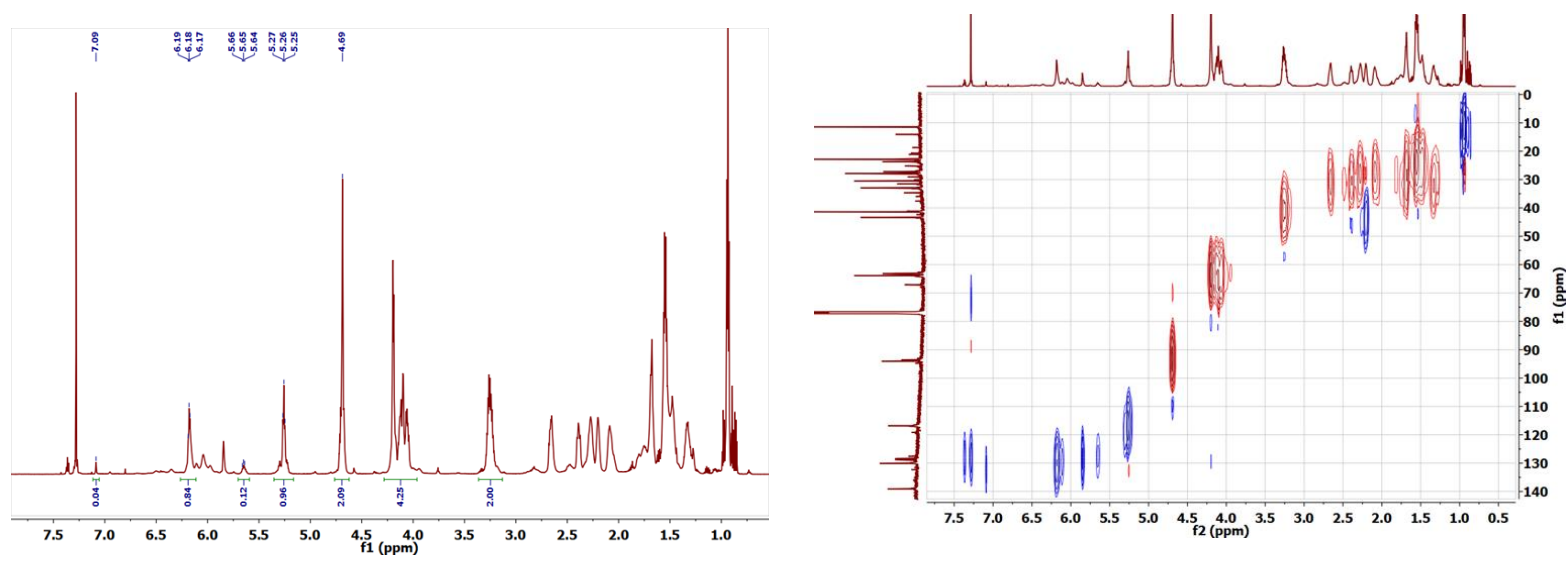

Figure S16 ${ }^{1} \mathrm{H}$ NMR (left) and HSQC NMR (right) 1a-alt-3b copolymer, (A) prepared in the presence of 1,4-benzoquinone, (B) prepared without addition of benzoquinone 

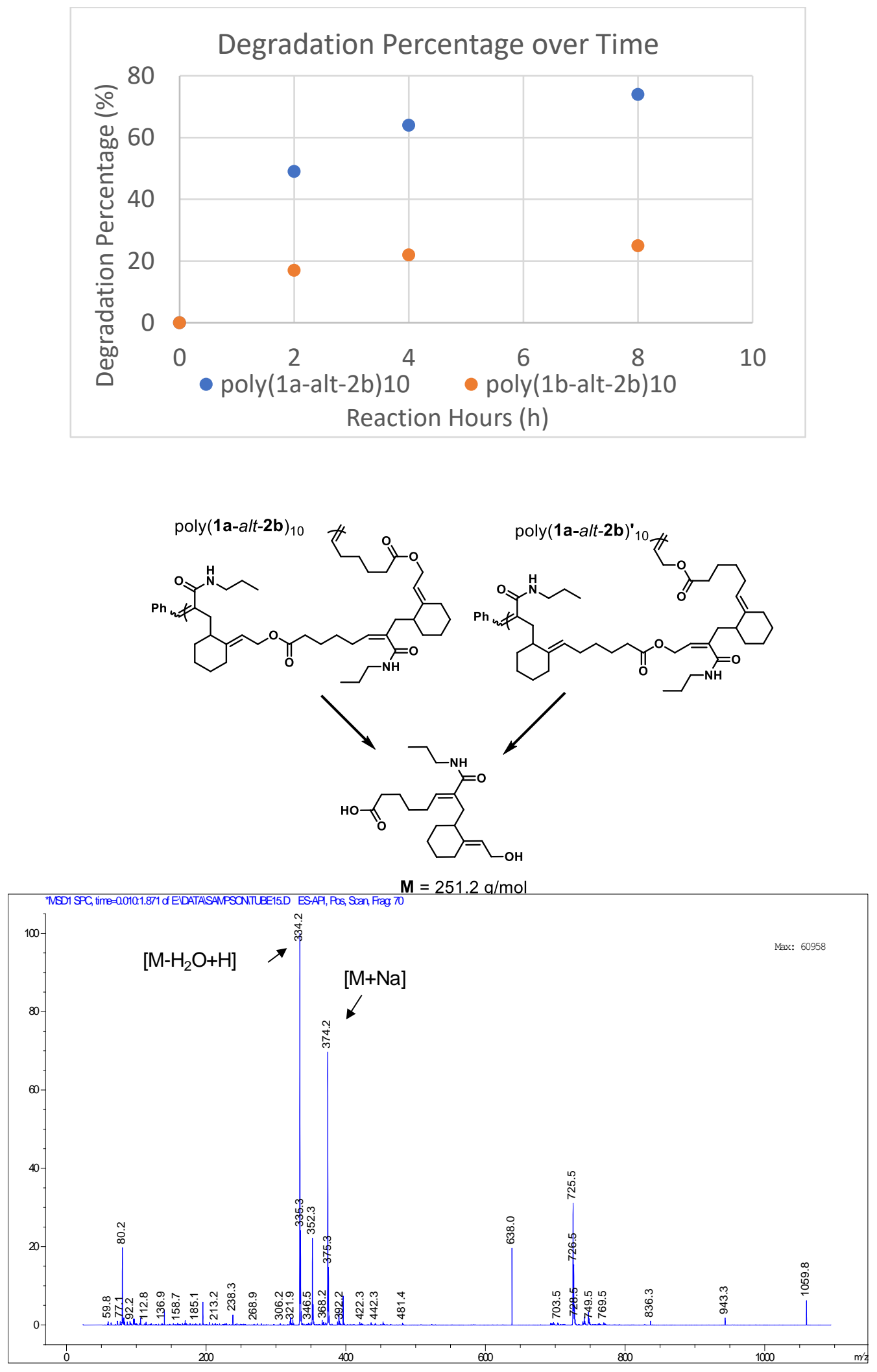

Figure S17 ESI-MS of degraded of $(\mathbf{1 a}-a / t-2 \mathbf{b})_{10}$ treated under $\mathrm{pH} 13$ for $8 \mathrm{~h}$ 


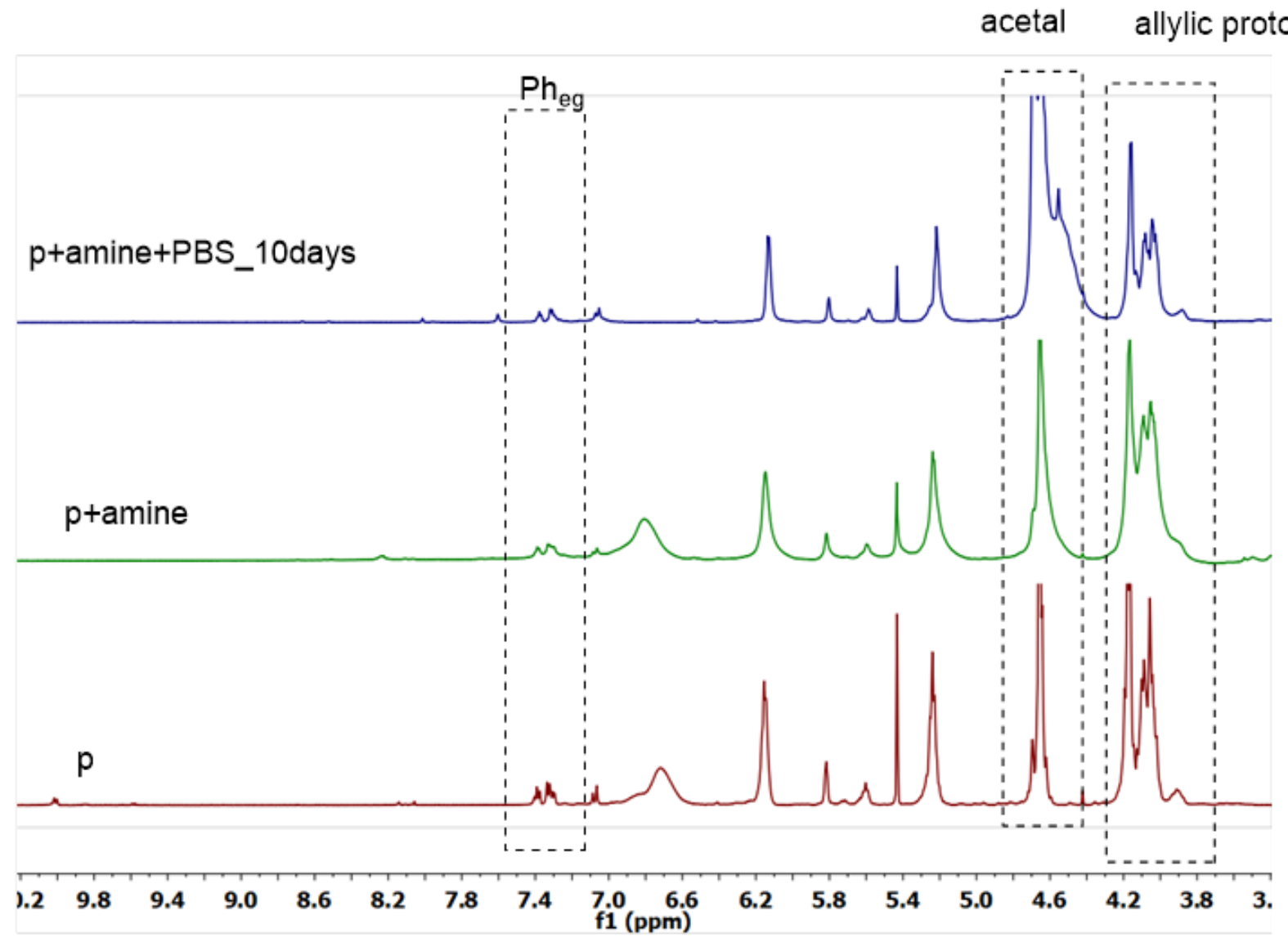

Figure S18 Selected region of ${ }^{1} \mathrm{H}$ NMR of poly(1a-alt-3a) $)_{20}$ treated with sodium phosphate buffer (pH 5) at $37^{\circ} \mathrm{C}$. Hexylamine was added as a scavenging agent for formaldehyde if any is evolved from the polymer 


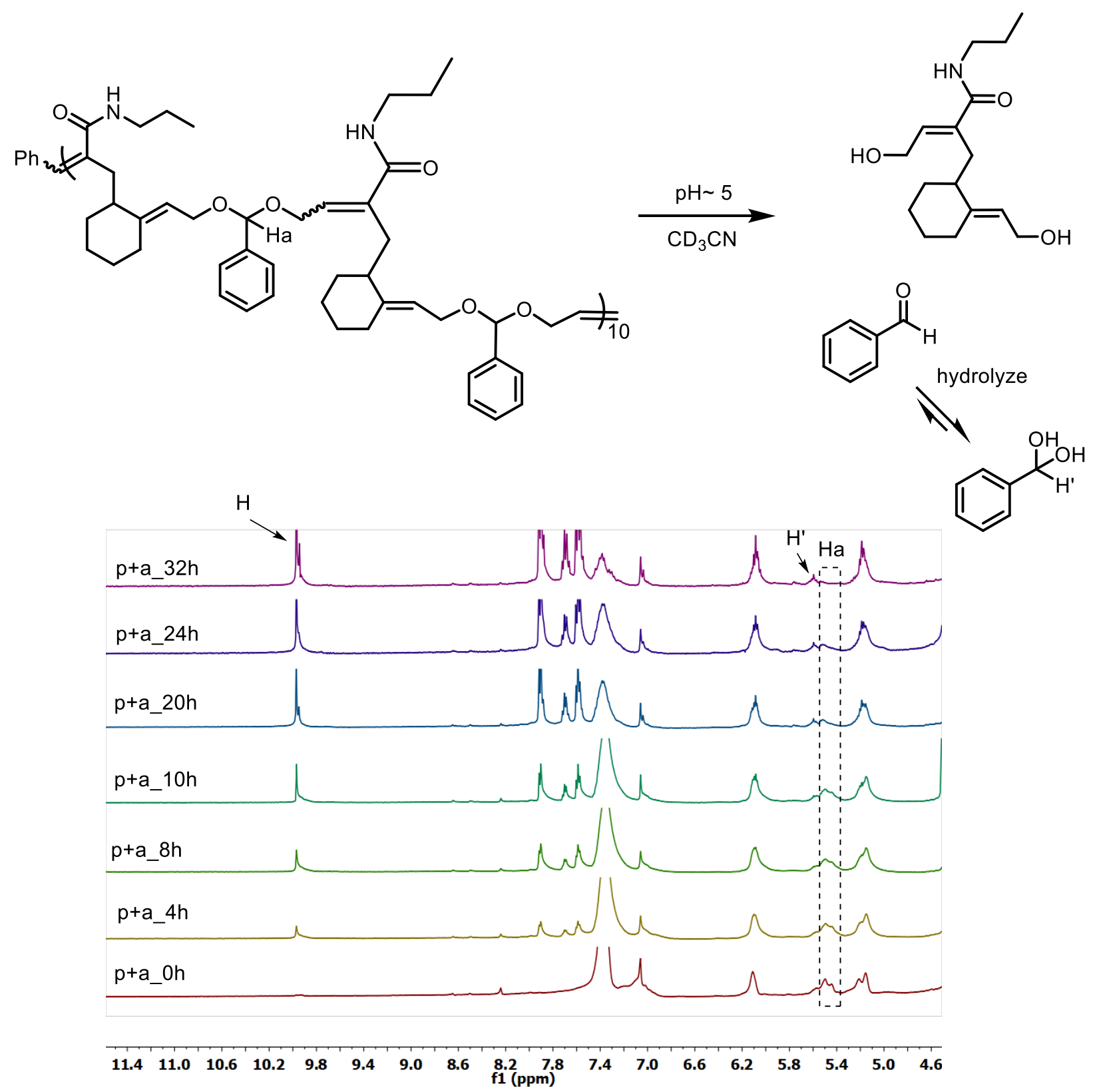

Figure S19 ${ }^{1} \mathrm{H}$ NMR kinetics of the hydrolytic degradation of poly $(\mathbf{1 a} \text {-alt-3b })_{20}$ at pH 5 and $37^{\circ} \mathrm{C}$. 


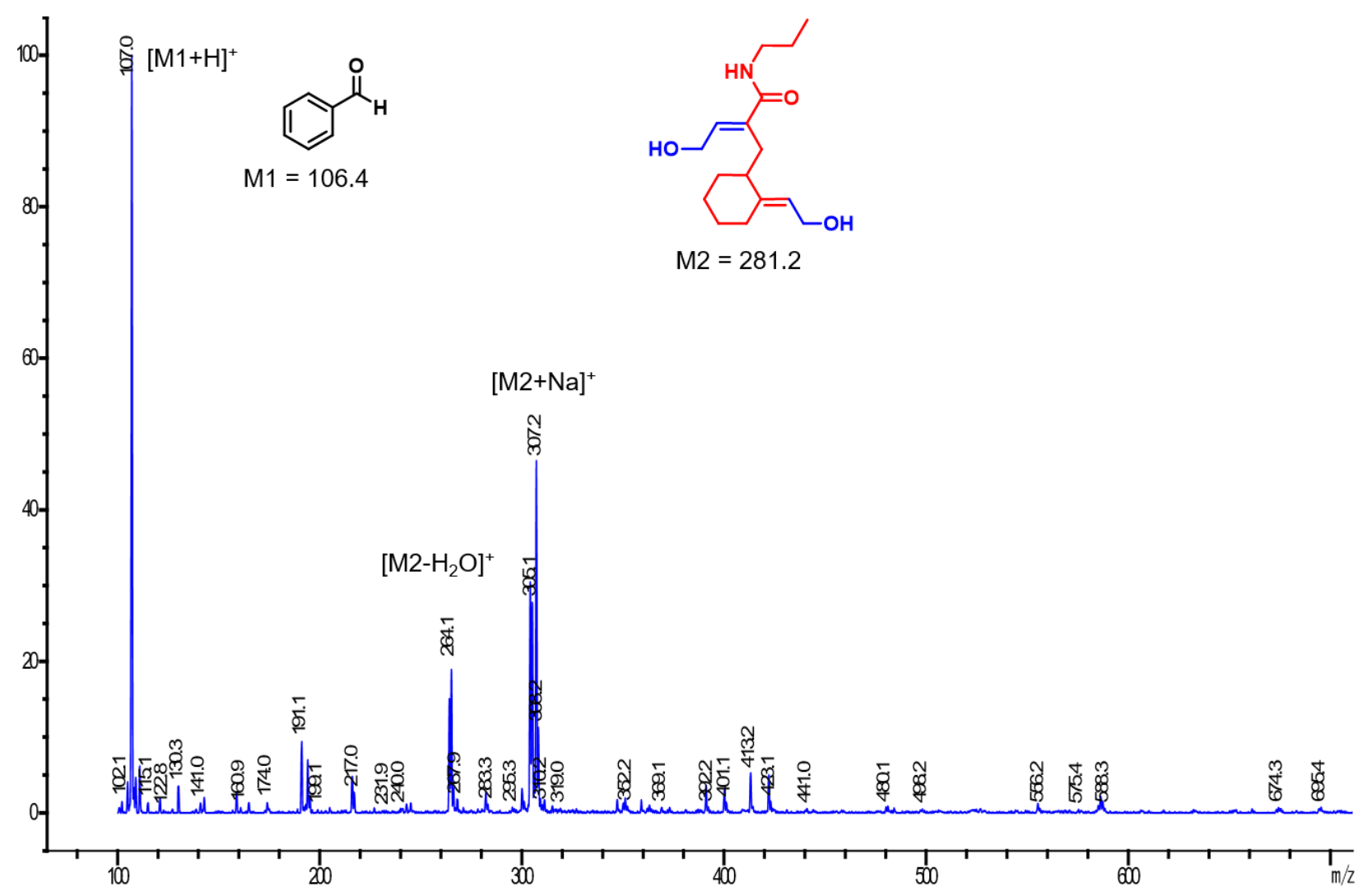

Figure S20 ESI-MS of hydrolytic mixture of (1a-alt-3b $)_{20}$ treated under $\mathrm{pH} 5$ for $30 \mathrm{~h}$. 
A based on 1a-alt-3a

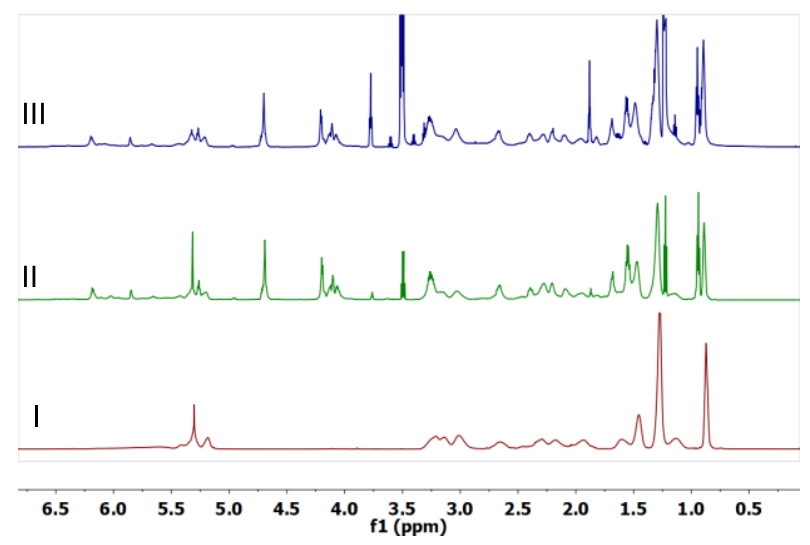

B based on 1a-alt-3b based

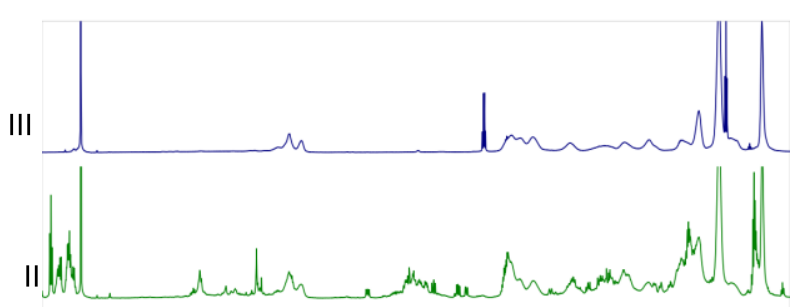

I

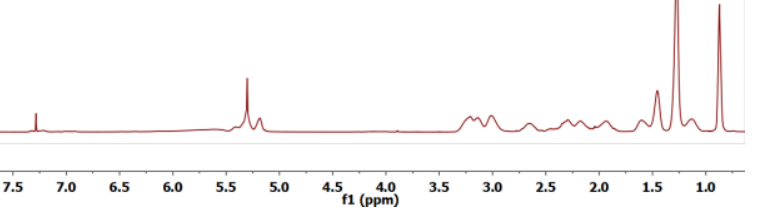

C based on 1a-alt-3c based

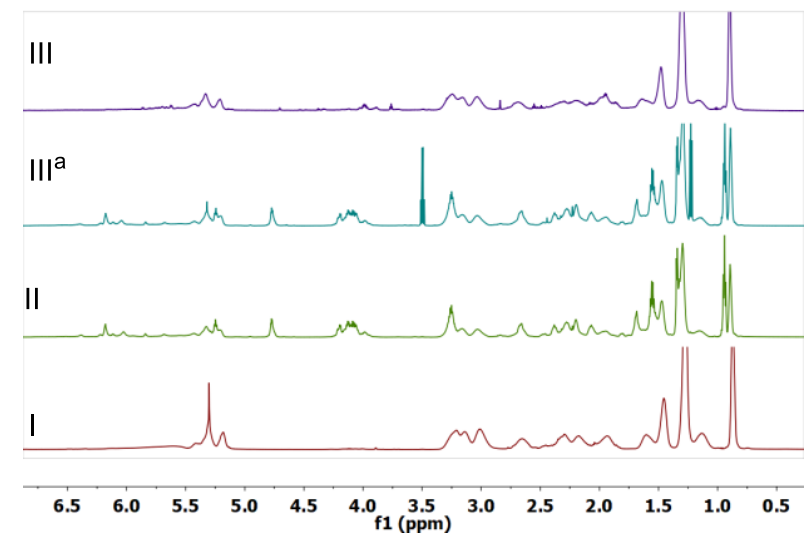

Figure S21 ${ }^{1} \mathrm{H}$ NMR depicting block copolymer before and after hydrolysis, (I) poly(4) (II) diblock copolymer poly $\mathbf{4})_{n}-b$-poly $(\mathbf{1} \mathbf{a}-a / t-3 a / b / c)_{m}$ before hydrolysis, (III) diblock copolymer poly $(\mathbf{4})_{n}-b$-poly $(\mathbf{1 a}-a / t-3 a / b / c)_{m}$ after treated with aqueous TFA, pH1, (III $\left.{ }^{a}\right)$ diblock copolymer poly $(\mathbf{4})_{n}-b$-poly $(\mathbf{1 a}-a / t-3 a / b / c)_{m}$ after treated with sodium phosphate buffer , pH5. 


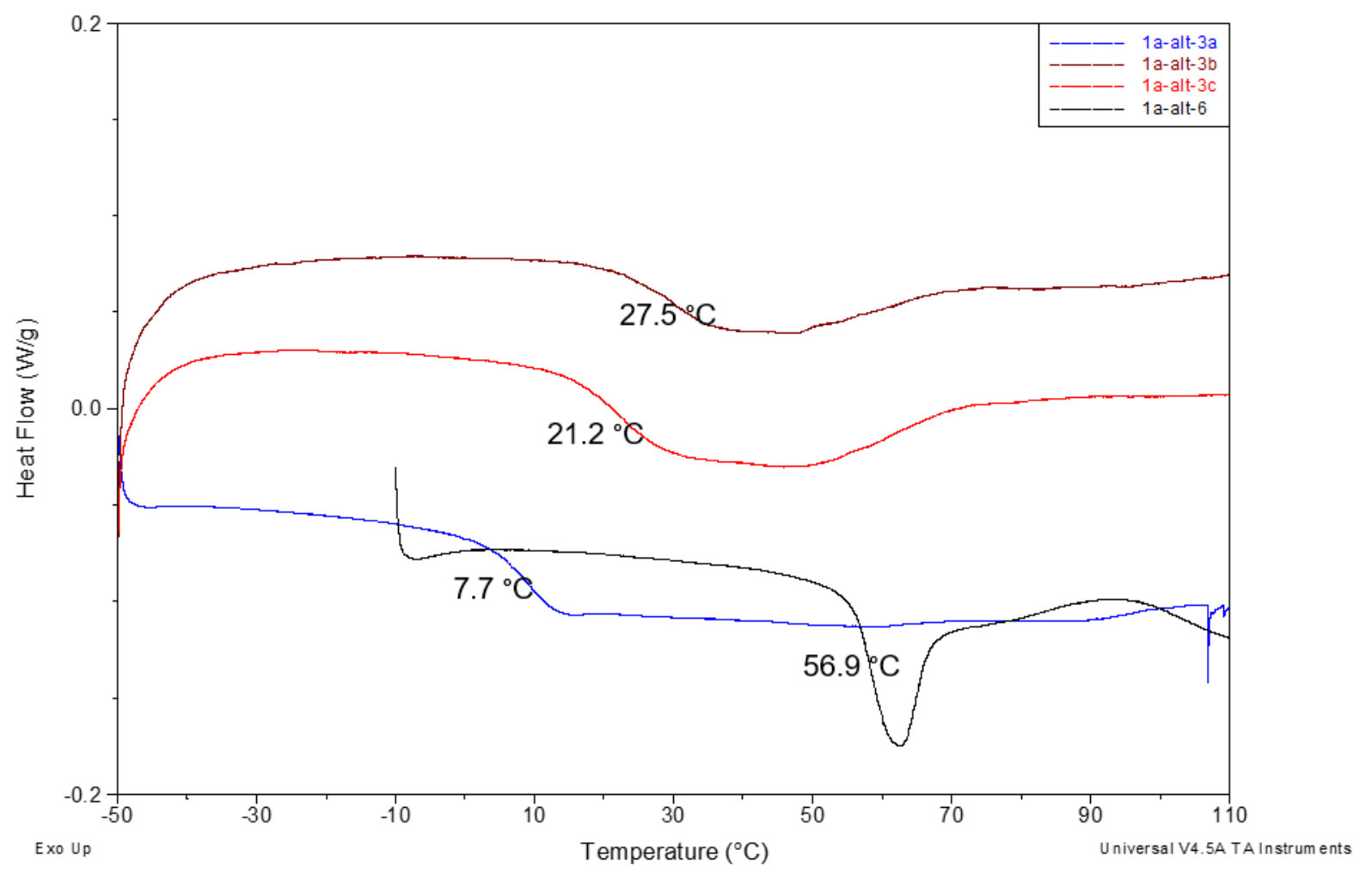

Figure S22 Discrete scanning calorimetry of acetal-based copolymers, poly(1a-alt-3) $)_{50}$. 3a (blue line), 3b (maroon line), 3c (red line), 6 (black line). 


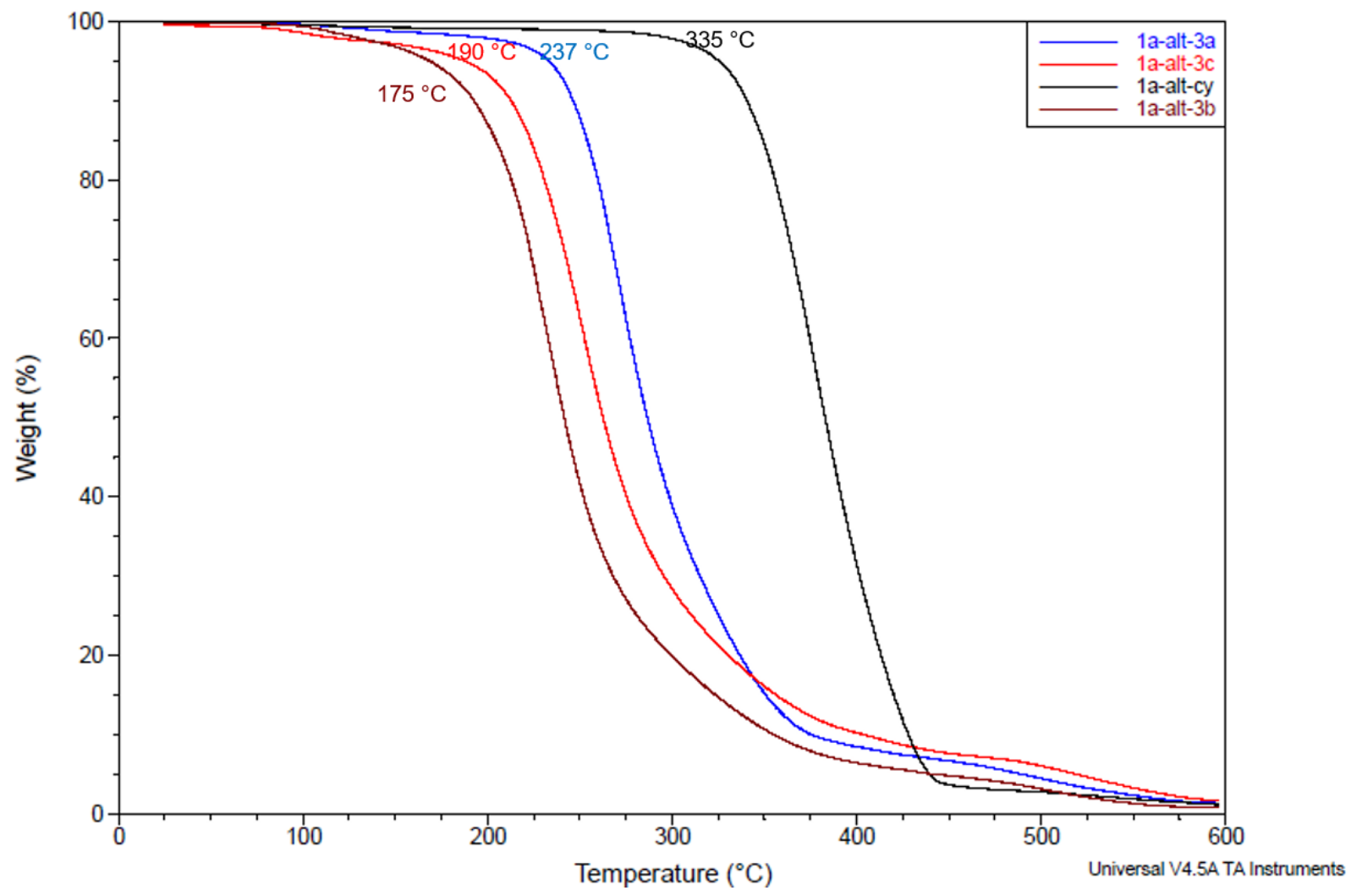

Figure S23 Thermogravimetric analysis (TGA) of acetal-based and cyclohexene-based copolymers, 50mer. 3a (blue line), 3b (maroon line), 3c (red line), and $\mathbf{6}$ (black line). 

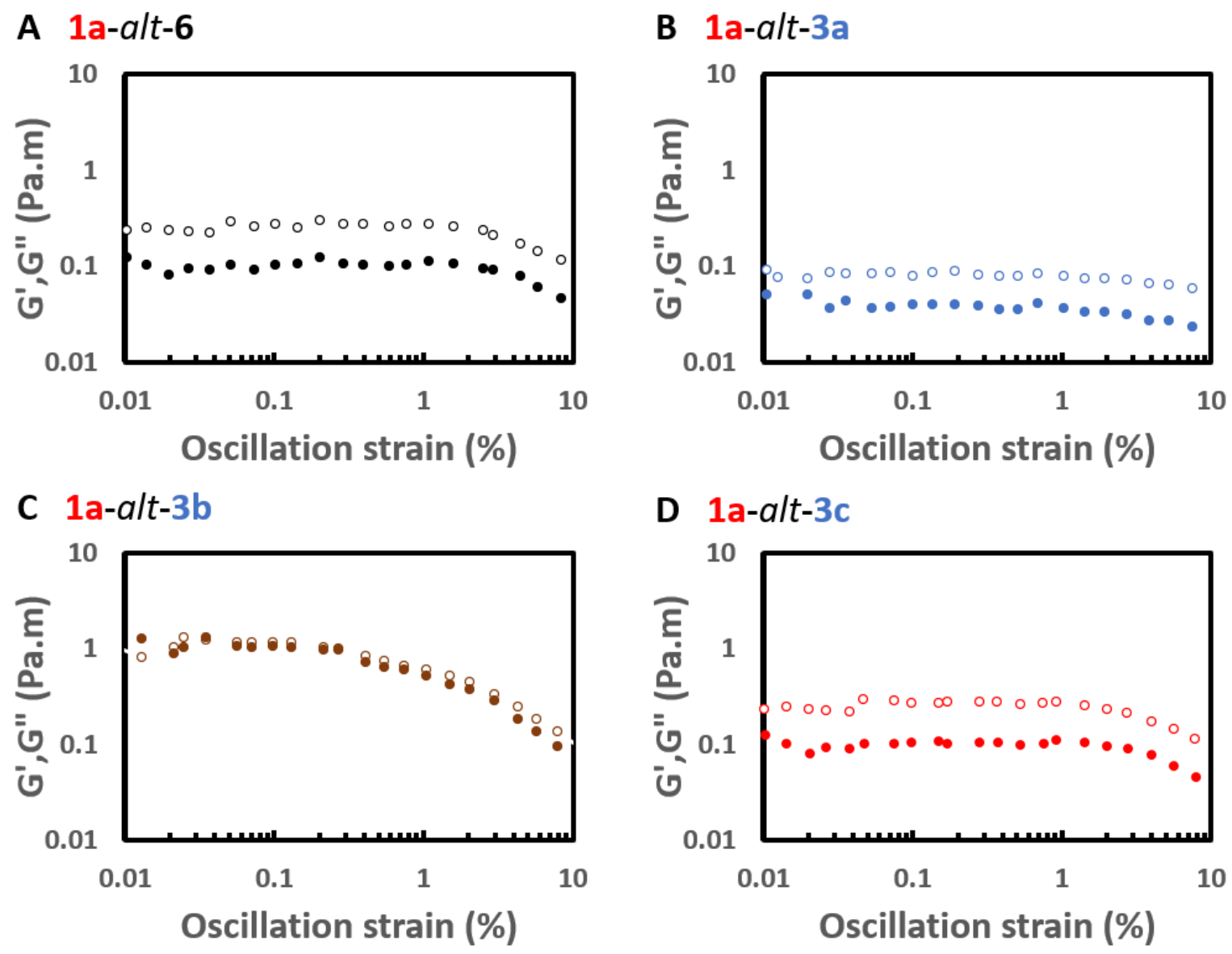

D 1a-alt-3c

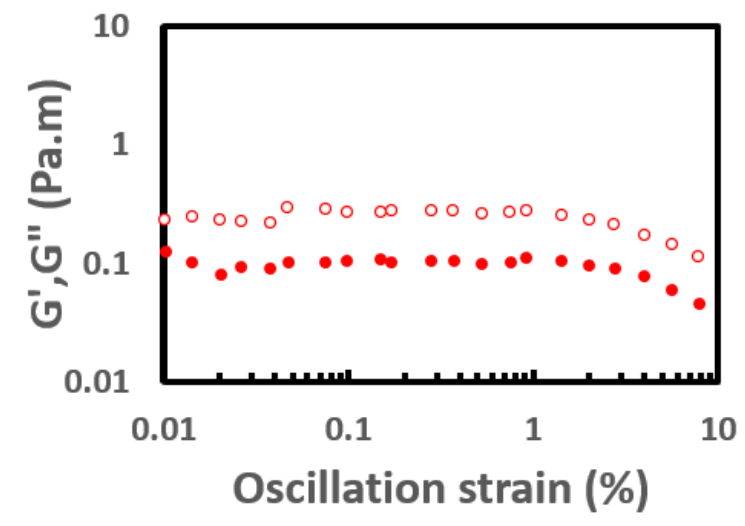

Figure S24 Amplitude sweep of poly(1a-alt-3 $)_{50}$ and poly(1a-alt-6) $)_{50}$. solid dots, storage modulus $\left(G^{\prime}\right)$ : hollow dots, loss modulus $\left(G^{\prime \prime}\right)$. 

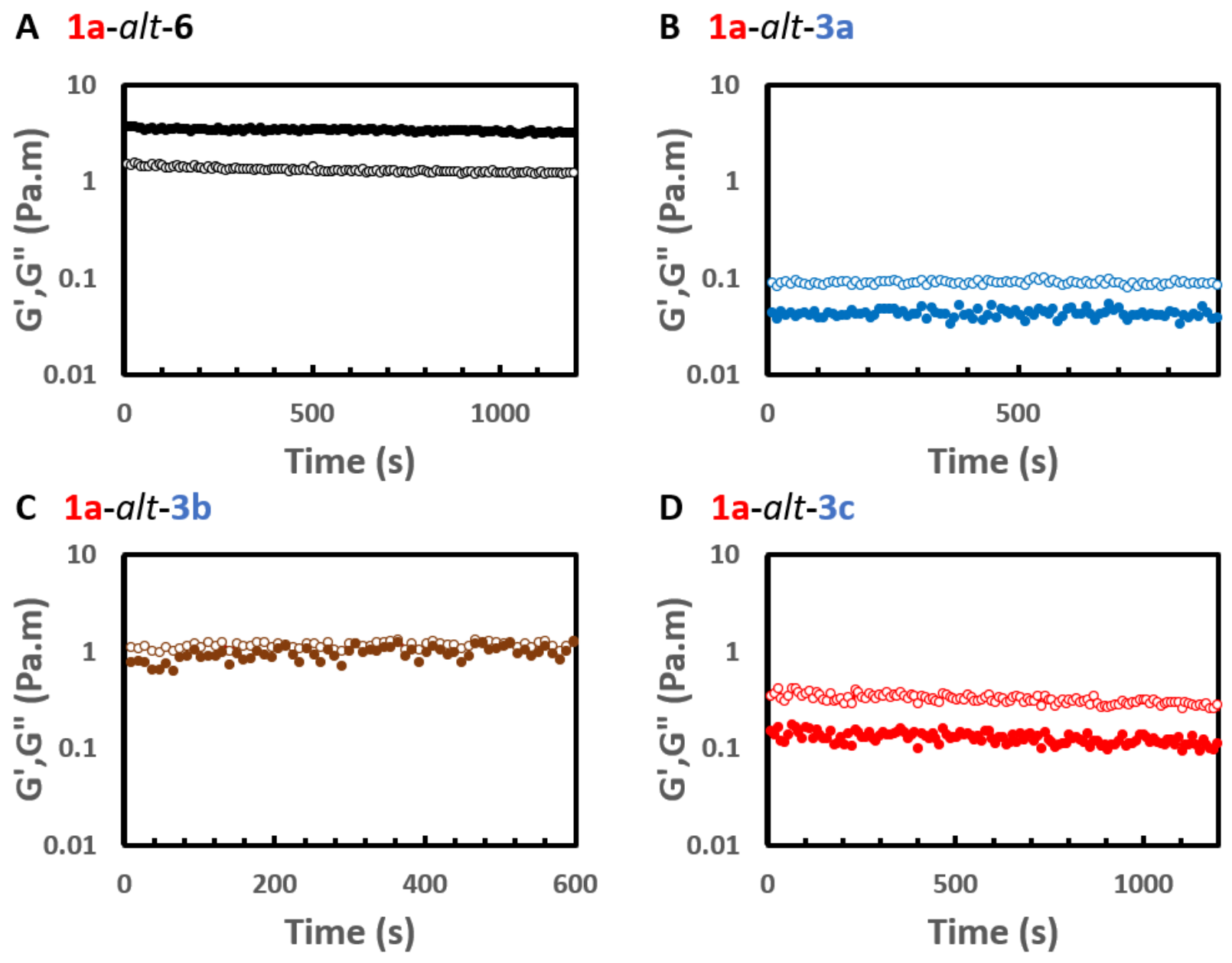

Figure S25 Time sweep of poly $(\mathbf{1 a}-a / t-3)_{50}$ and poly(1a-alt-6) $)_{50}$. solid dots, storage modulus $\left(G^{\prime}\right)$ : hollow dots, loss modulus $\left(G^{\prime \prime}\right)$. 


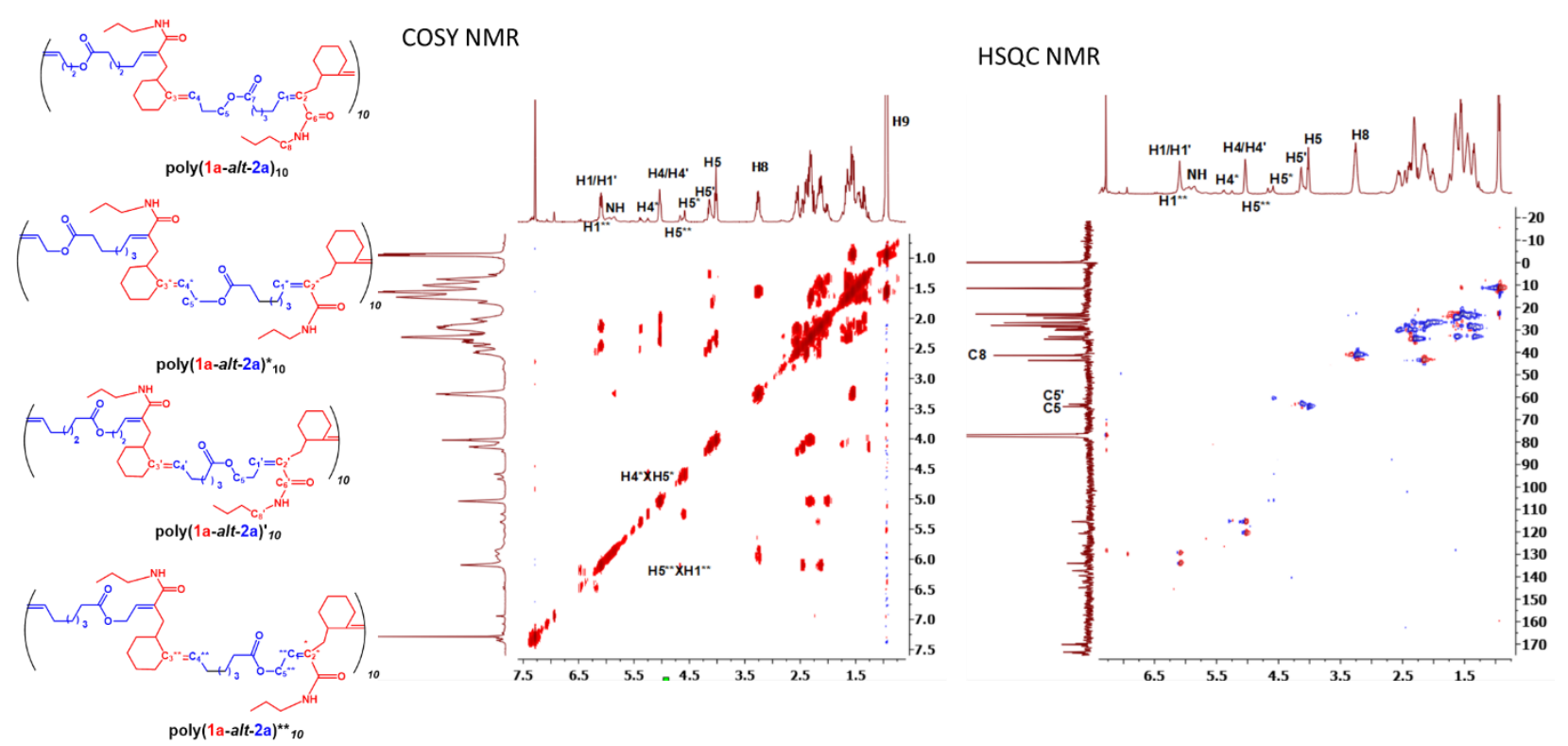

Figure S26 HSQC and COSY NMR of poly(1a-alt-2a $)_{10}$
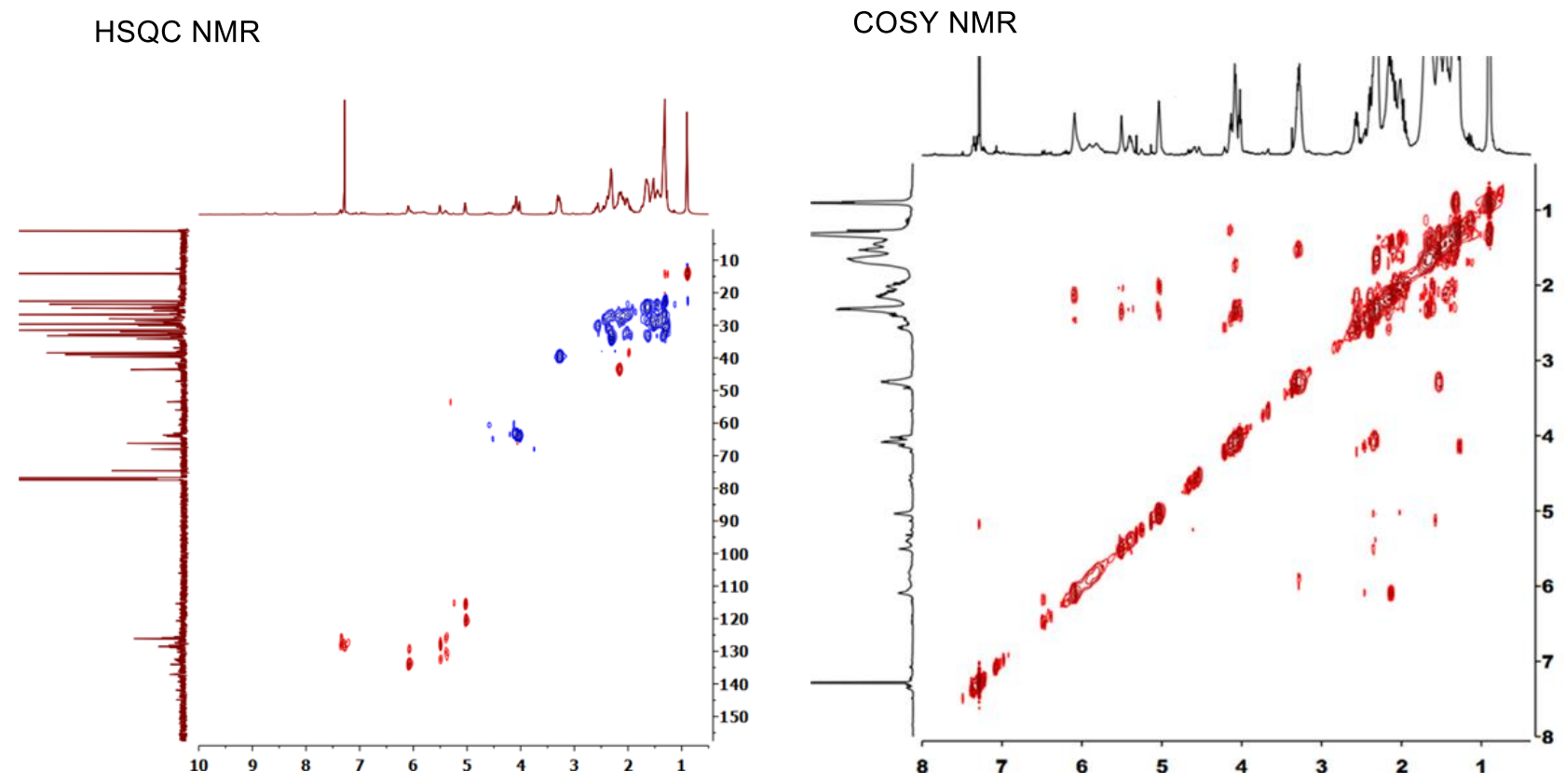

Figure S27 HSQC and COSY NMR of poly $(\mathbf{1} \mathbf{b}-a / t-2 \mathbf{a})_{10}$ 


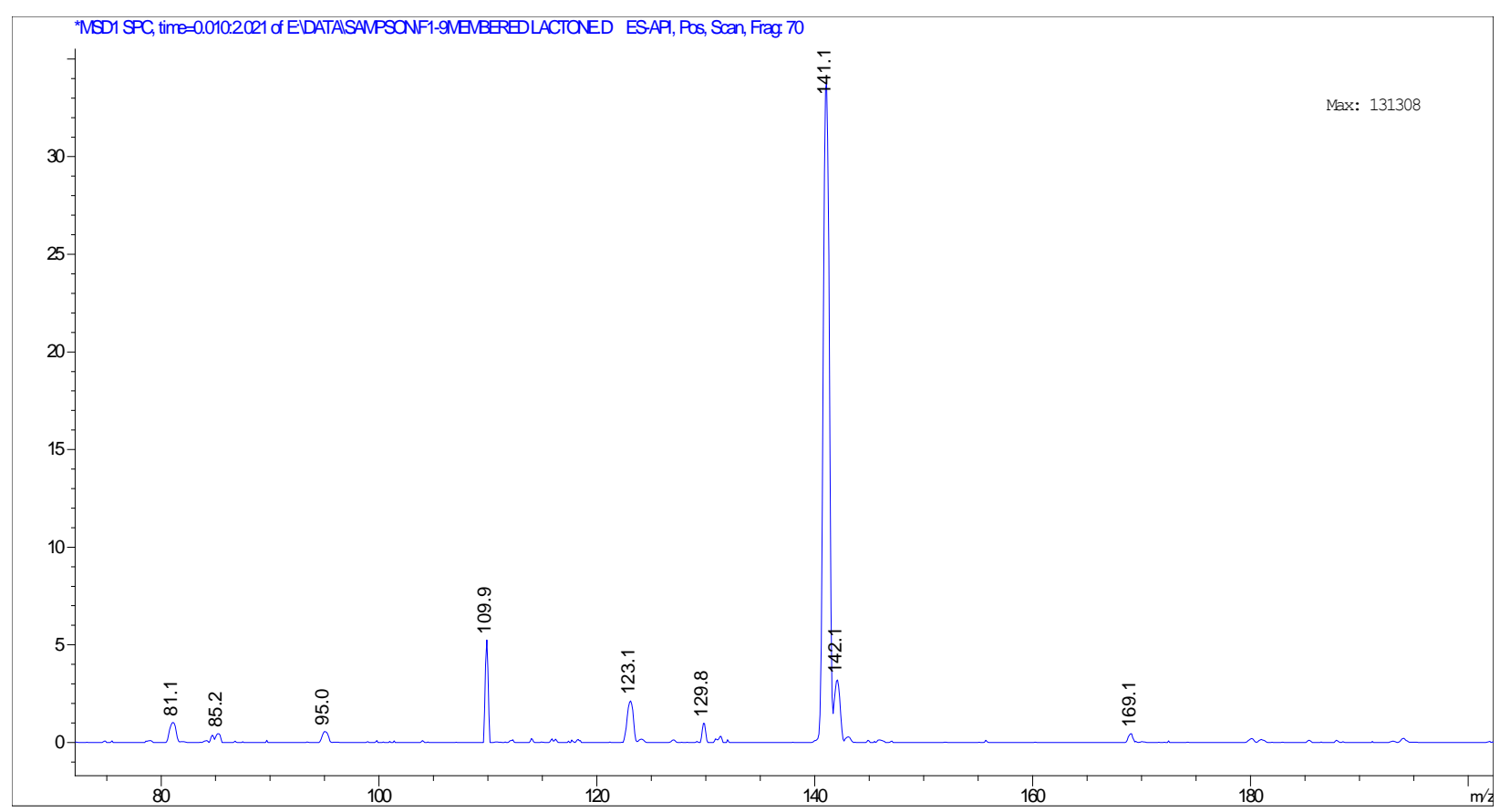

Figure S28 ESI-Mass spectrum of 2b

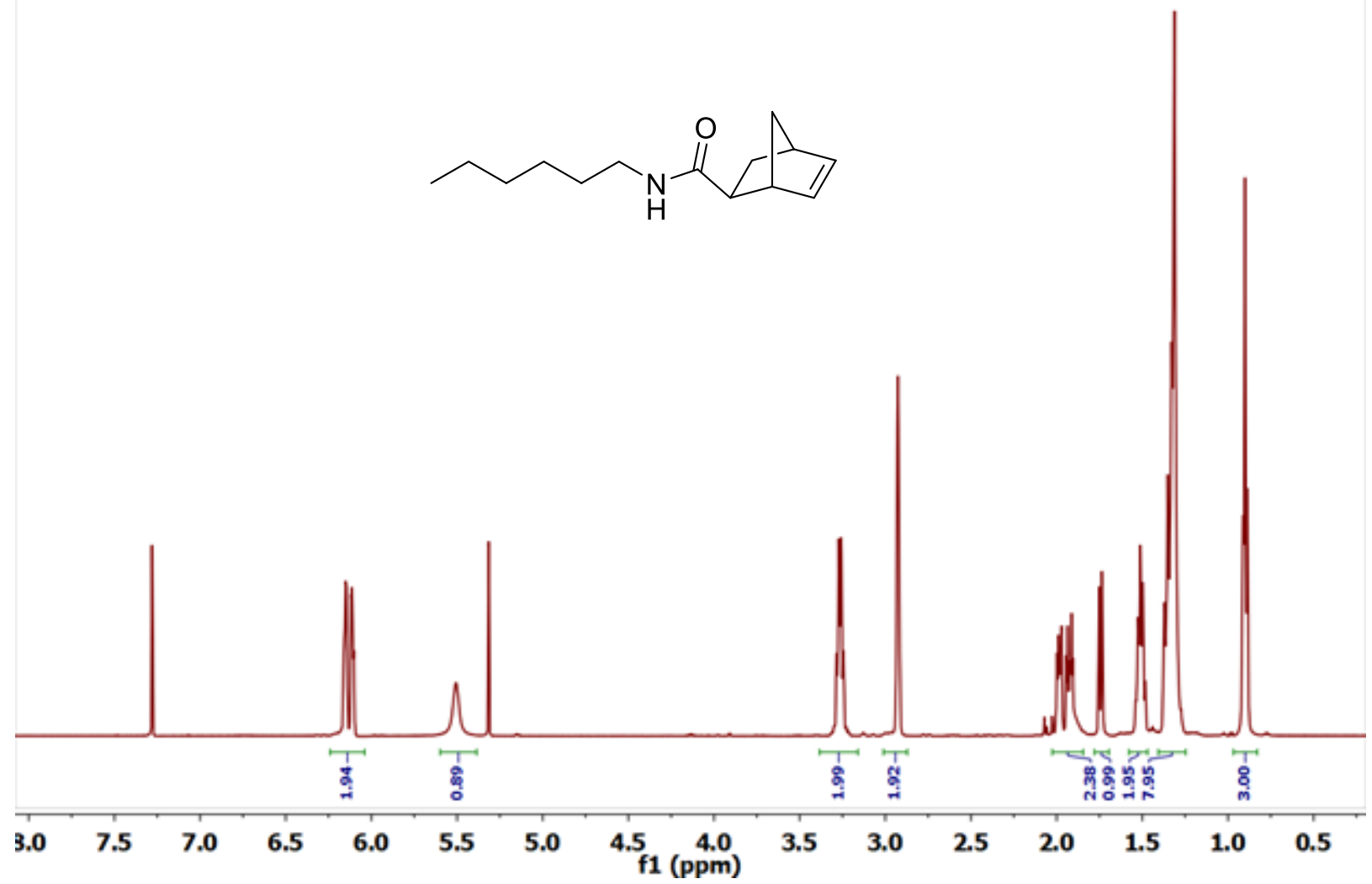

Figure $\mathrm{S} 2{ }^{1} \mathrm{H} \mathrm{NMR}\left(500 \mathrm{MHz}, \mathrm{CDCl}_{3}\right)$ of monomer 4 


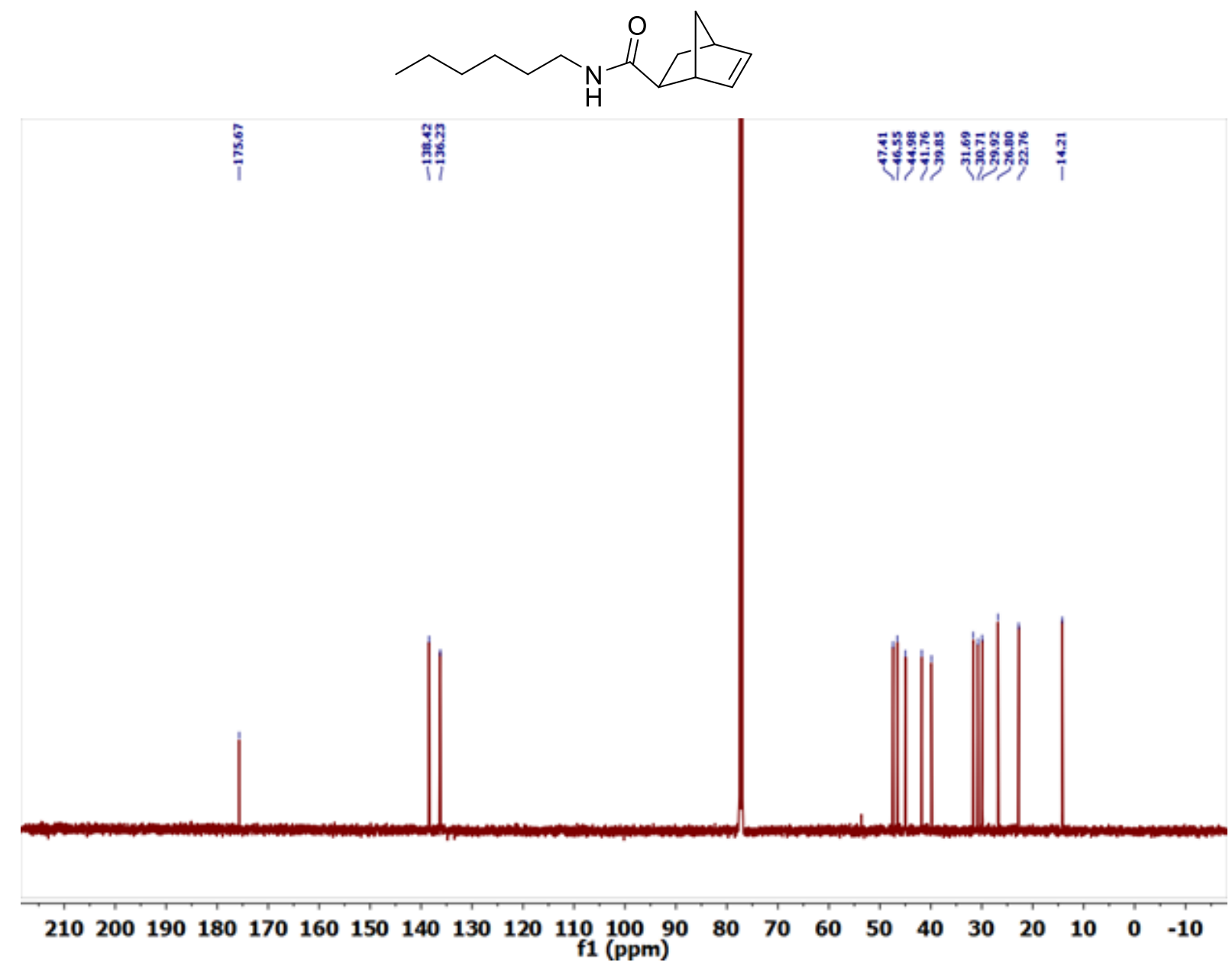

Figure $\mathrm{S} 30{ }^{13} \mathrm{C} \mathrm{NMR}\left(500 \mathrm{MHz}, \mathrm{CDCl}_{3}\right)$ of monomer 4 


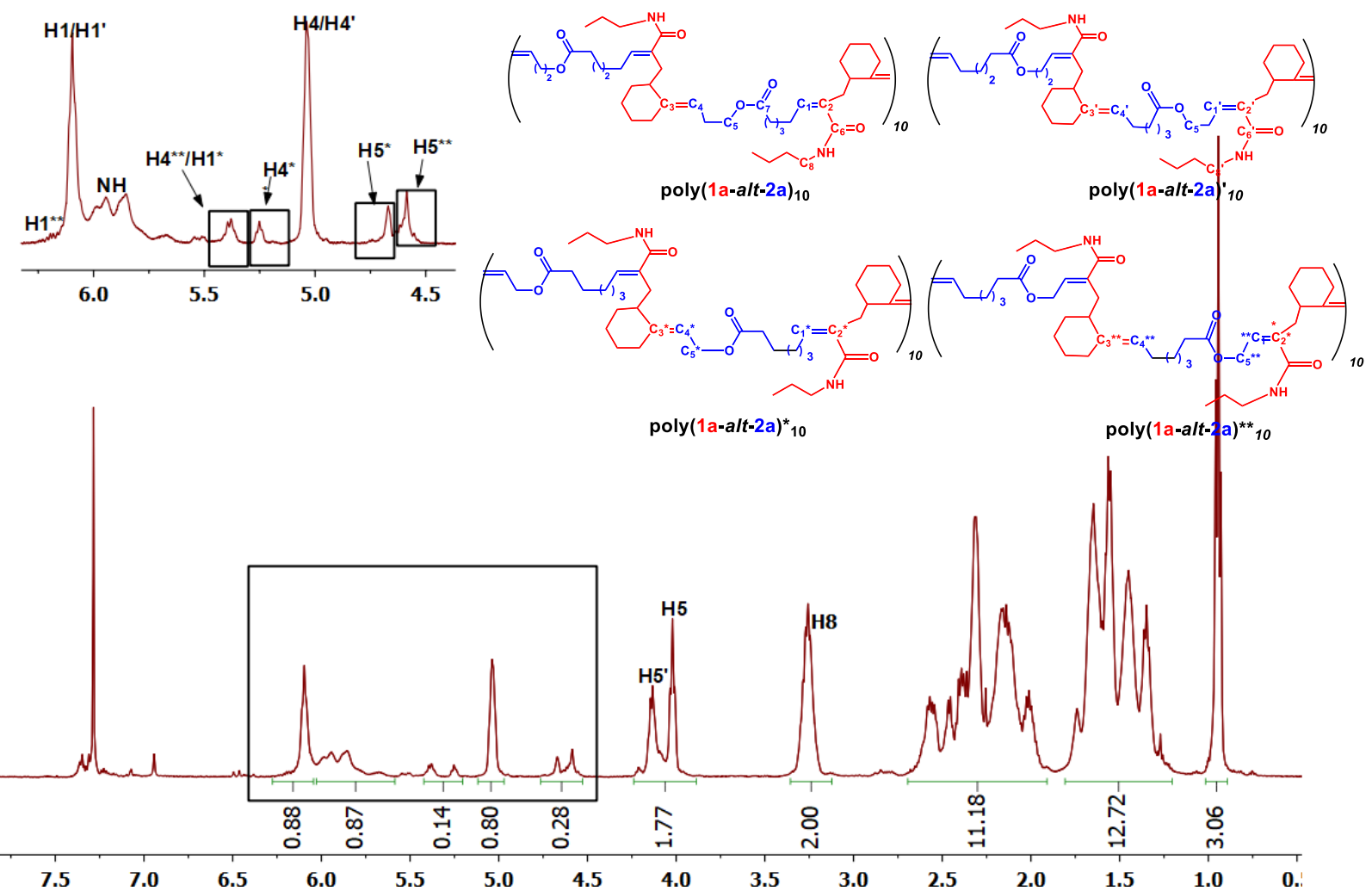

Figure S31 ${ }^{1} \mathrm{H}$ NMR of poly $(\mathbf{1 a}-\text { alt-2a })_{10}$

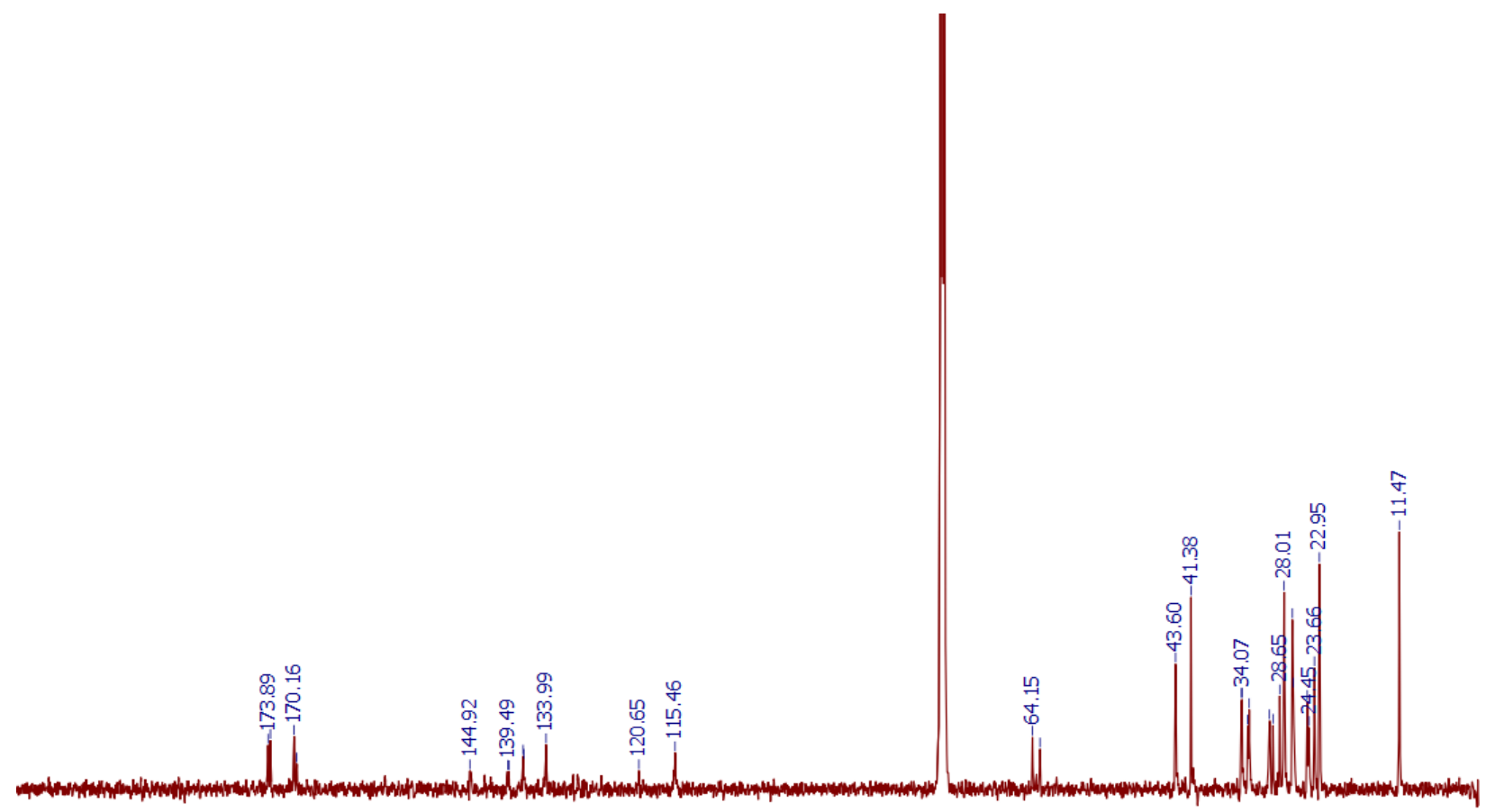

$\begin{array}{lllllllllllllllllllllll}10 & 200 & 190 & 180 & 170 & 160 & 150 & 140 & 130 & 120 & 110 & 100 & 90 & 80 & 70 & 60 & 50 & 40 & 30 & 20 & 10 & 1\end{array}$

Figure S32 ${ }^{13} \mathrm{C}$ NMR of poly $(1 \mathbf{a}-a \text { alt-2a })_{10}$ 


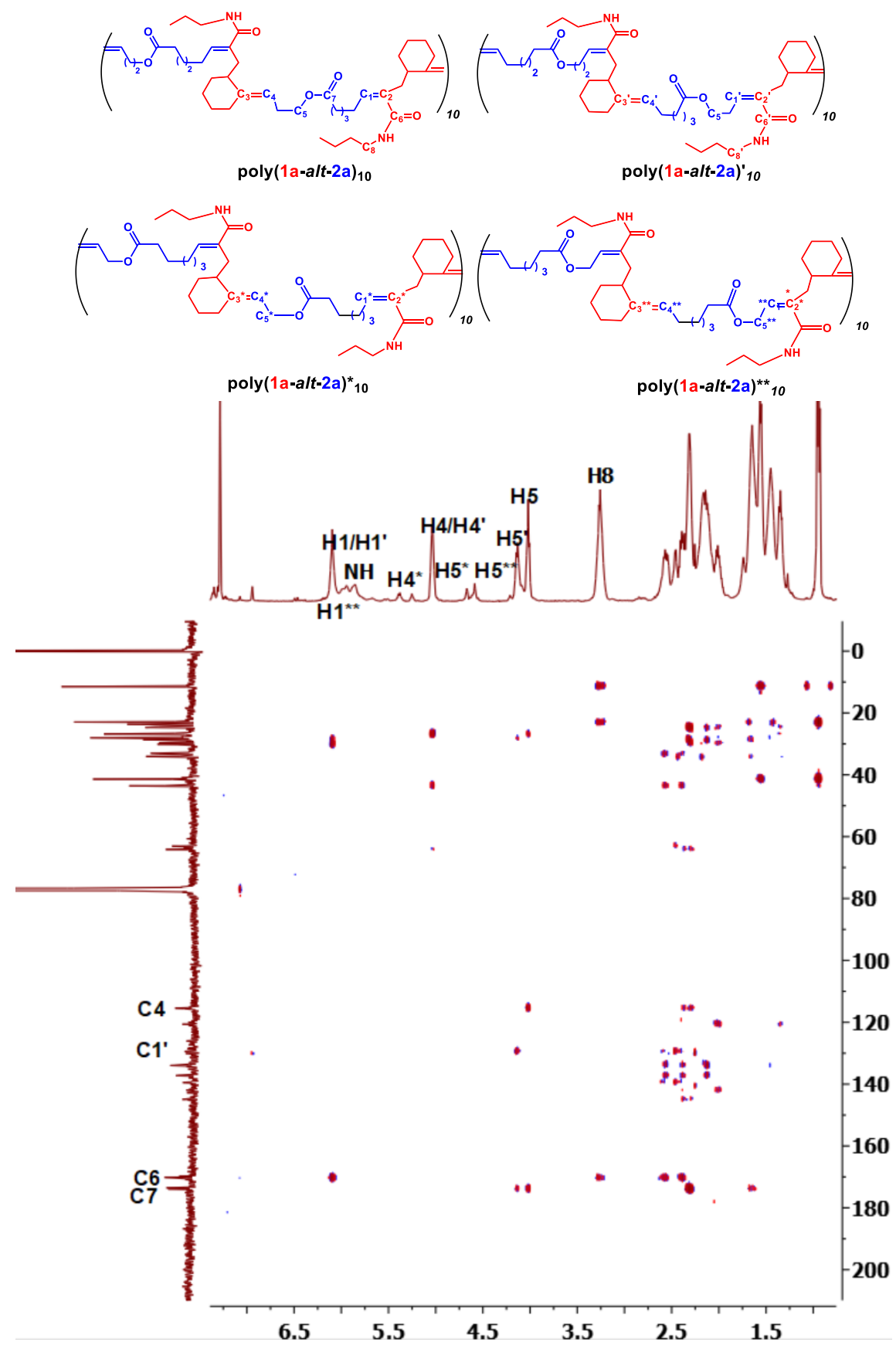

Figure S33 HMBC NMR of poly(1a-alt-2a $)_{10}$ 


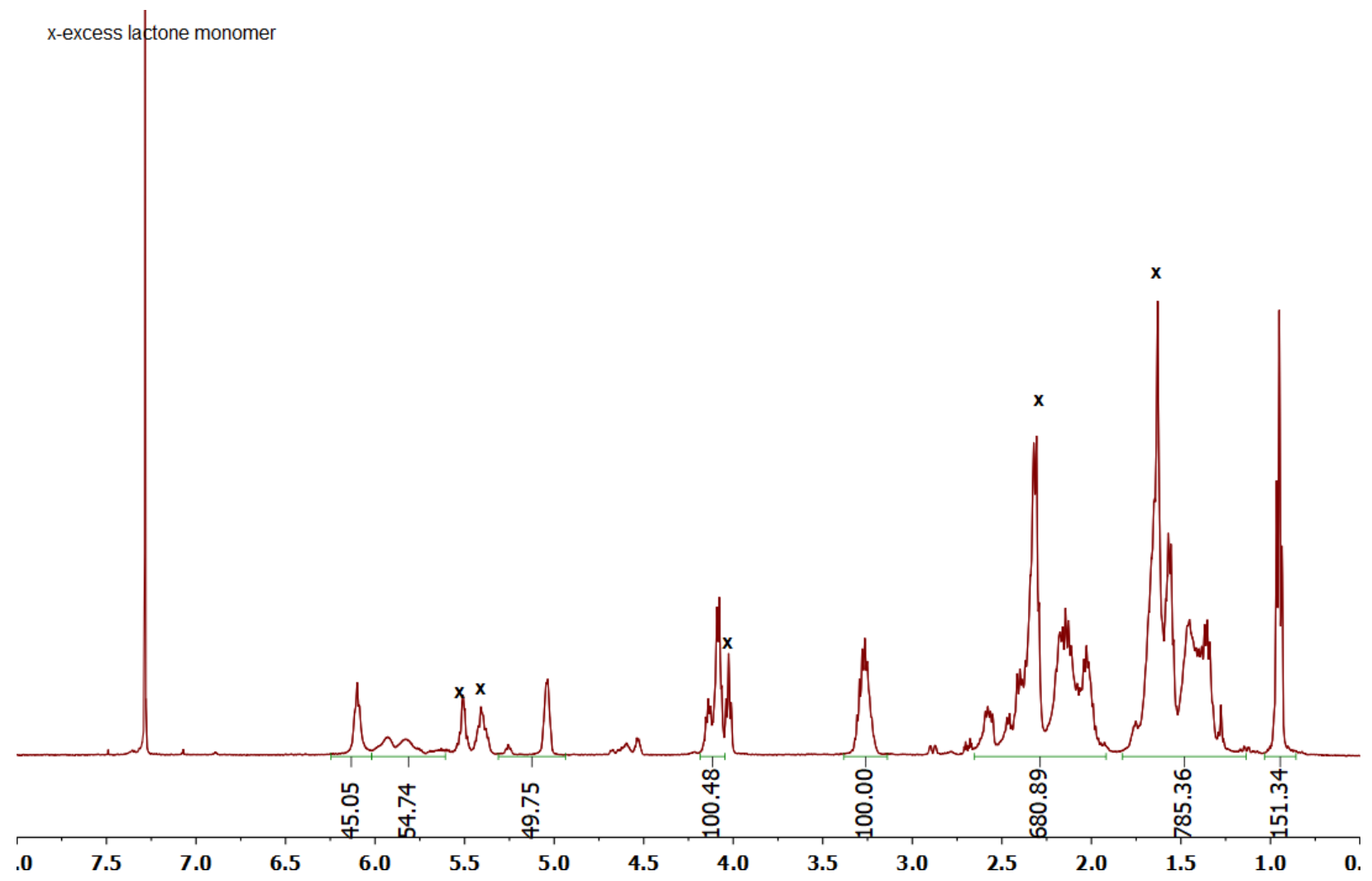

Figure S34 ${ }^{1} \mathrm{H}$ NMR of poly $(1 \mathbf{a}-a / t-2 a)_{50}$

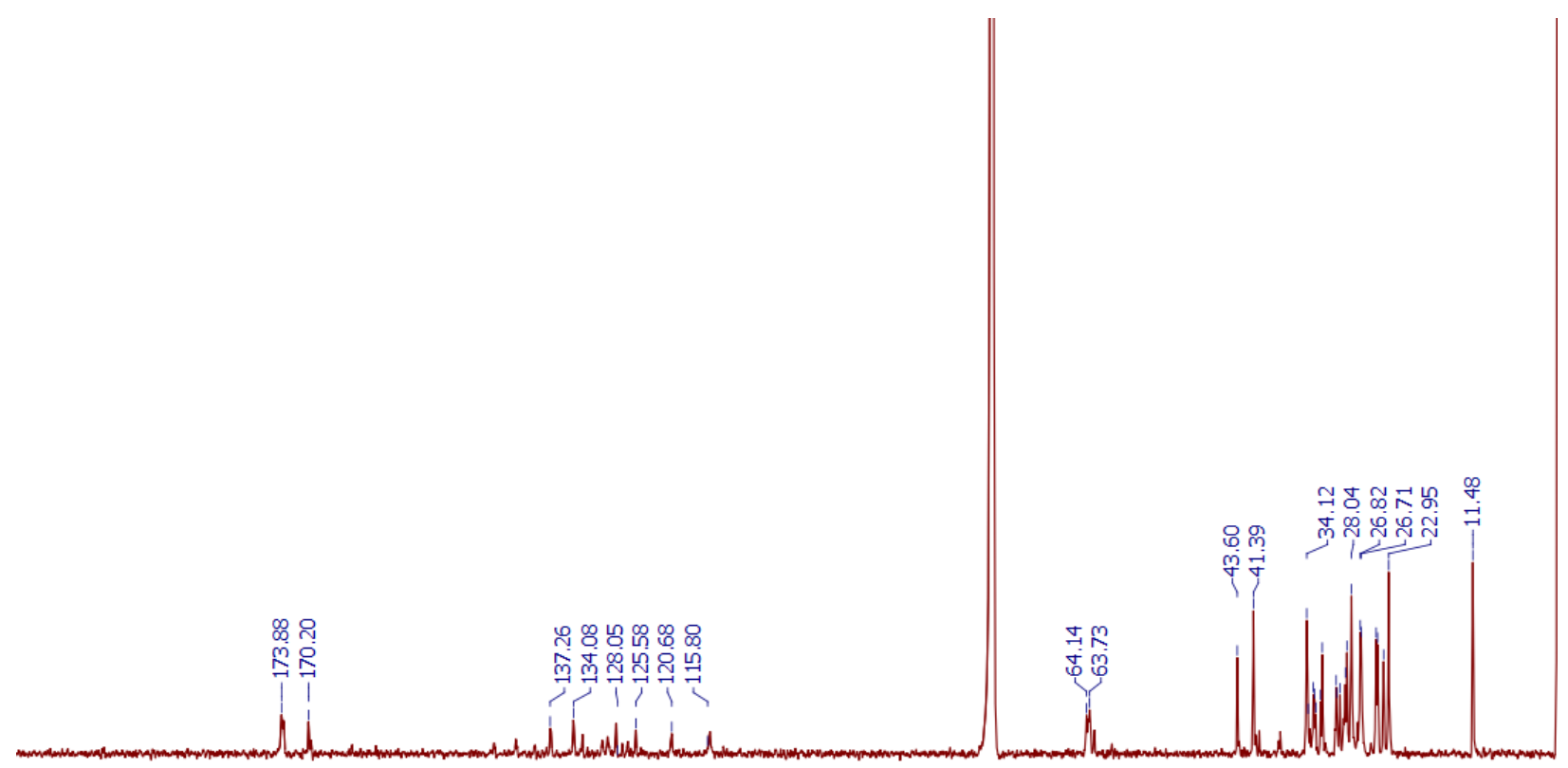

$\begin{array}{lllllllllllllllllllllll}10 & 200 & 190 & 180 & 170 & 160 & 150 & 140 & 130 & 120 & 110 & 100 & 90 & 80 & 70 & 60 & 50 & 40 & 30 & 20 & 10 & \text { ( }\end{array}$

Figure $\mathrm{S} 35{ }^{13} \mathrm{C}$ NMR of poly(1a-alt-2a) $)_{50}$ 


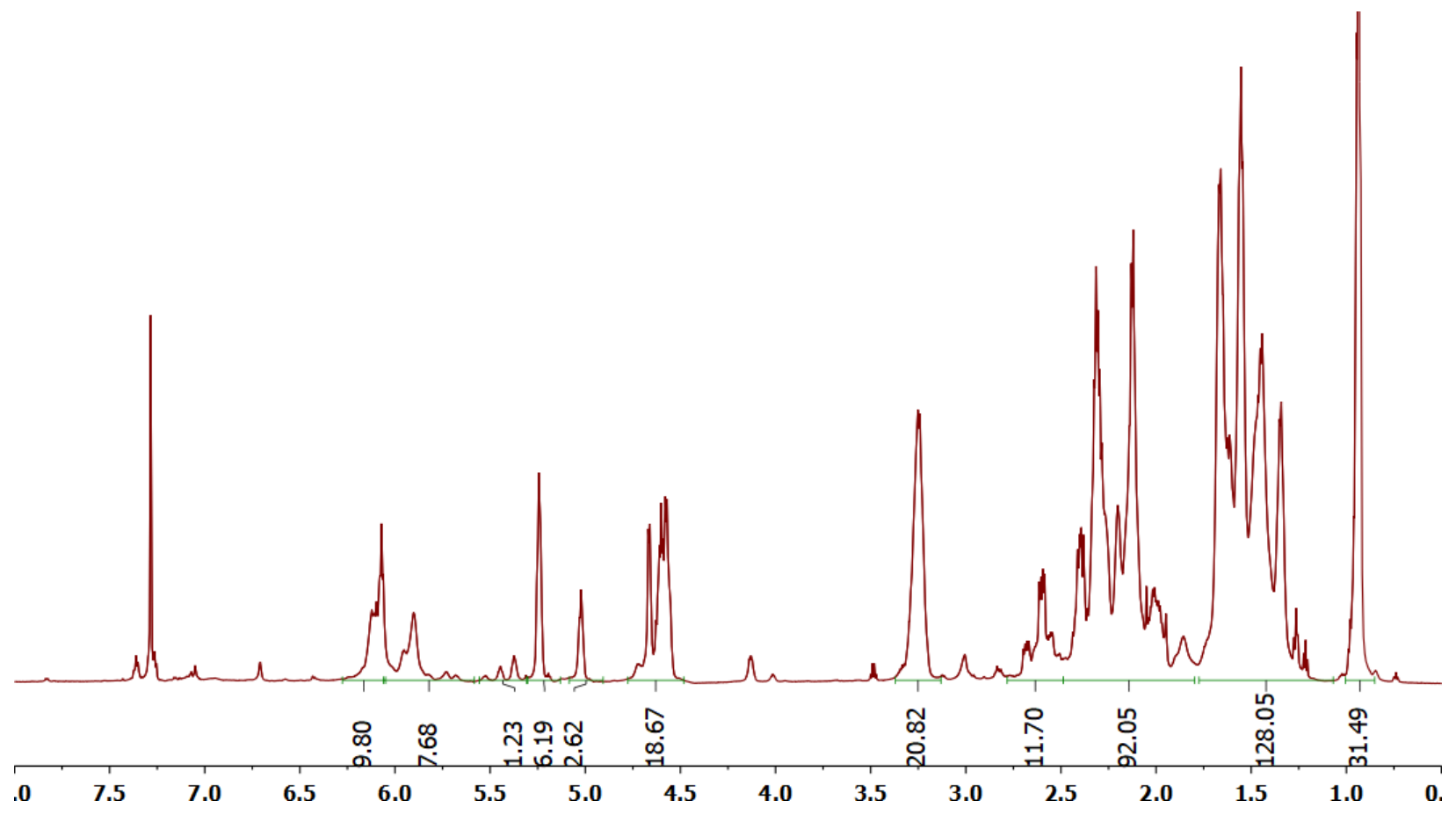

Figure S36 ${ }^{1} \mathrm{H}$ NMR of poly $(\mathbf{1 a}-a / t-2 \mathbf{b})_{10}$

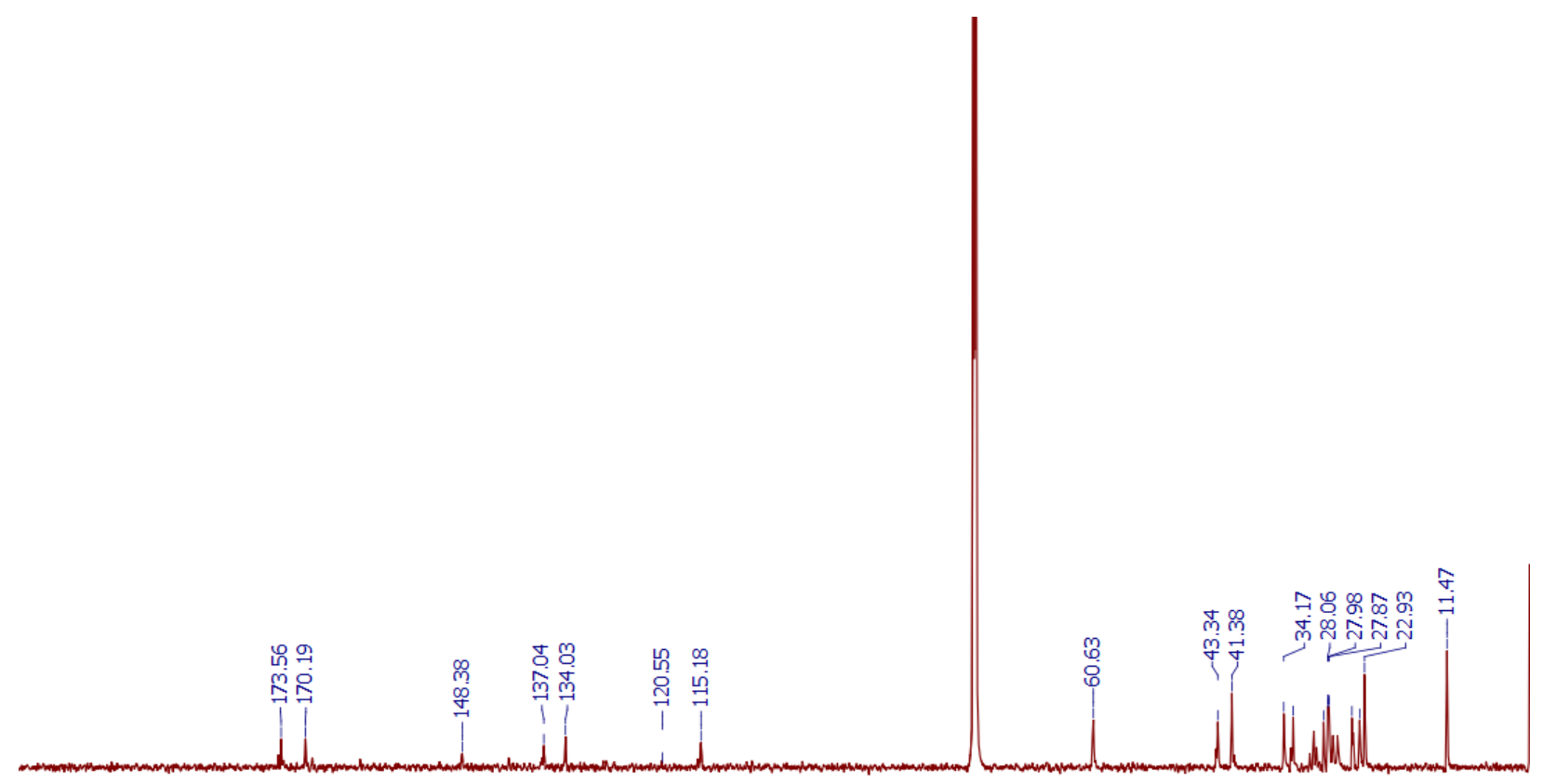

$\begin{array}{llllllllllllllllllllllll}10 & 200 & 190 & 180 & 170 & 160 & 150 & 140 & 130 & 120 & 110 & 100 & 90 & 80 & 70 & 60 & 50 & 40 & 30 & 20 & 10 & \text { ( }\end{array}$

Figure S37 ${ }^{13} \mathrm{C}$ NMR of poly $(\mathbf{1 a}-\text { alt-2b) })_{10}$ 

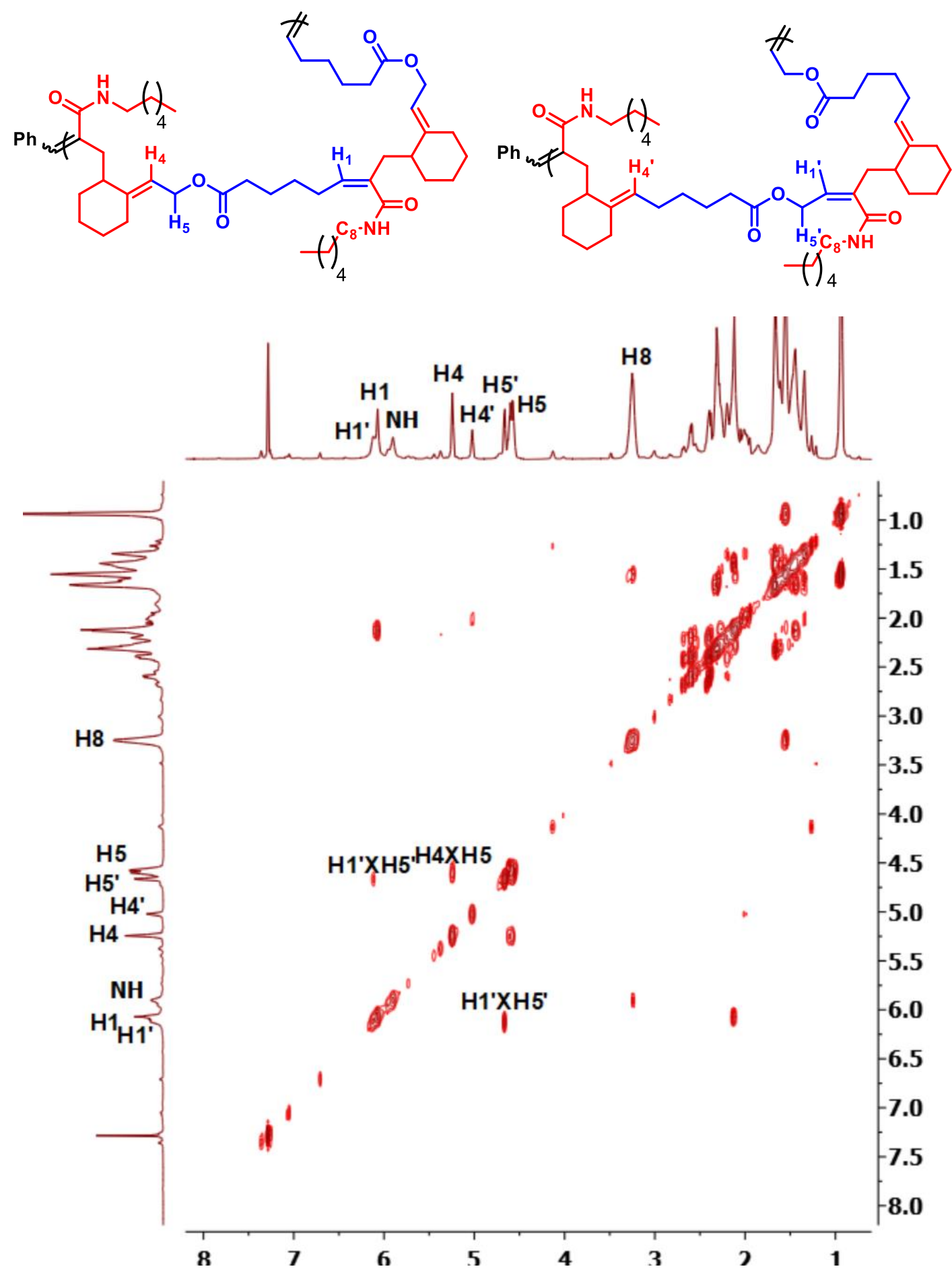

Figure S38 COSY NMR of poly $(\mathbf{1 a}-a / t-2 b)_{10}$ 

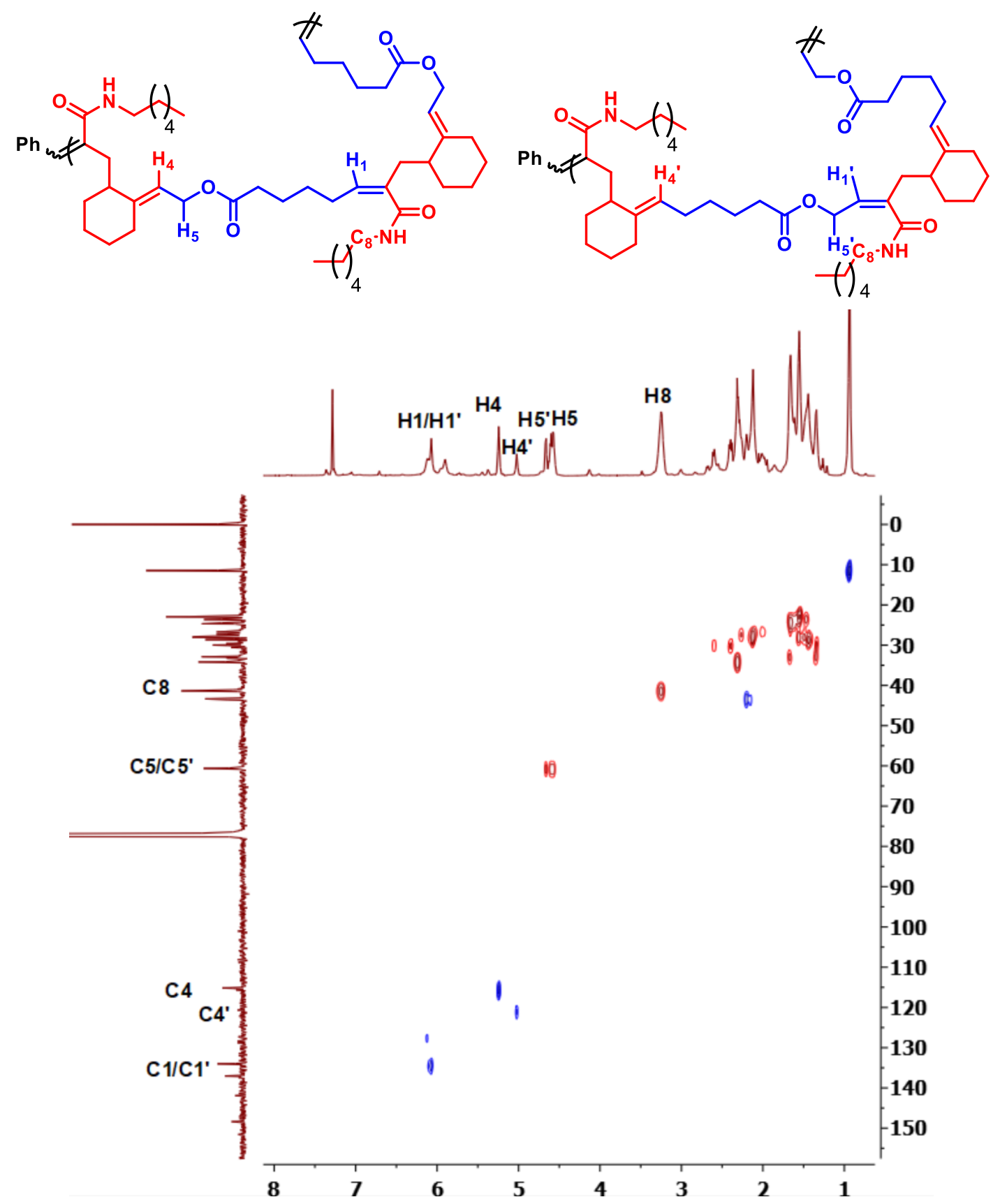

Figure S39 HSQC NMR of poly $(\mathbf{1} \mathbf{a}-a / t-2 \mathbf{b})_{10}$ 


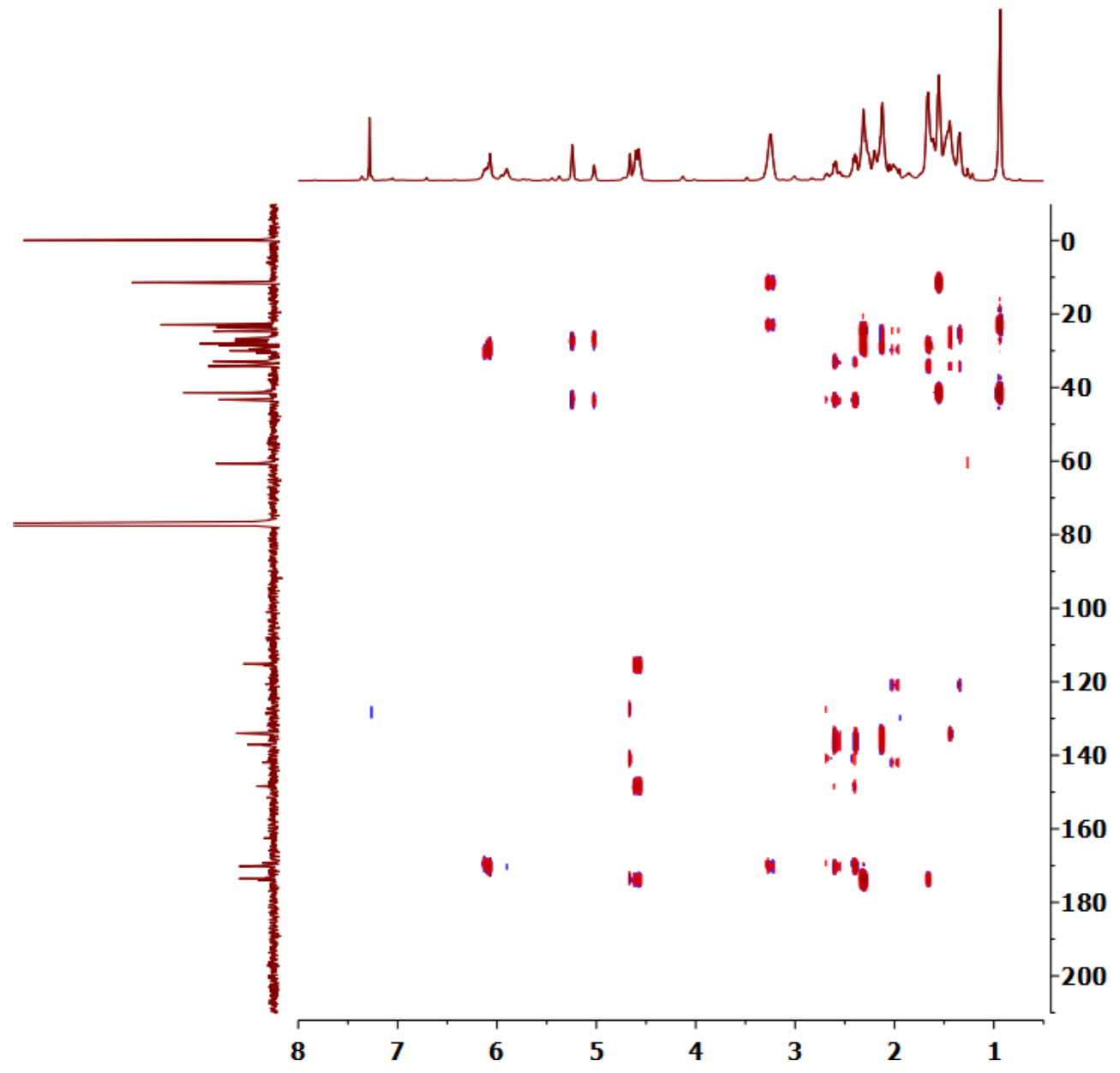

Figure S40 HMBC NMR of poly(1a-alt-2b $)_{10}$ 


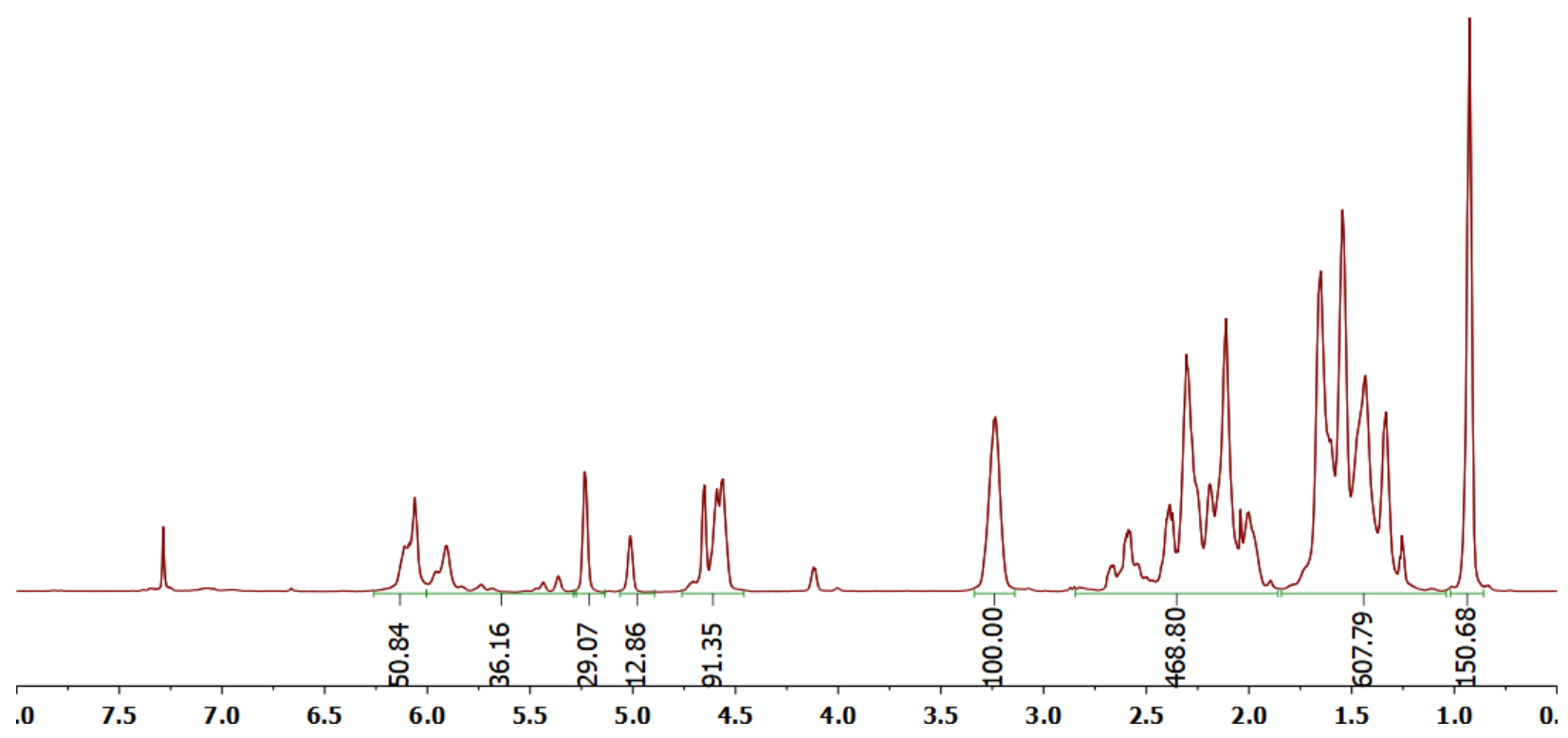

Figure S41 ${ }^{1} \mathrm{H}$ NMR of poly $(\mathbf{1} \mathbf{a}-a / t-2 b)_{50}$

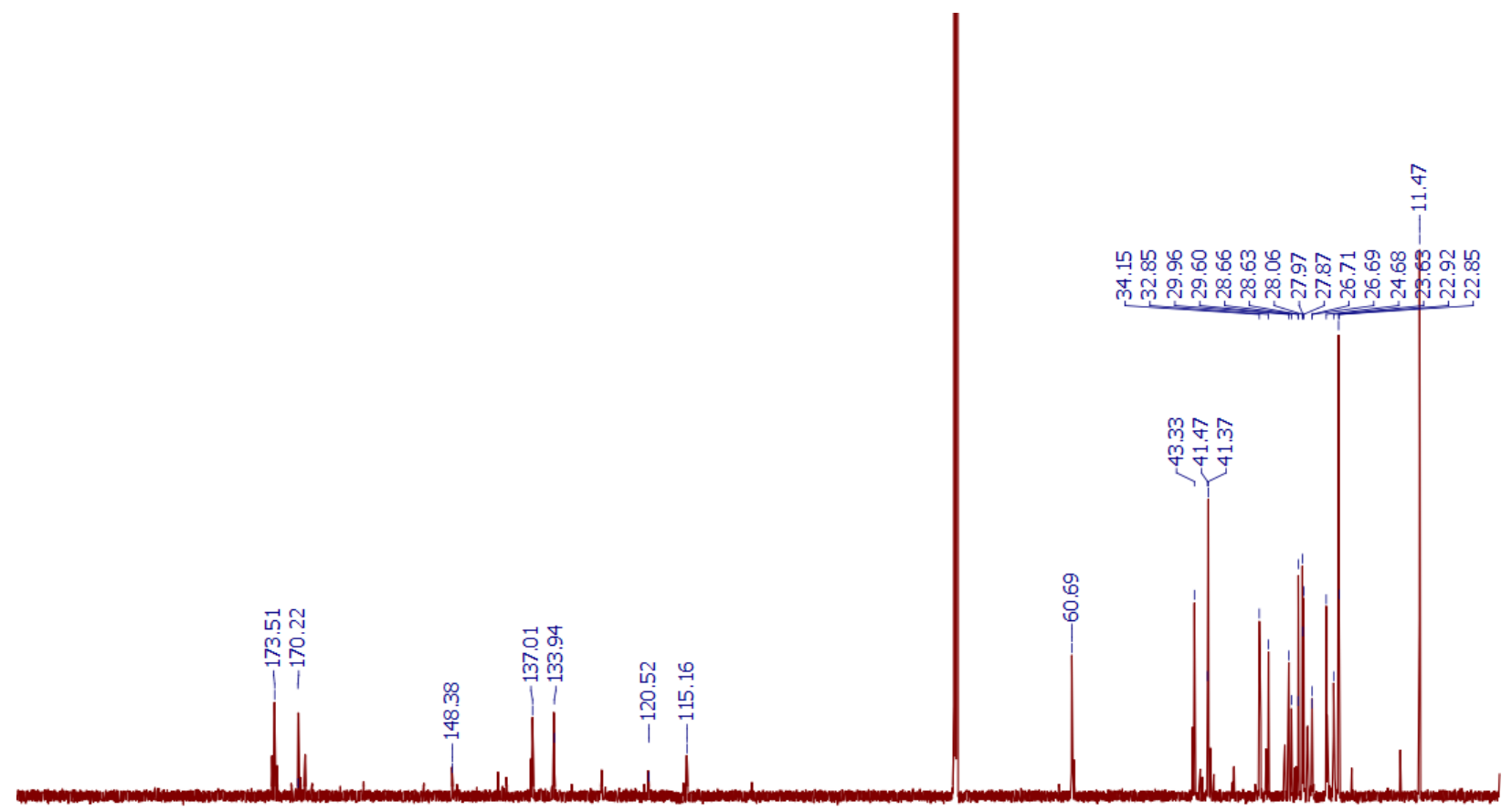

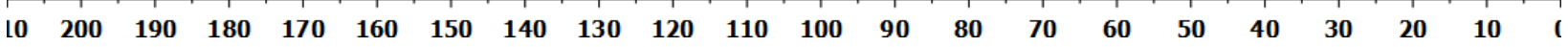

Figure $\mathbf{S 4 2}{ }^{13} \mathrm{C}$ NMR of poly $(1 \mathbf{a}-\text { alt-2b })_{50}$ 


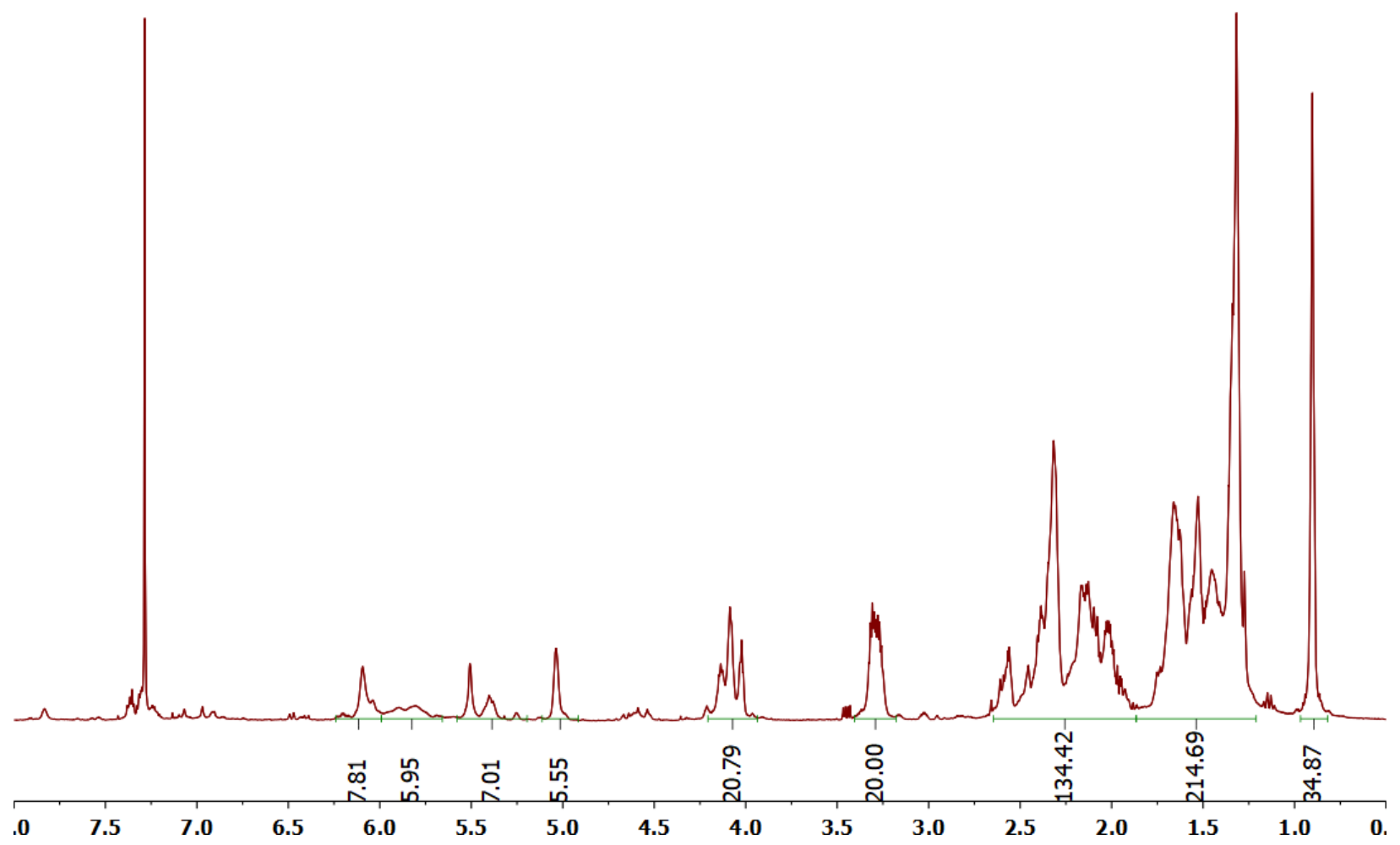

Figure S43 ${ }^{1} \mathrm{H}$ NMR of poly(1b-alt-2a $)_{10}$ 


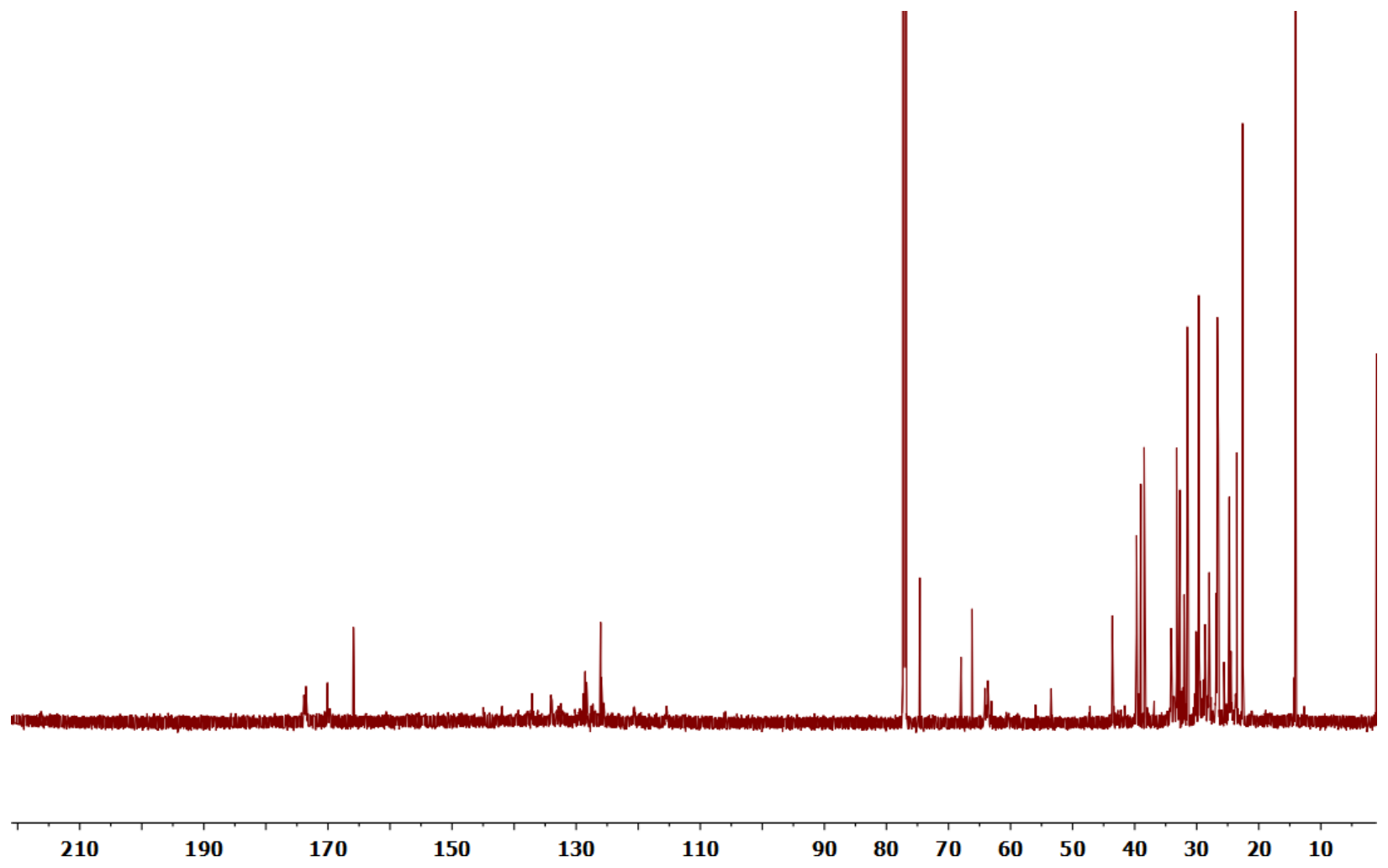

Figure S44 ${ }^{13} \mathrm{C}$ NMR of poly(1)-alt-2a $)_{10}$ 


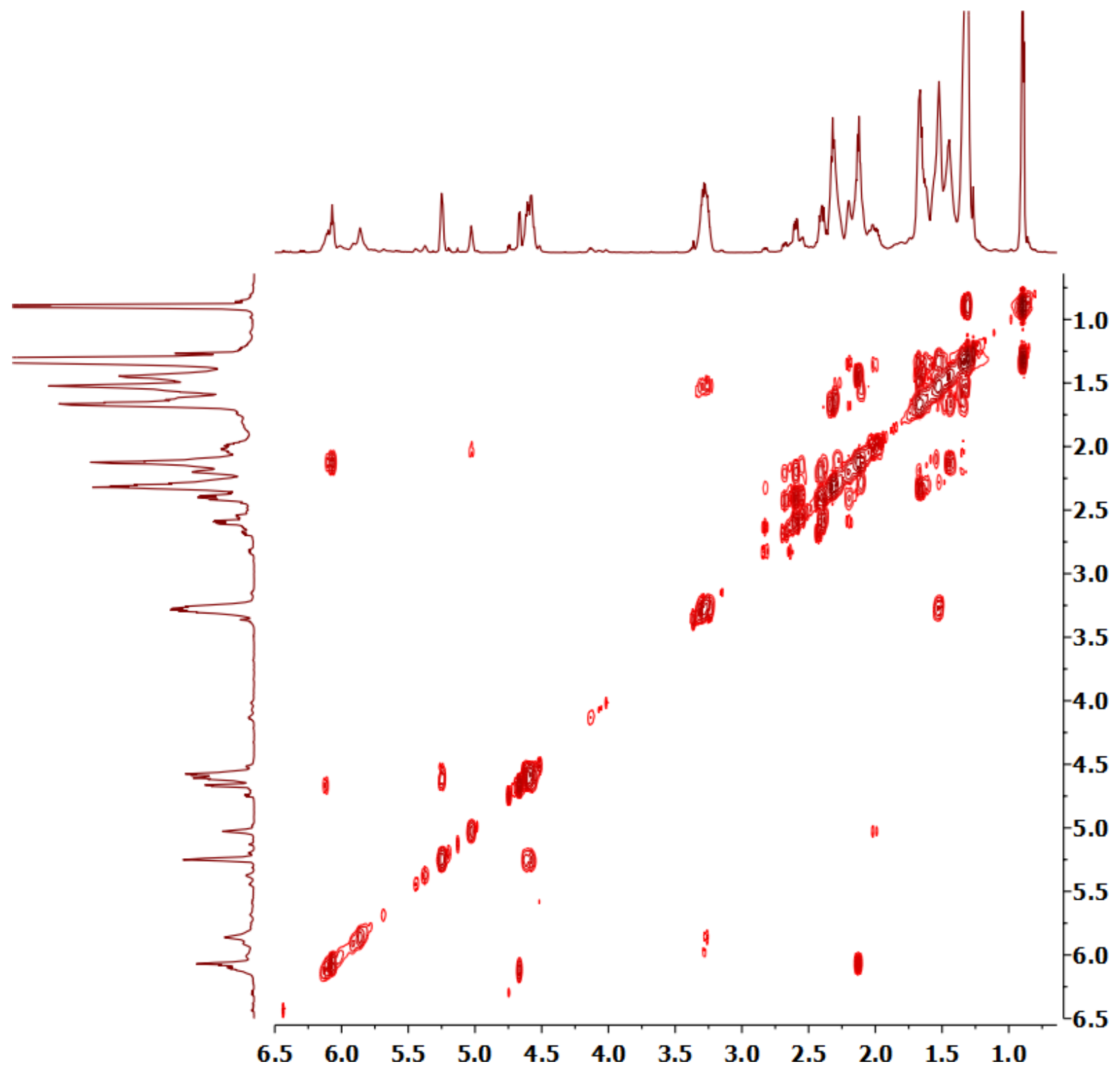

Figure S45 COSY of poly(1)-alt-2b $)_{10}$ 


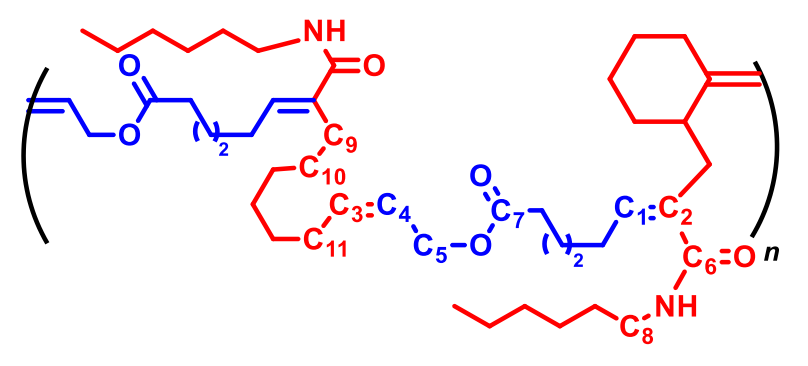

poly(1b-alt-2b)

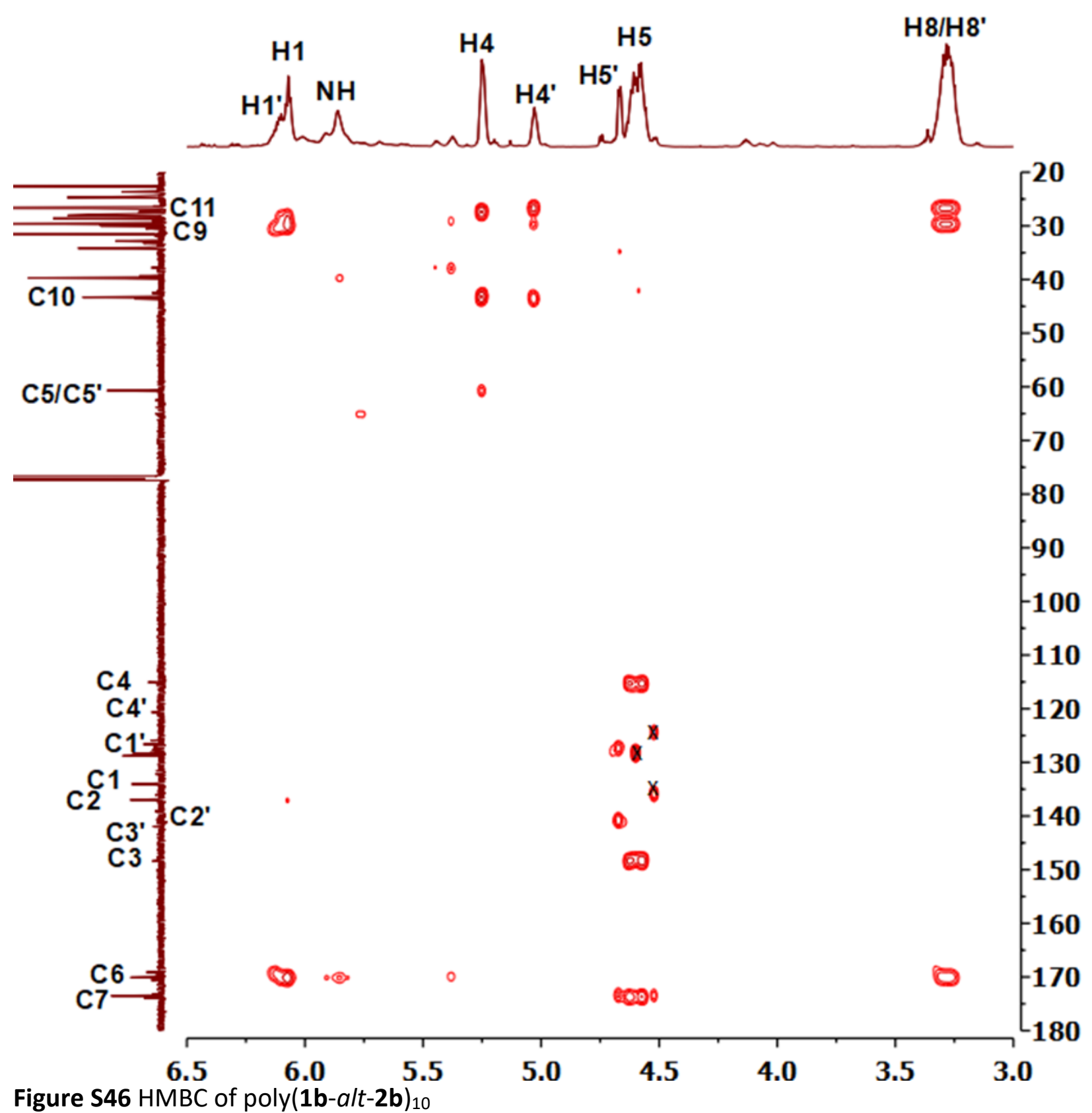



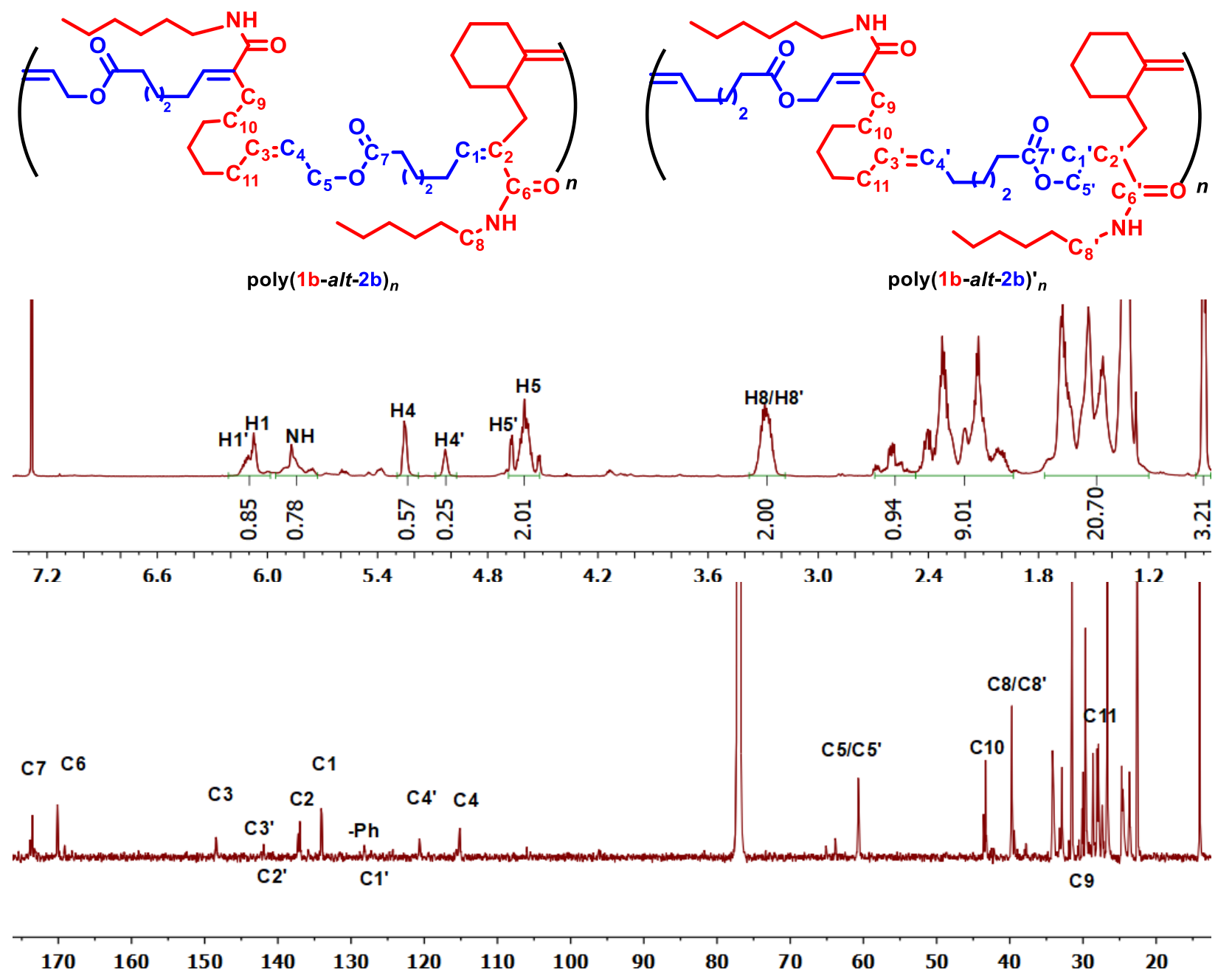

Figure $\mathbf{S 4 7}{ }^{1} \mathrm{H}$ and ${ }^{13} \mathrm{C}$ NMR of poly(1)-alt-2b $)_{50}$ 

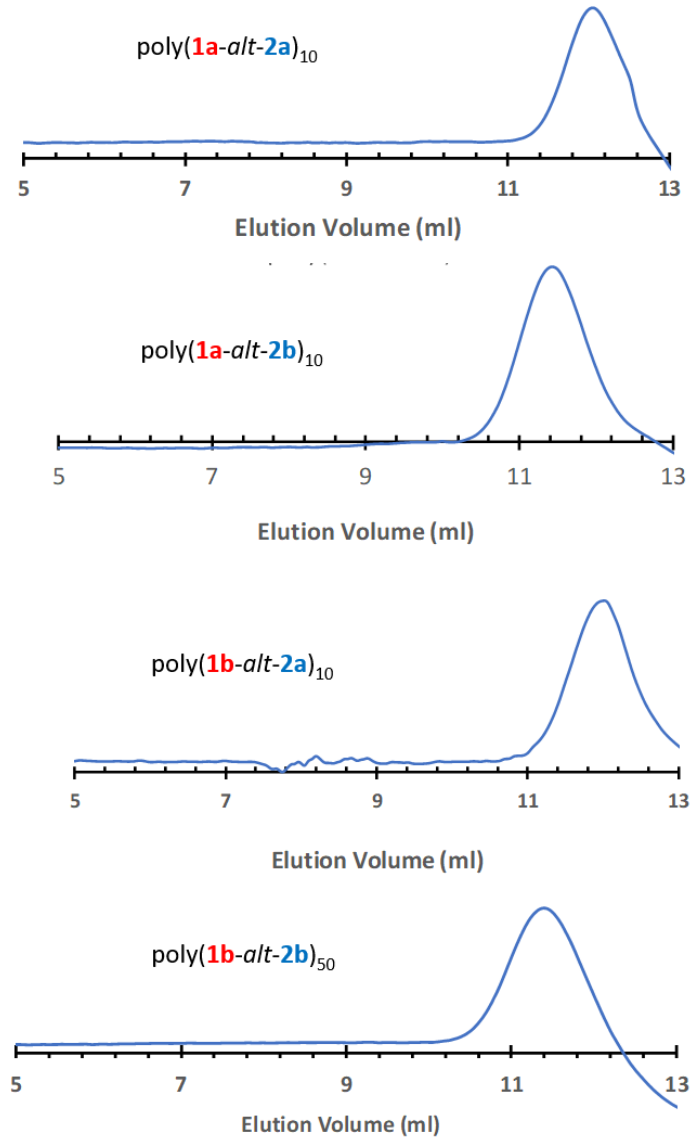

Figure S48 GPC traces of 1-alt-2 copolymers
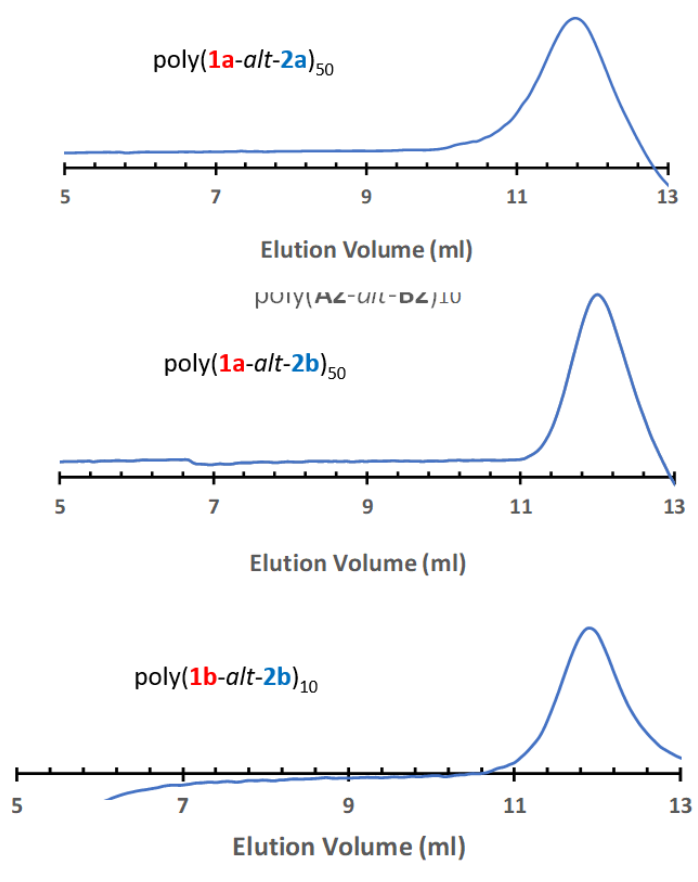


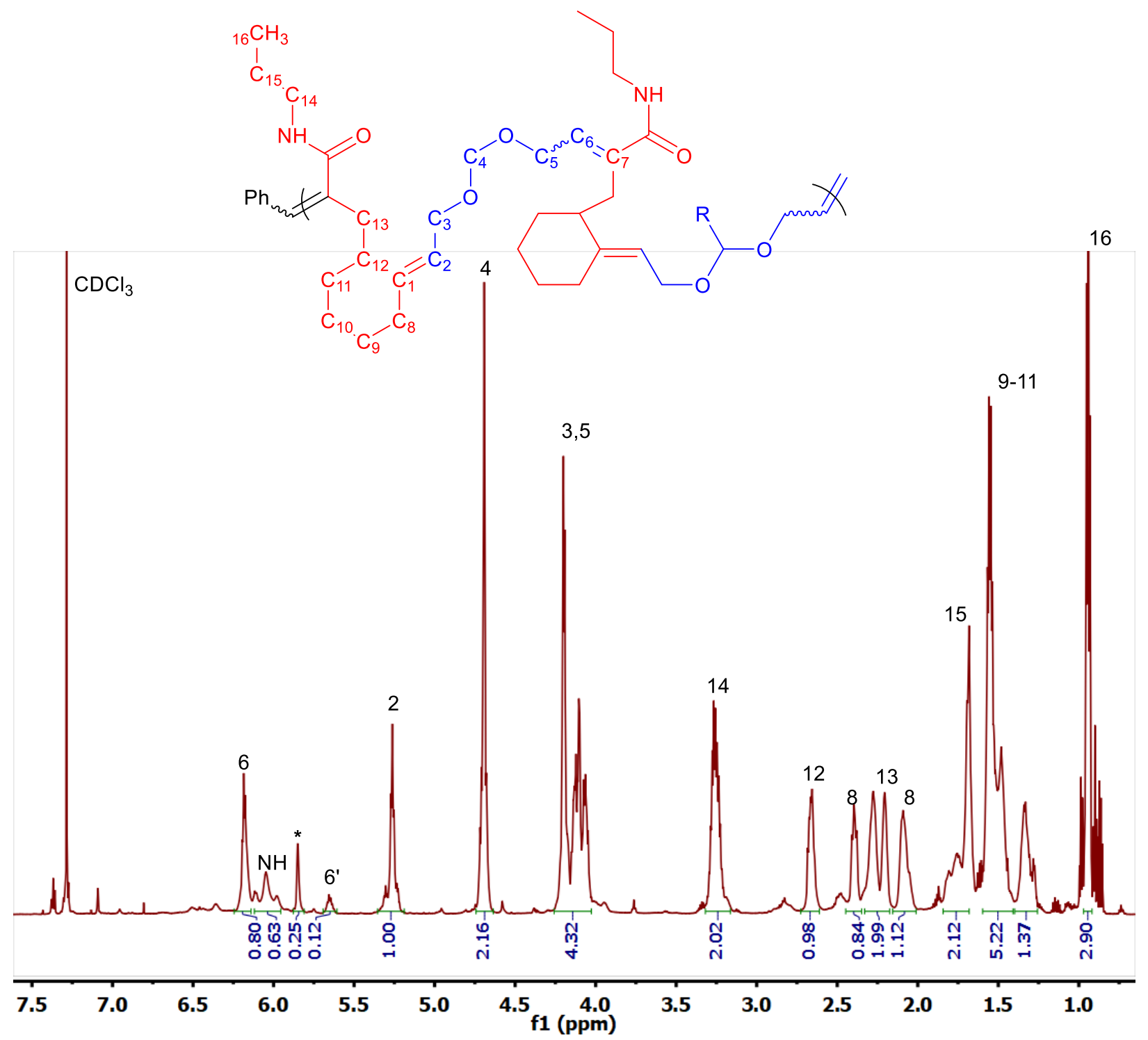

Figure S49 assigned ${ }^{1} \mathrm{H}-\mathrm{NMR}$ spectrum of 1a-alt-3a copolymer. Peak marked asterisked is artifact arising impurity in monomer $\mathbf{3 a}$. It is a singlet proton and does not arise from homoaddtion of 3a. 


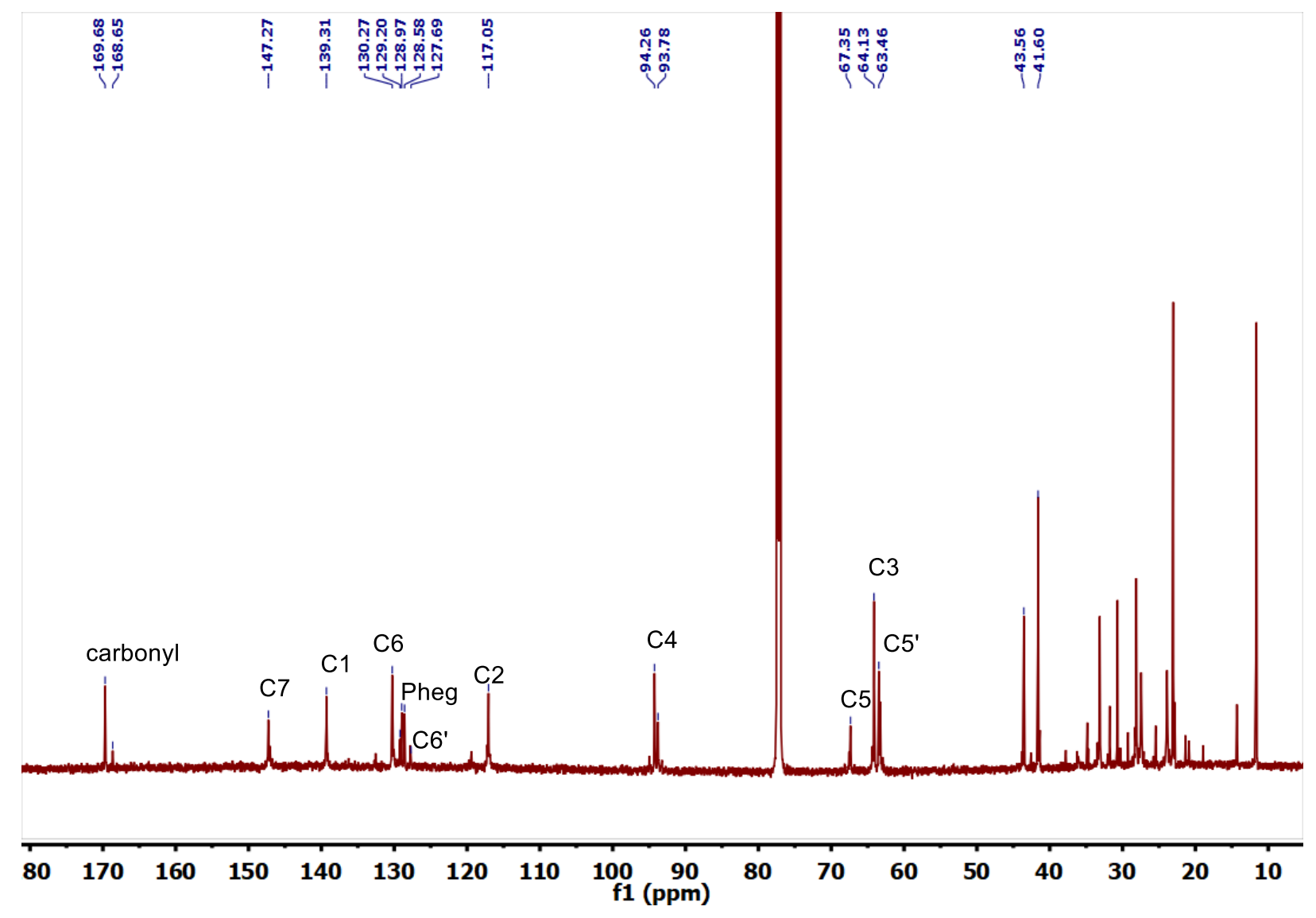

Figure S50 ${ }^{13} \mathrm{C}$ NMR of 1a-alt-3a copolymer. Clearly, there 4 four major olefin carbons and 1 olefin isomer $\mathrm{C6}^{\prime}$ 


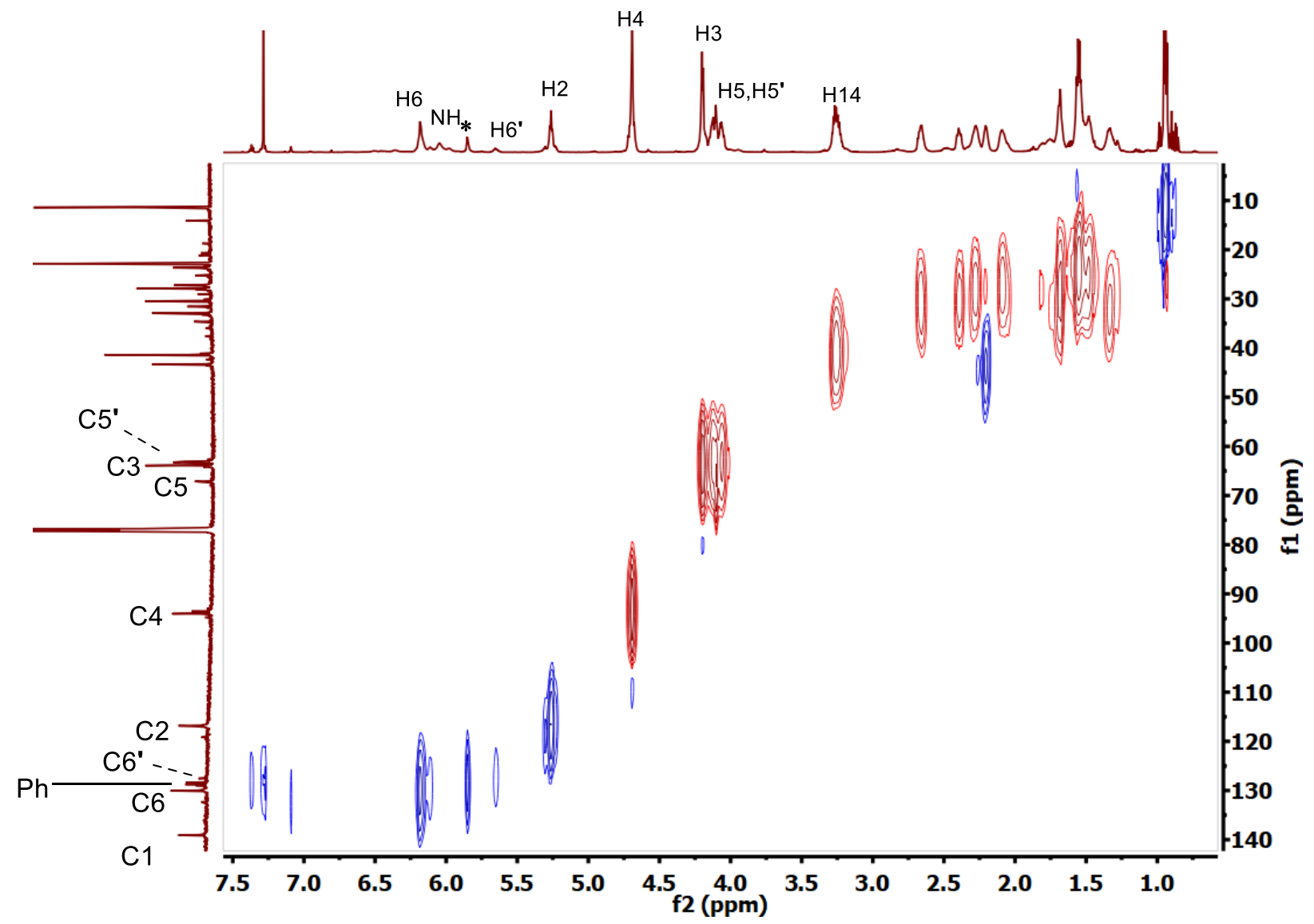

Figure $\mathbf{S} 51{ }^{1} \mathrm{H}_{-}{ }^{13} \mathrm{C}$ HSQC NMR of 1a-alt-3a copolymer 


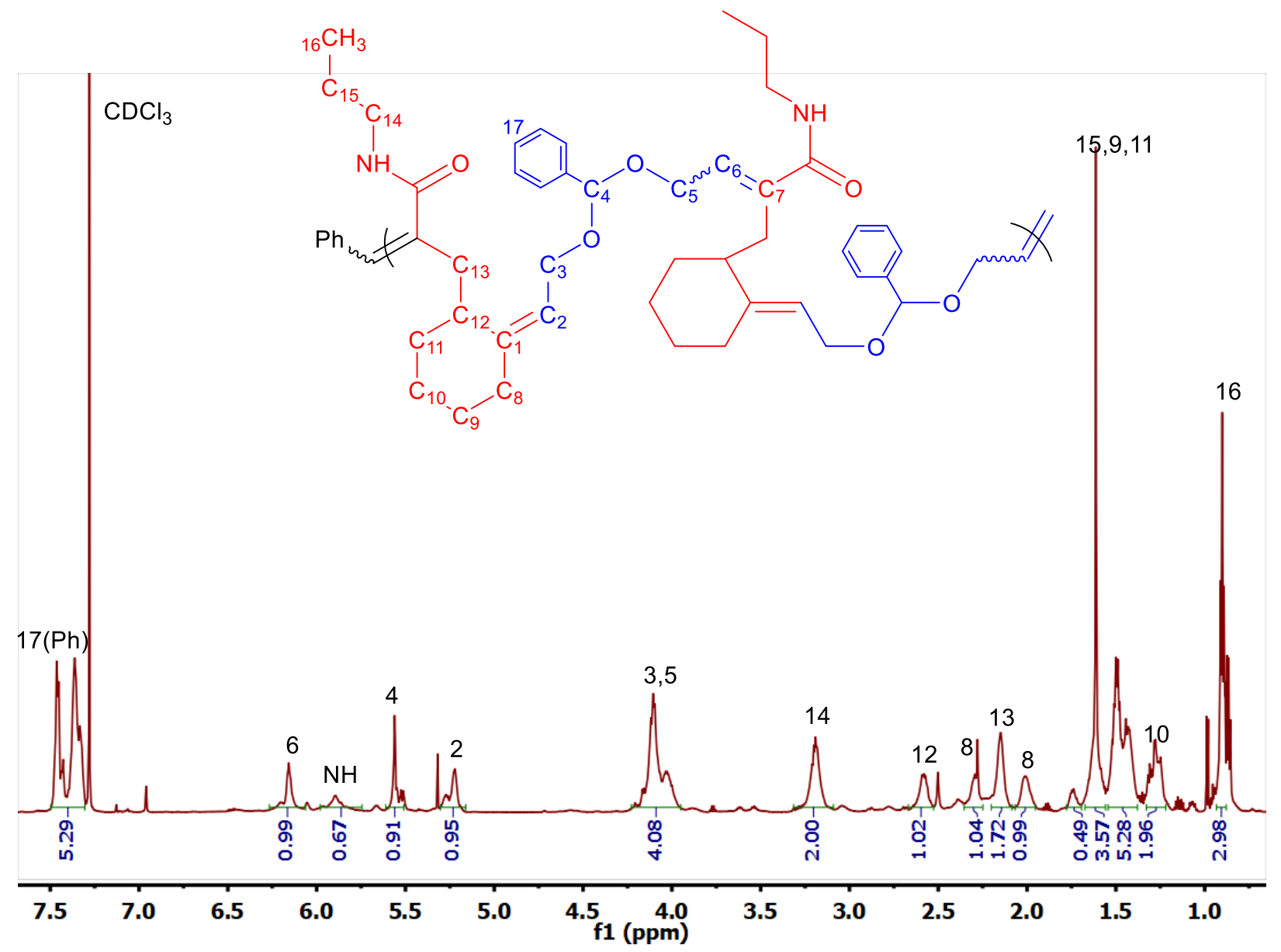

Figure S52 assigned ${ }^{1} \mathrm{H}-\mathrm{NMR}$ spectrum of $\mathbf{1} \mathbf{a}$-alt-3b copolymer 


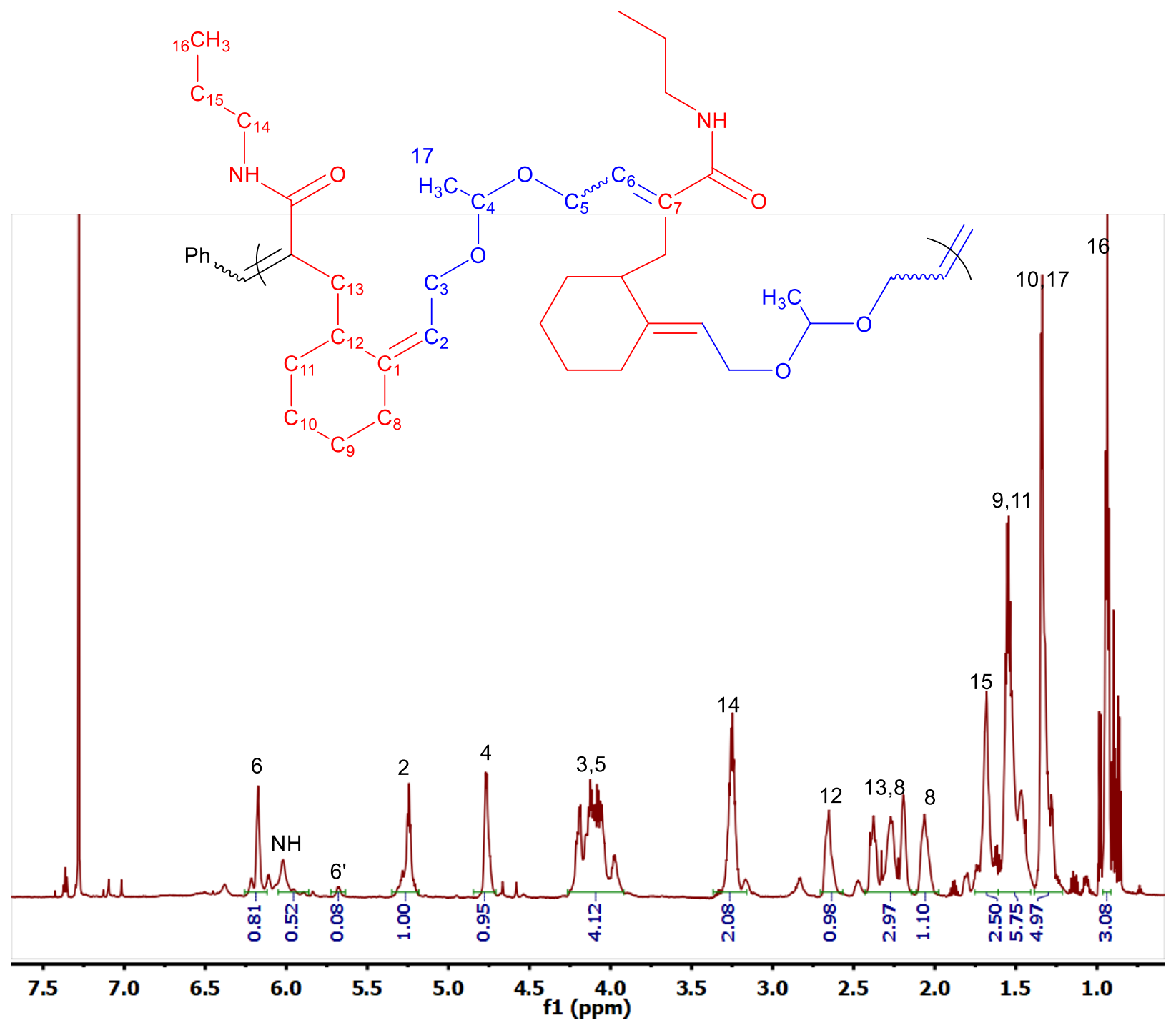

Figure S53 assigned ${ }^{1} \mathrm{H}-\mathrm{NMR}$ spectrum of $1 \mathrm{a}$-alt-3c copolymer 


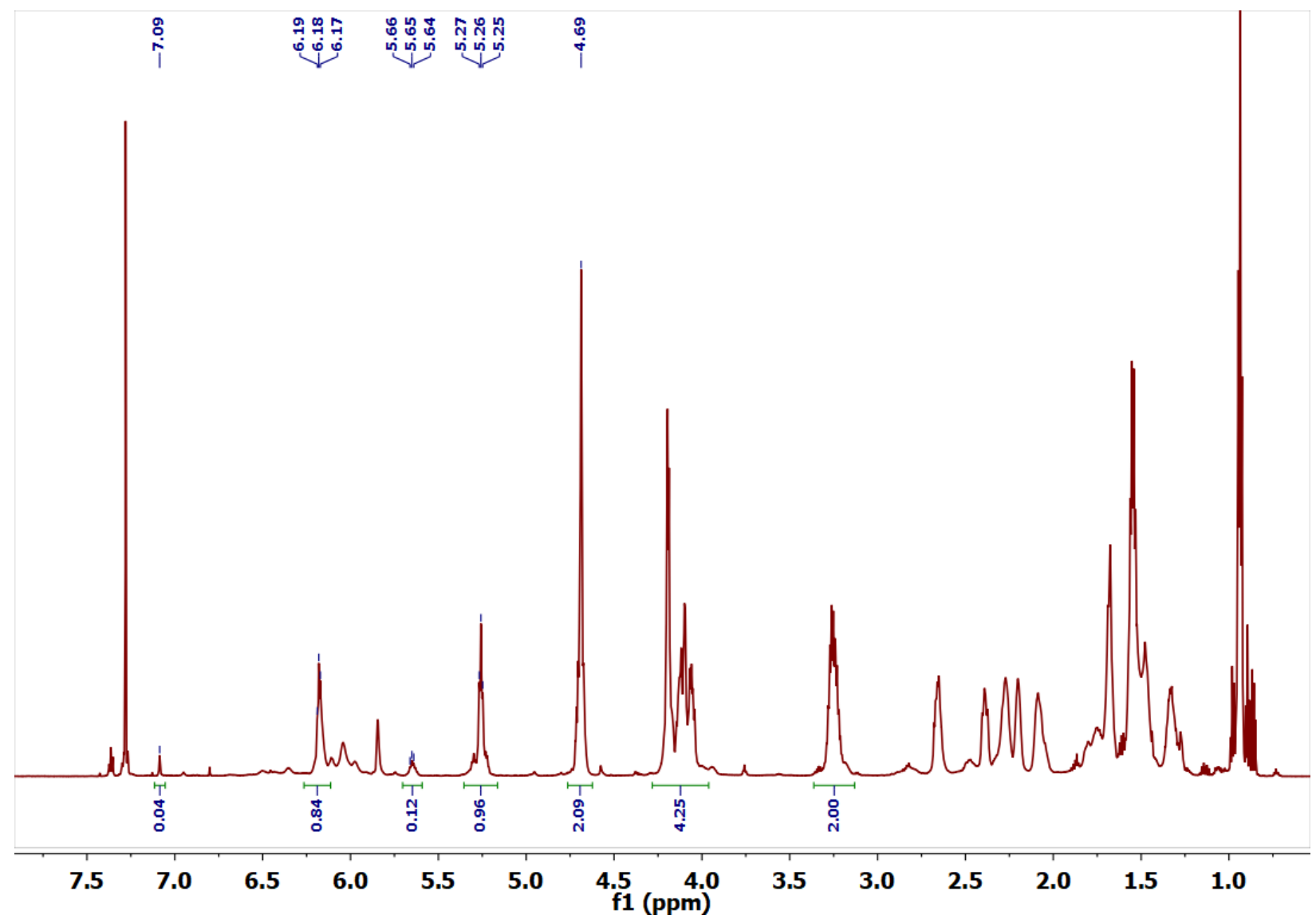

Figure $554{ }^{1} \mathrm{H}$ NMR $\left(700 \mathrm{MHz}, \mathrm{CDCl}_{3}\right)$ of poly $(1 \mathbf{a}-\text { alt-3a) })_{20}$ 


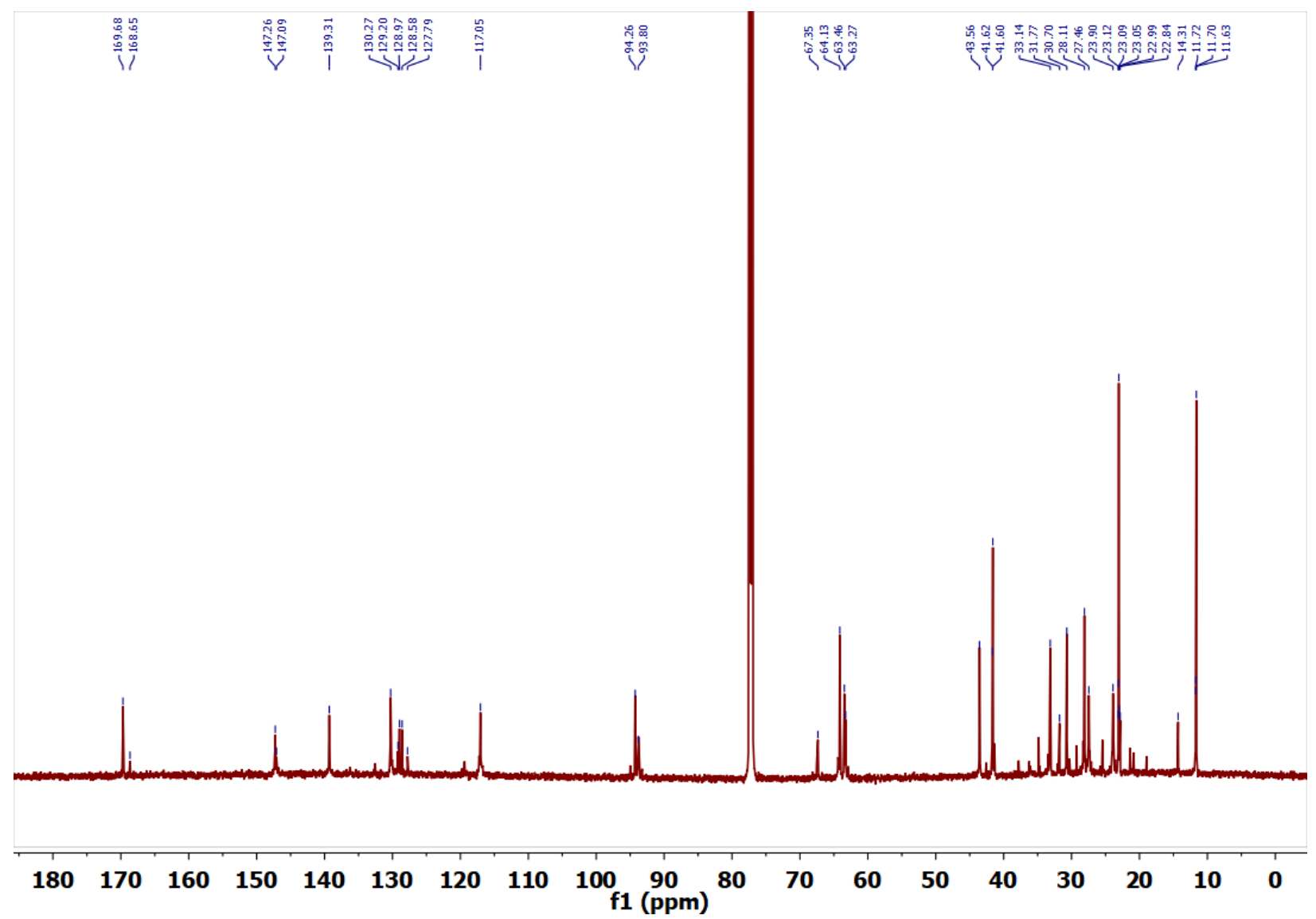

Figure $\mathbf{S} 55{ }^{13} \mathrm{C} \mathrm{NMR}\left(700 \mathrm{MHz}, \mathrm{CDCl}_{3}\right)$ of poly(1a-alt-3a) $)_{20}$ 


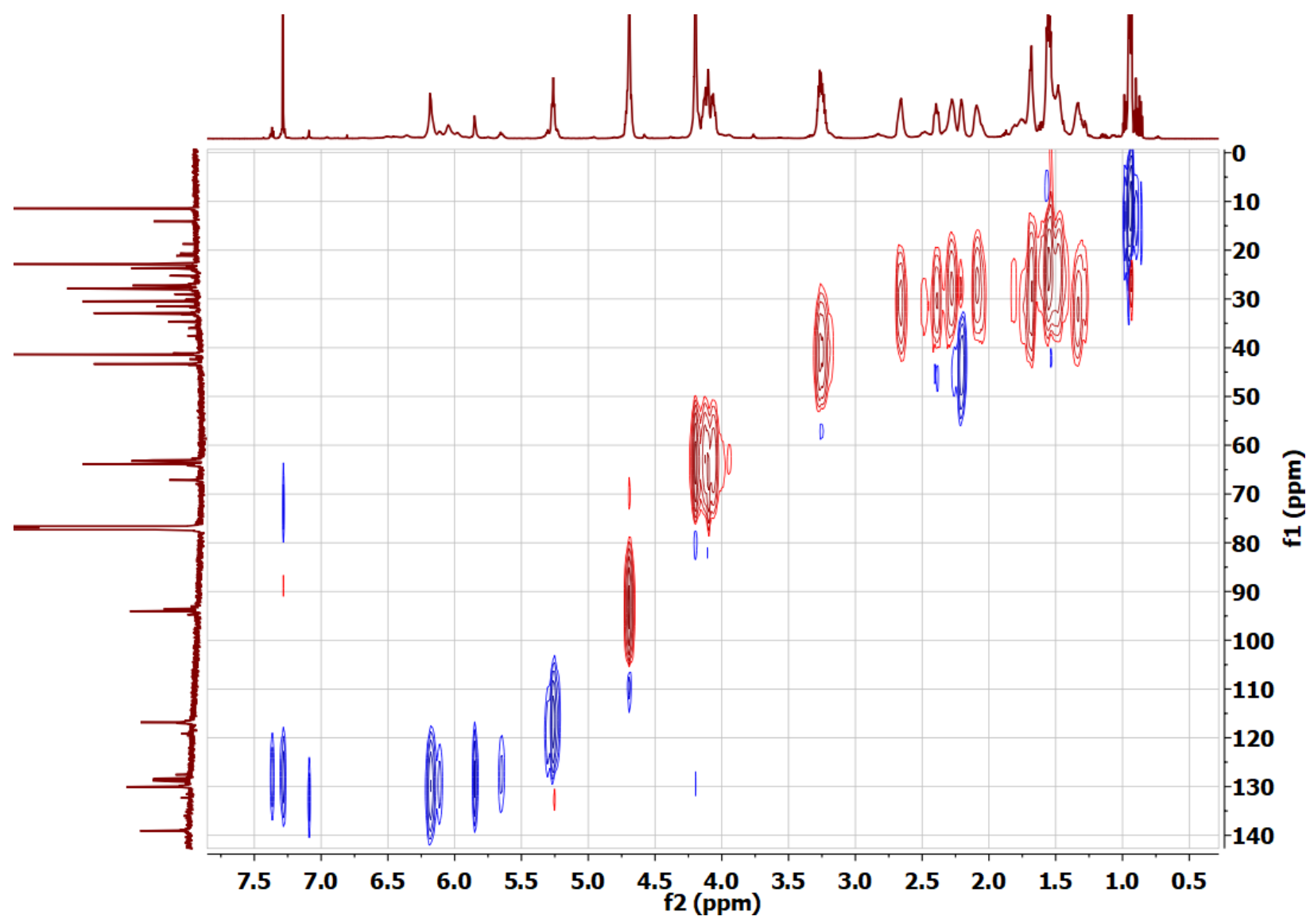

Figure S56 HSQC NMR (700 MHz, CDCl 3 ) of poly(1a-alt-3a $)_{20}$ 


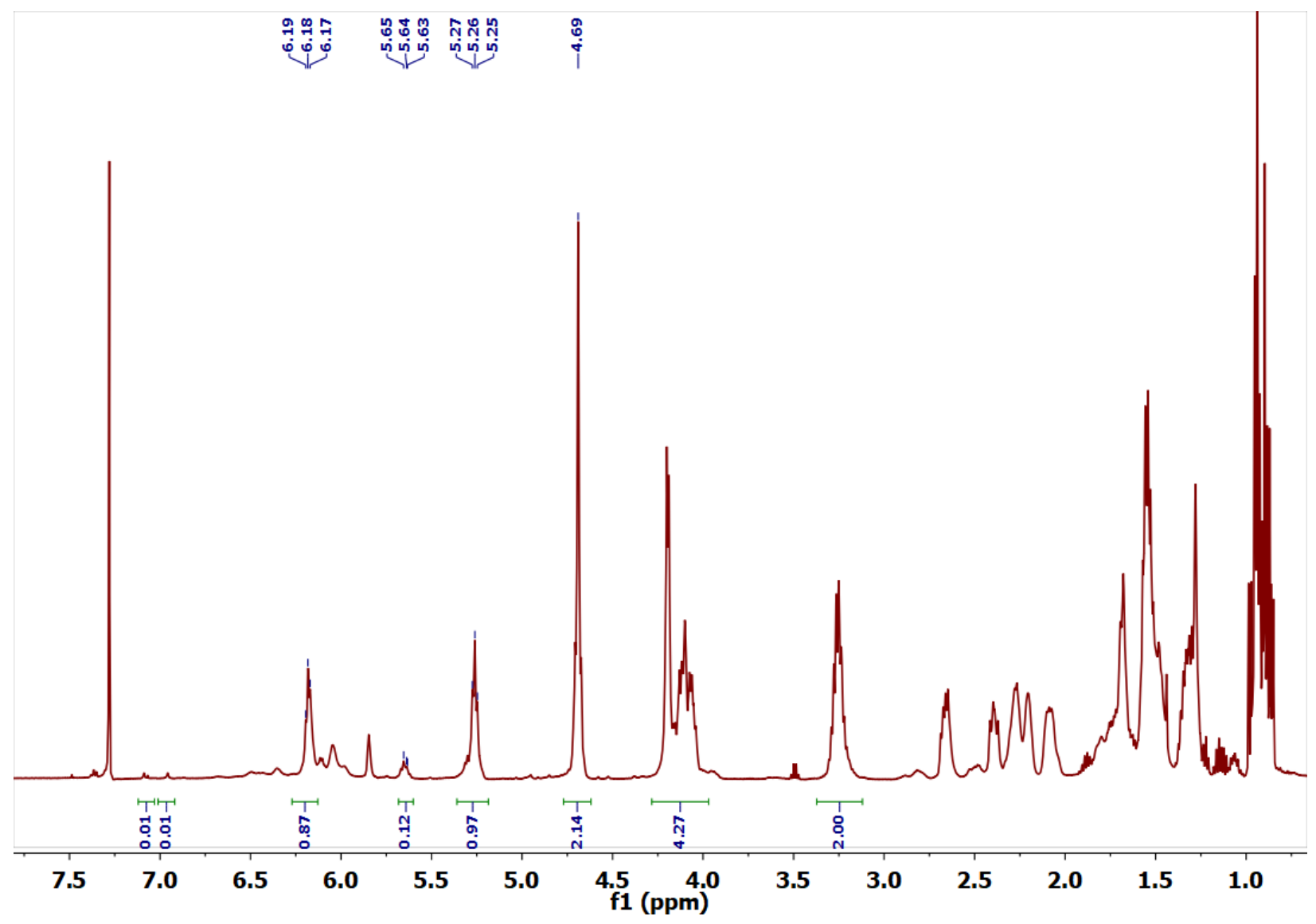

Figure $S 57{ }^{1} \mathrm{H}$ NMR $\left(700 \mathrm{MHz}, \mathrm{CDCl}_{3}\right)$ of poly(1a-alt-3a) $)_{50}$ 


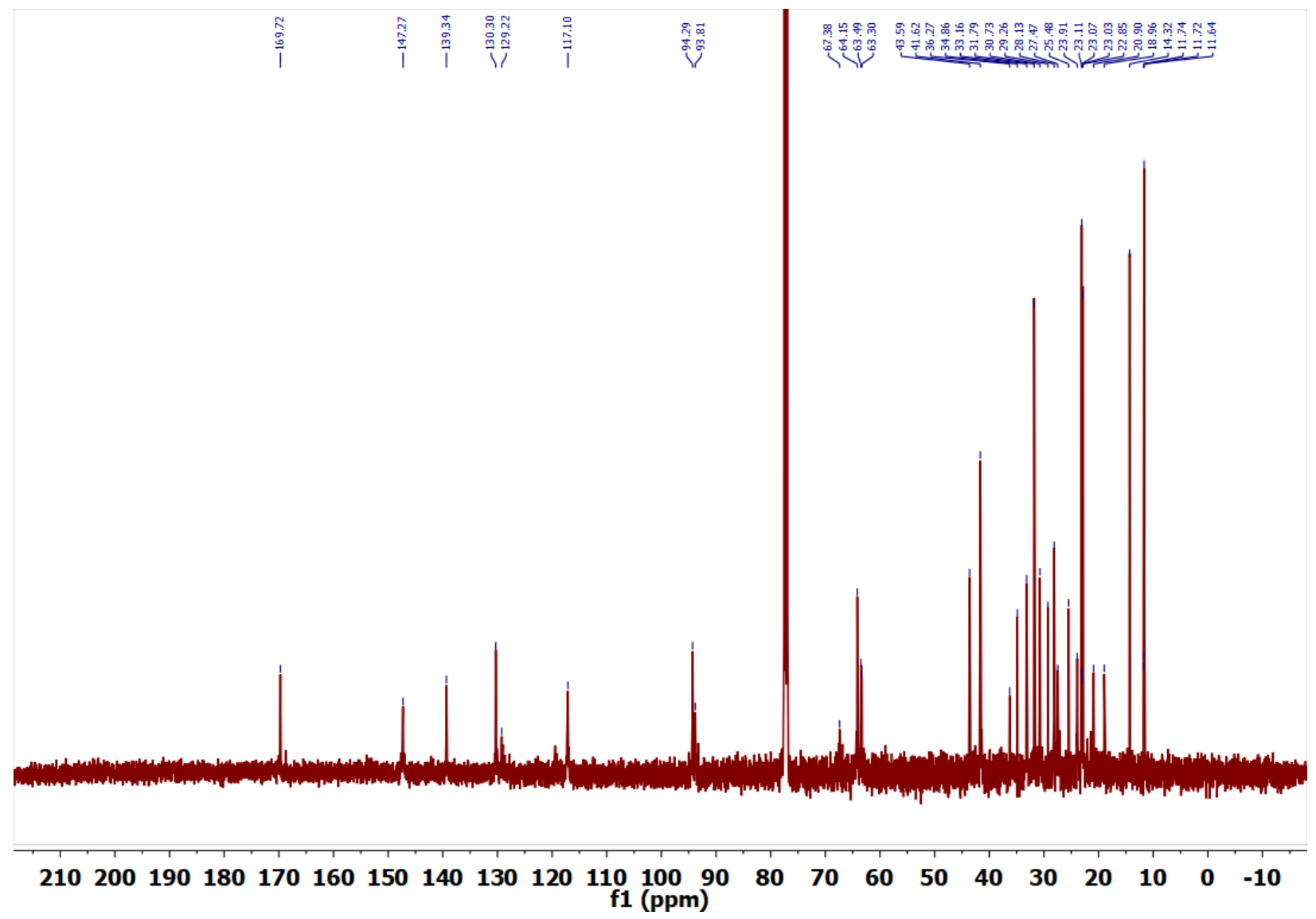

Figure S58 ${ }^{13} \mathrm{C} \mathrm{NMR}\left(700 \mathrm{MHz}, \mathrm{CDCl}_{3}\right)$ of poly(1a-alt-3a) $)_{50}$ 


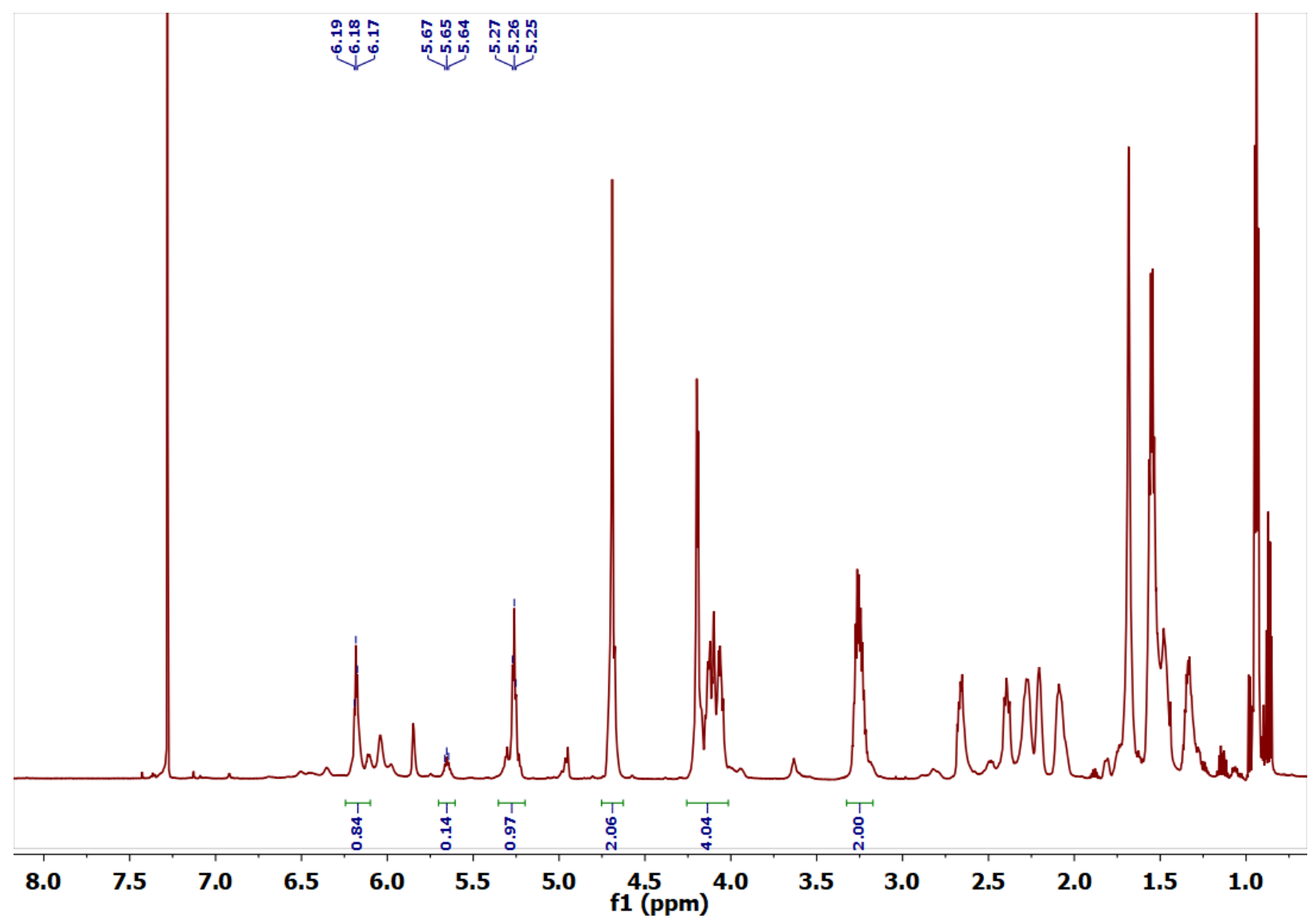

Figure S59 ${ }^{1} \mathrm{H}$ NMR $\left(700 \mathrm{MHz}, \mathrm{CDCl}_{3}\right)$ of poly(1a-alt-3a) ${ }_{100}$ 


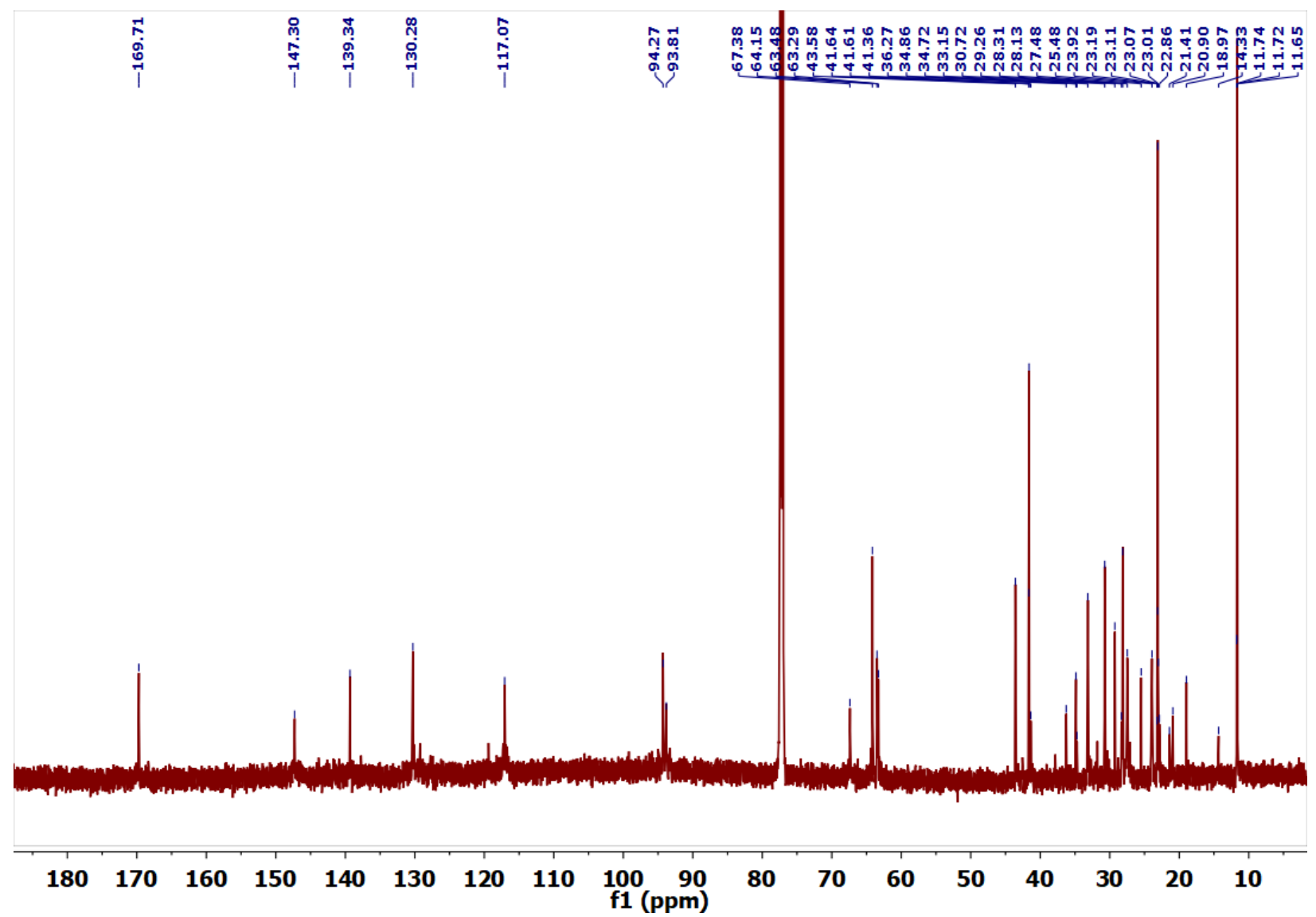

Figure $\mathrm{S} 60{ }^{13} \mathrm{C}$ NMR $\left(700 \mathrm{MHz}, \mathrm{CDCl}_{3}\right)$ of poly(1a-alt-3a) $)_{100}$ 


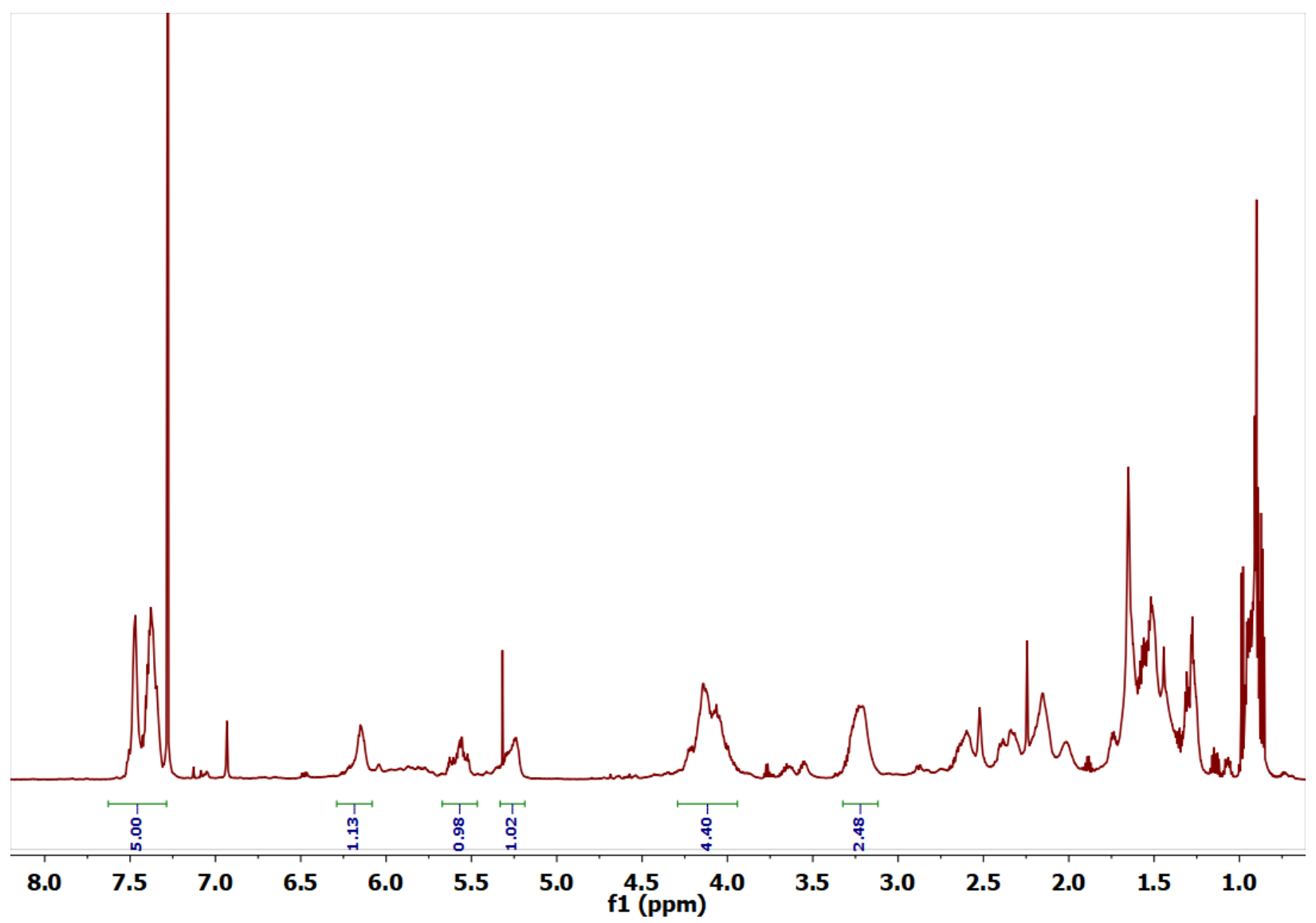

Figure $\mathrm{S} 61{ }^{1} \mathrm{H} \mathrm{NMR}\left(700 \mathrm{MHz}, \mathrm{CDCl}_{3}\right)$ of poly $(1 \mathbf{a} \text {-alt-3b })_{20}$ 


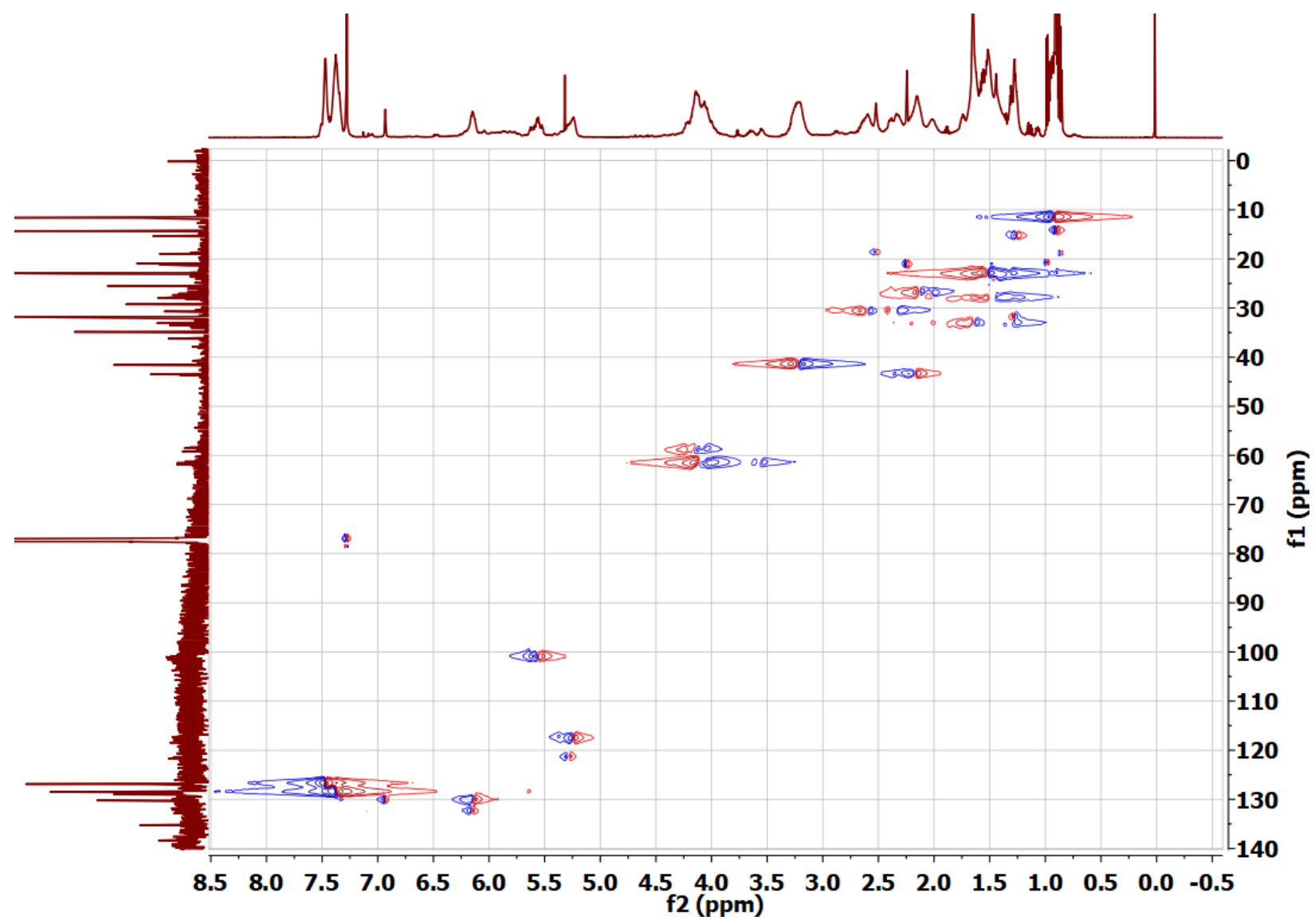

Figure S62 HSQC NMR (700 MHz, CDCl $)$ of poly(1a-alt-3b $)_{20}$ 


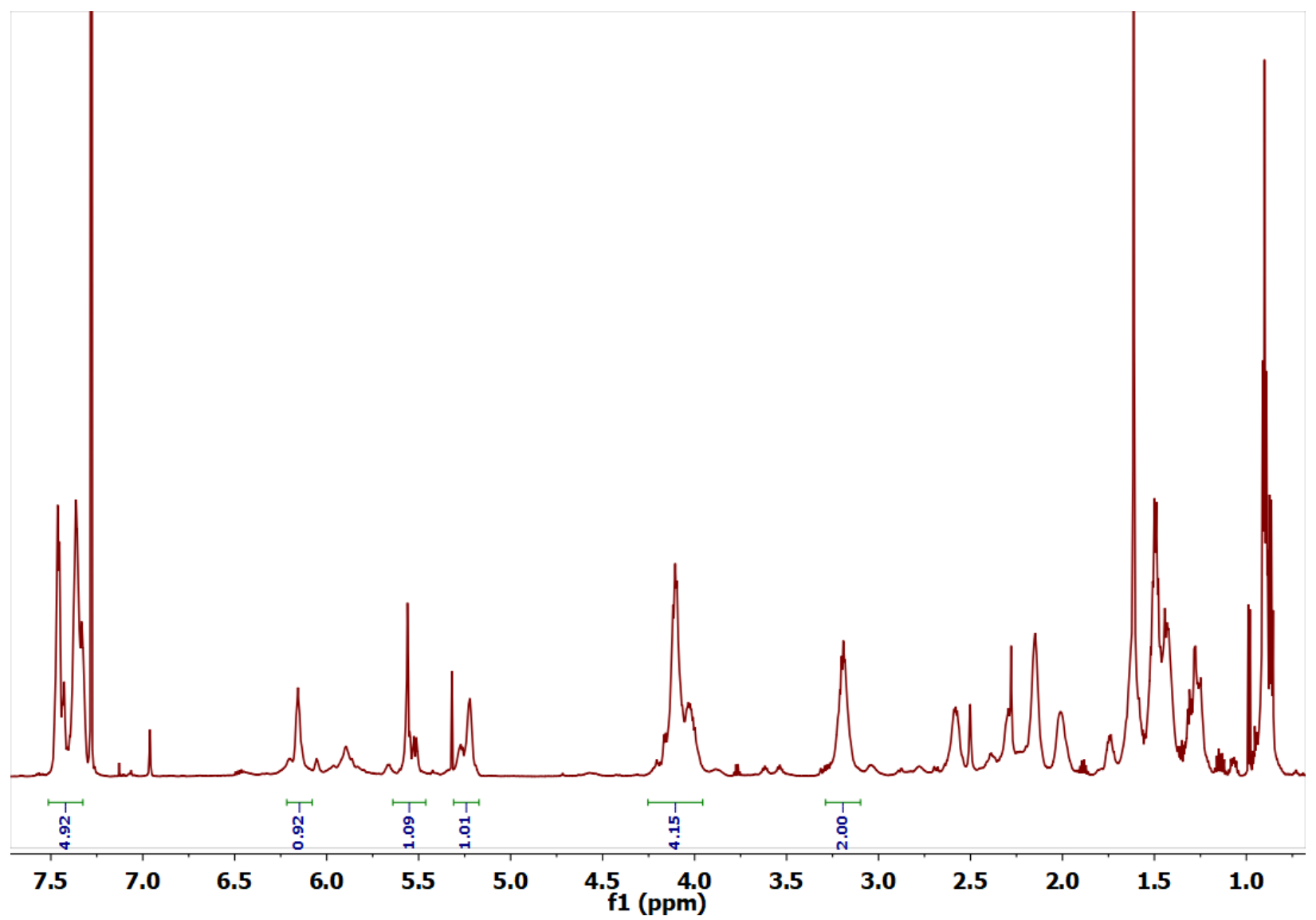

Figure $\mathrm{S} 63{ }^{1} \mathrm{H}$ NMR $\left(700 \mathrm{MHz}, \mathrm{CDCl}_{3}\right)$ of poly $(1 \mathbf{a} \text {-alt-3b) })_{50}$ 


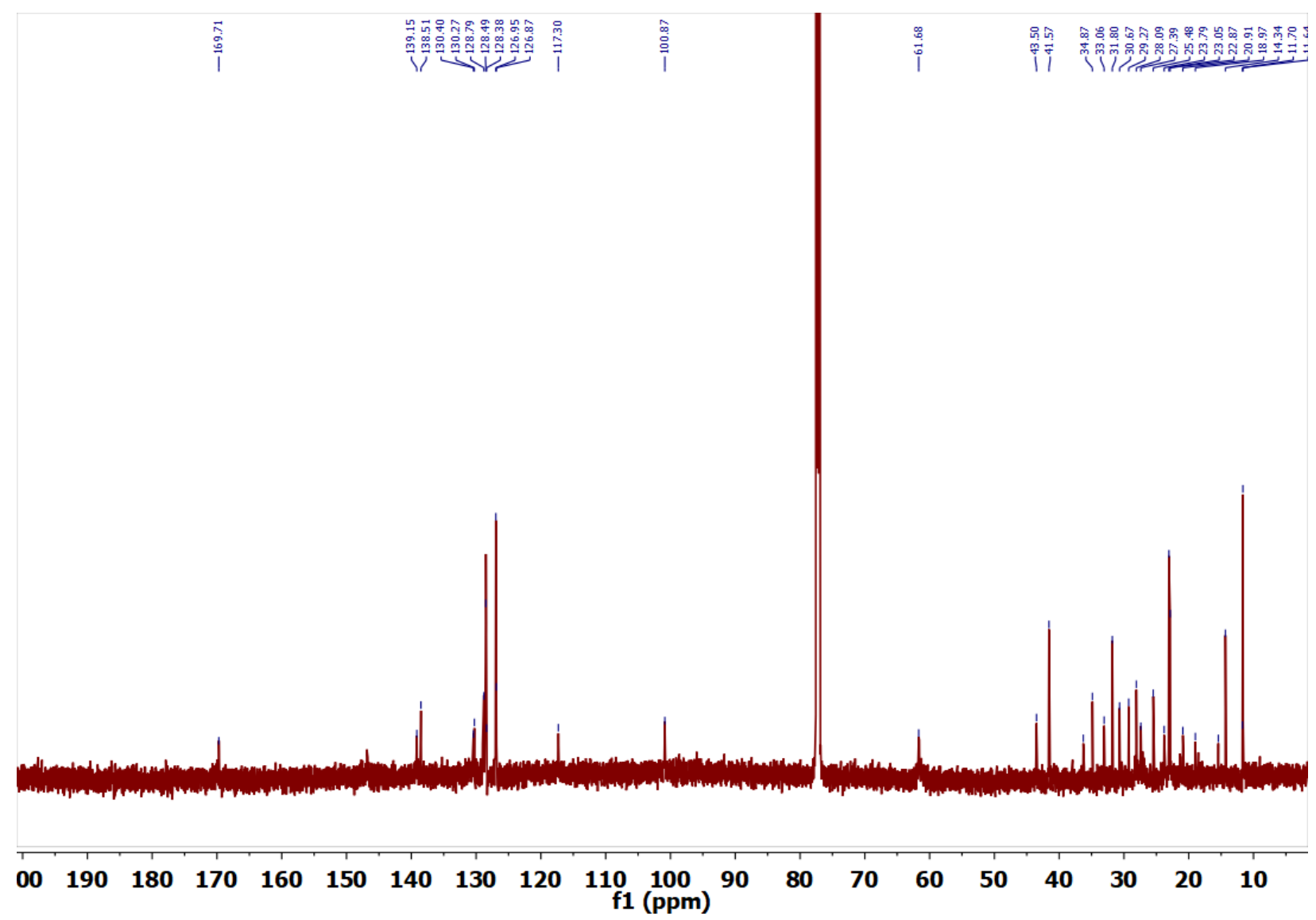

Figure $564{ }^{13} \mathrm{C} \mathrm{NMR}\left(700 \mathrm{MHz}, \mathrm{CDCl}_{3}\right)$ of poly(1a-alt-3b) $)_{50}$ 


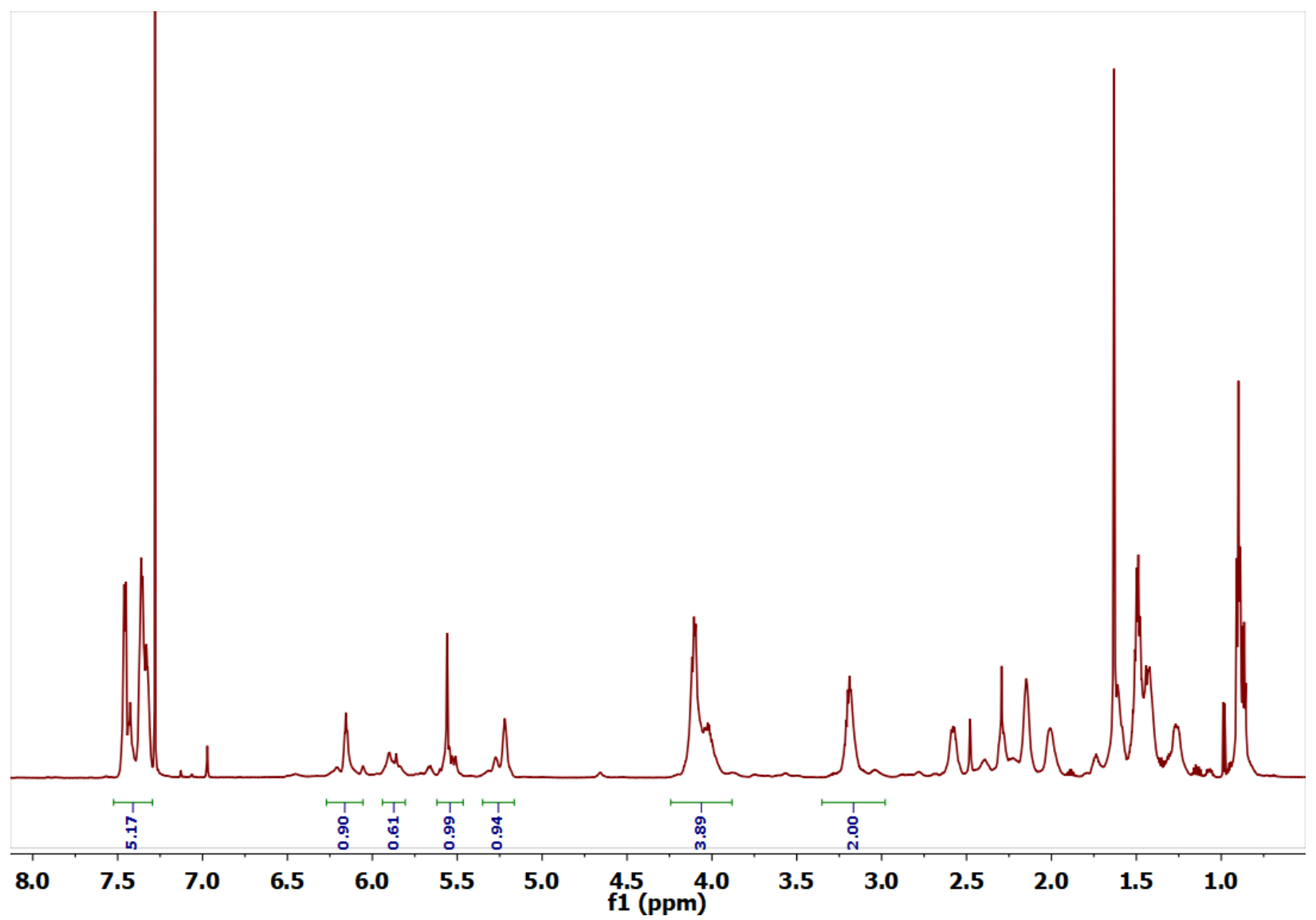

Figure $\mathrm{S} 65{ }^{1} \mathrm{H}$ NMR $\left(700 \mathrm{MHz}, \mathrm{CDCl}_{3}\right)$ of poly $(\mathbf{1 a} \text {-alt-3b })_{100}$ 


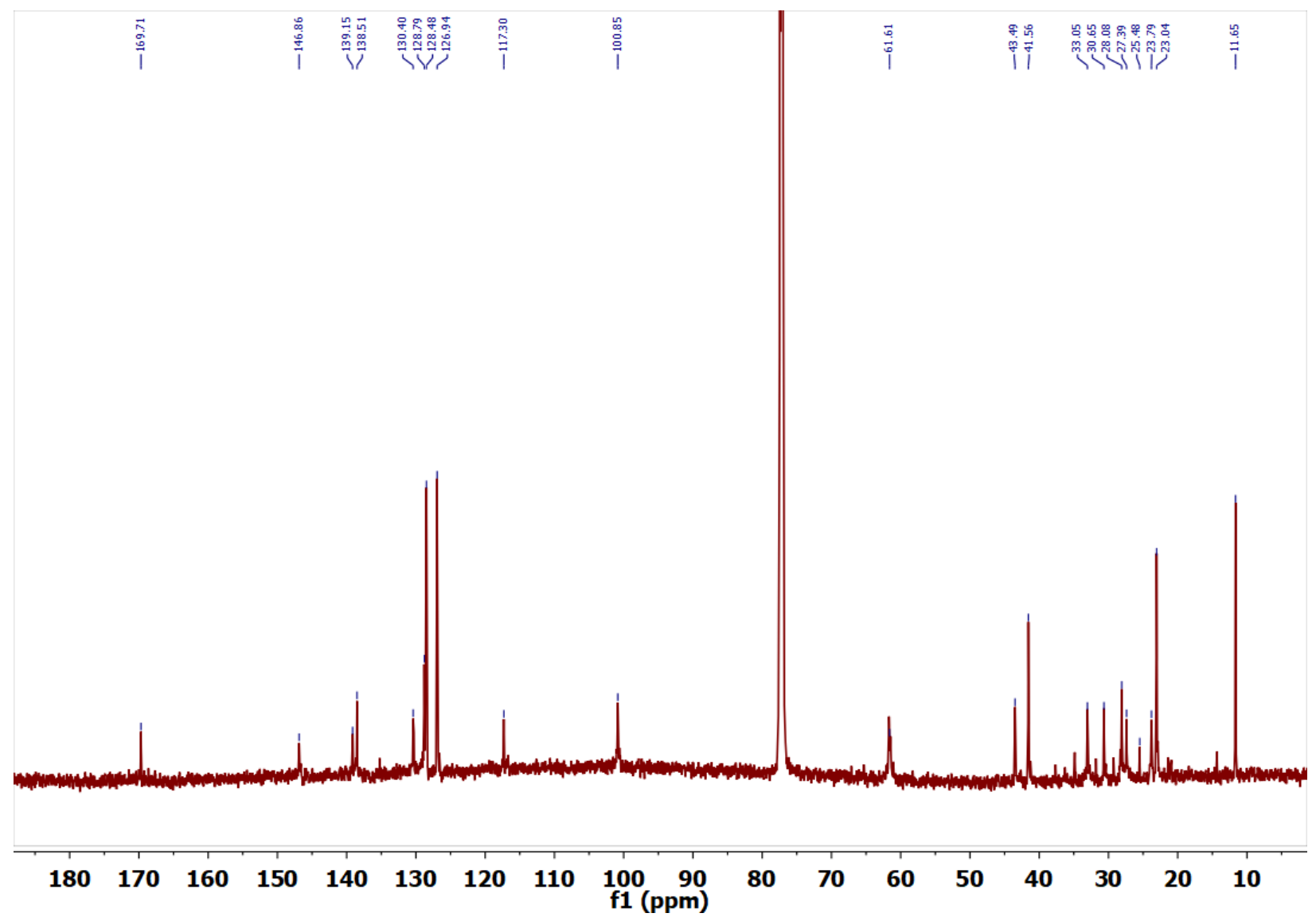

Figure S66 ${ }^{13} \mathrm{C}$ NMR $\left(700 \mathrm{MHz}, \mathrm{CDCl}_{3}\right)$ of poly(1a-alt-3b) $)_{100}$ 


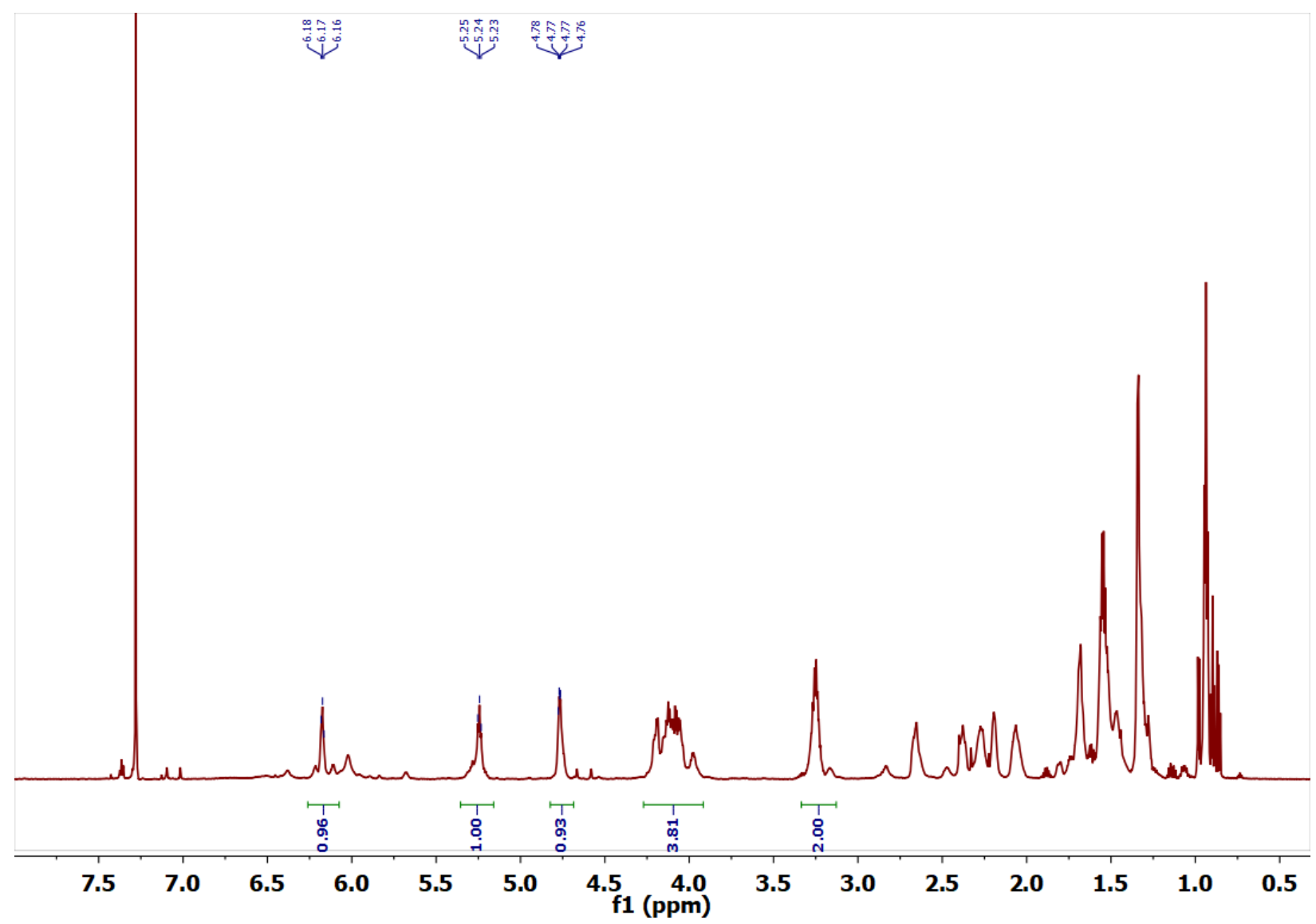

Figure $S 67{ }^{1} \mathrm{H} \mathrm{NMR}\left(700 \mathrm{MHz}, \mathrm{CDCl}_{3}\right)$ of poly $(1 \mathrm{a}-\text { alt-3c })_{20}$ 


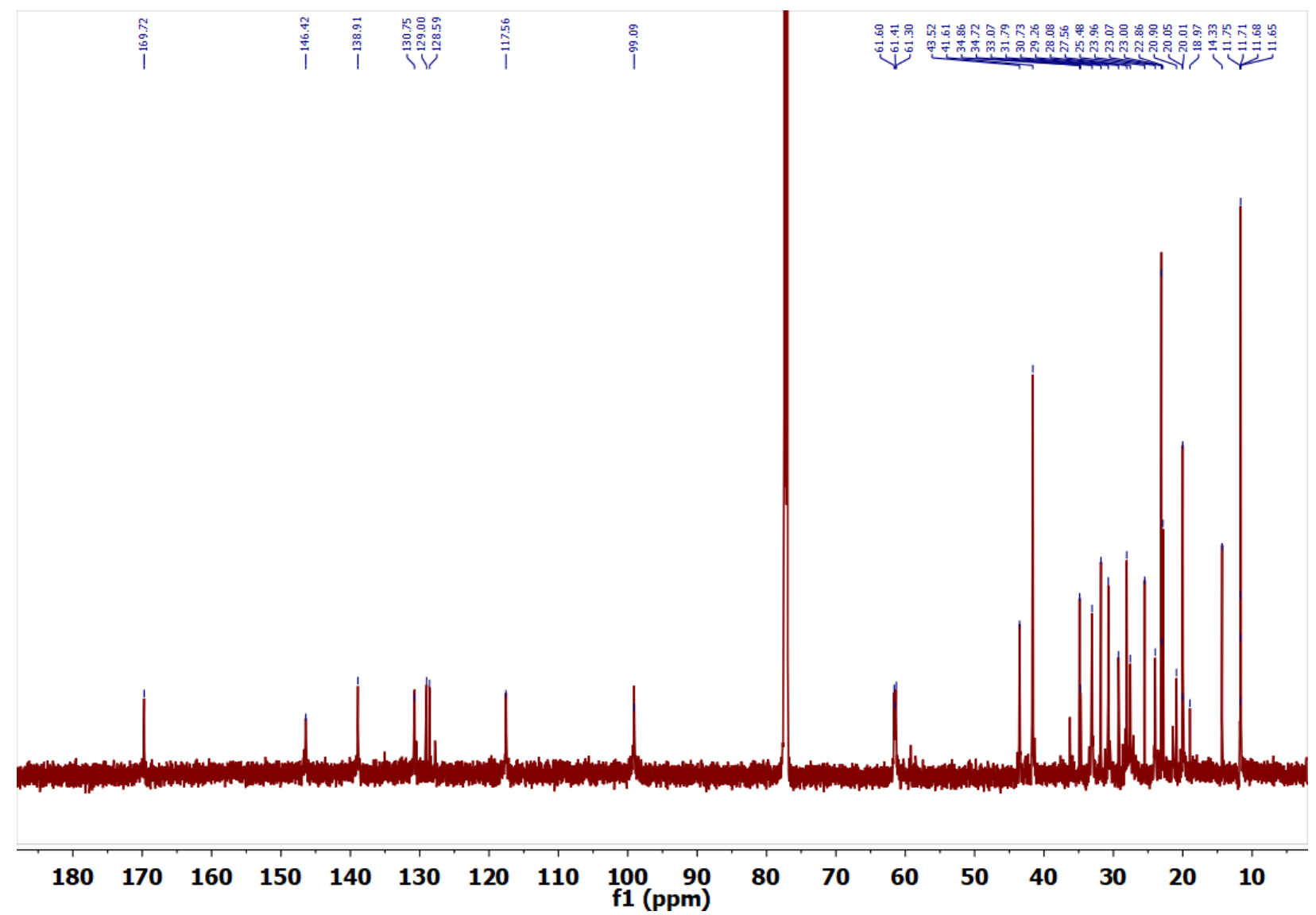

Figure $\mathbf{S 6 8}{ }^{13} \mathrm{C} \mathrm{NMR}\left(700 \mathrm{MHz}, \mathrm{CDCl}_{3}\right)$ of poly(1a-alt-3c $)_{20}$ 


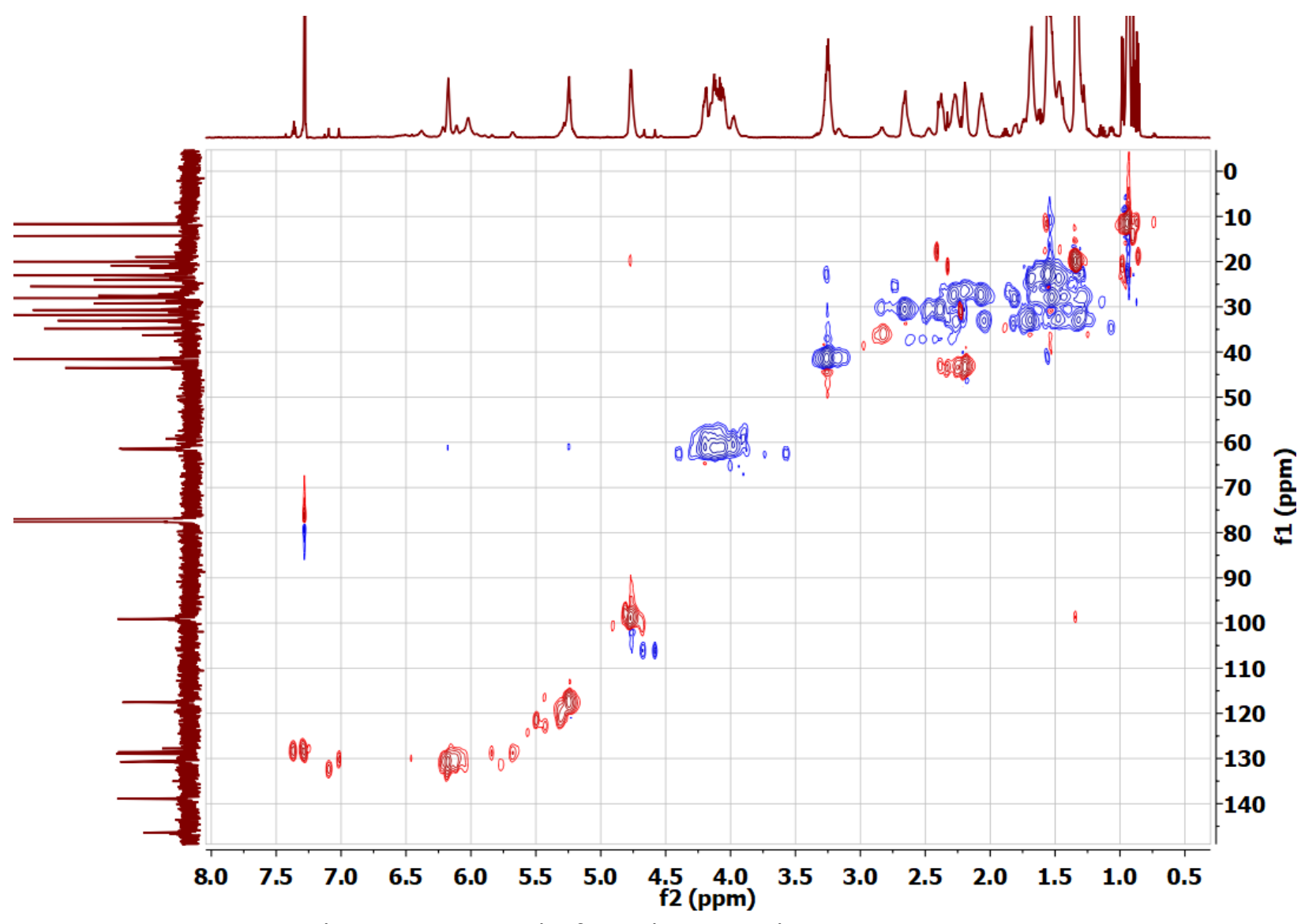

Figure S69 HSQC NMR (700 MHz, CDCl 3 ) of poly(1a-alt-3c $)_{20}$ 


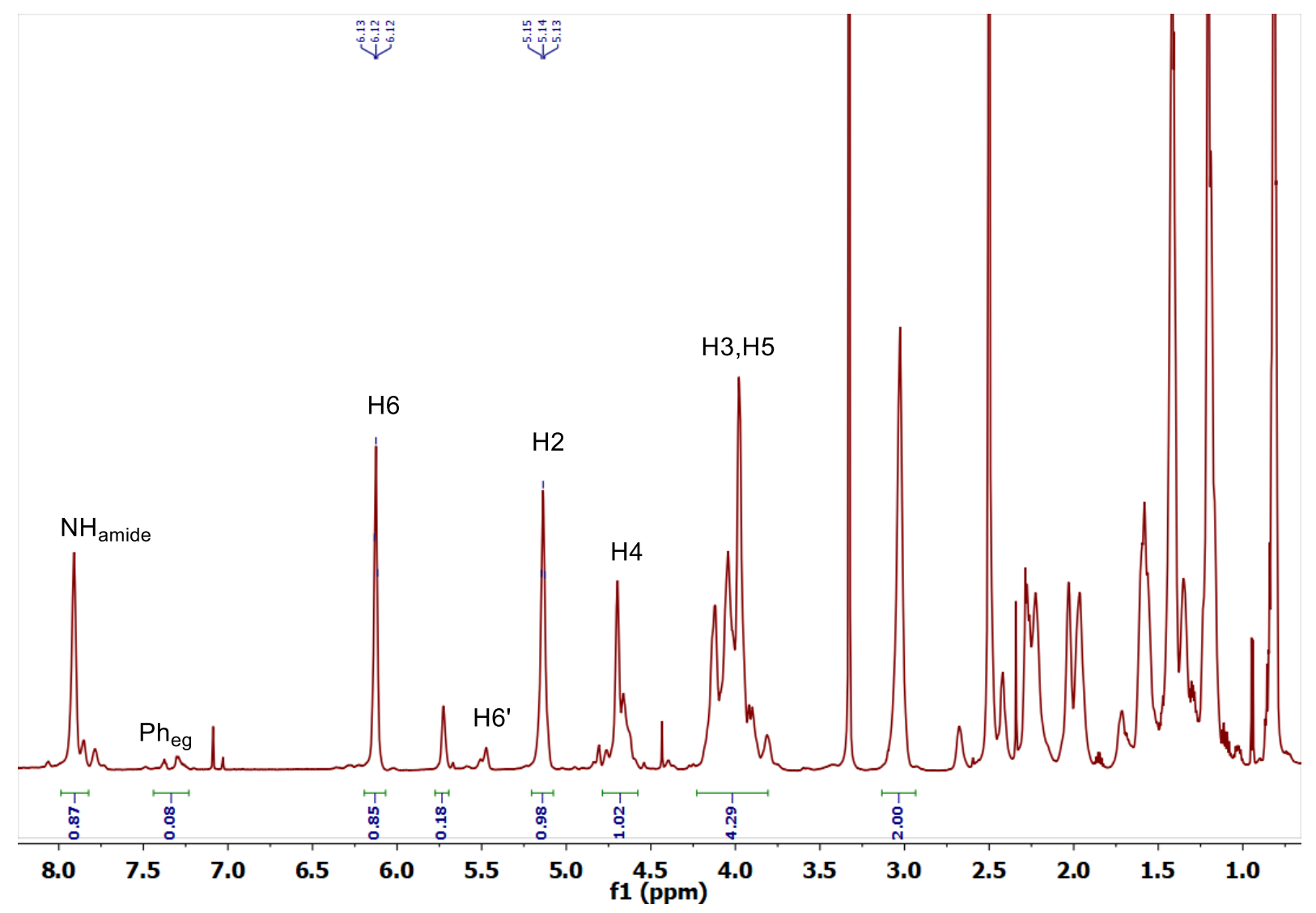

Figure $570{ }^{1} \mathrm{H}$ NMR $\left(700 \mathrm{MHz}\right.$, DMSO-d $\left.\mathrm{d}^{6}\right)$ of poly(1a-alt-3c) $)_{50}$ 


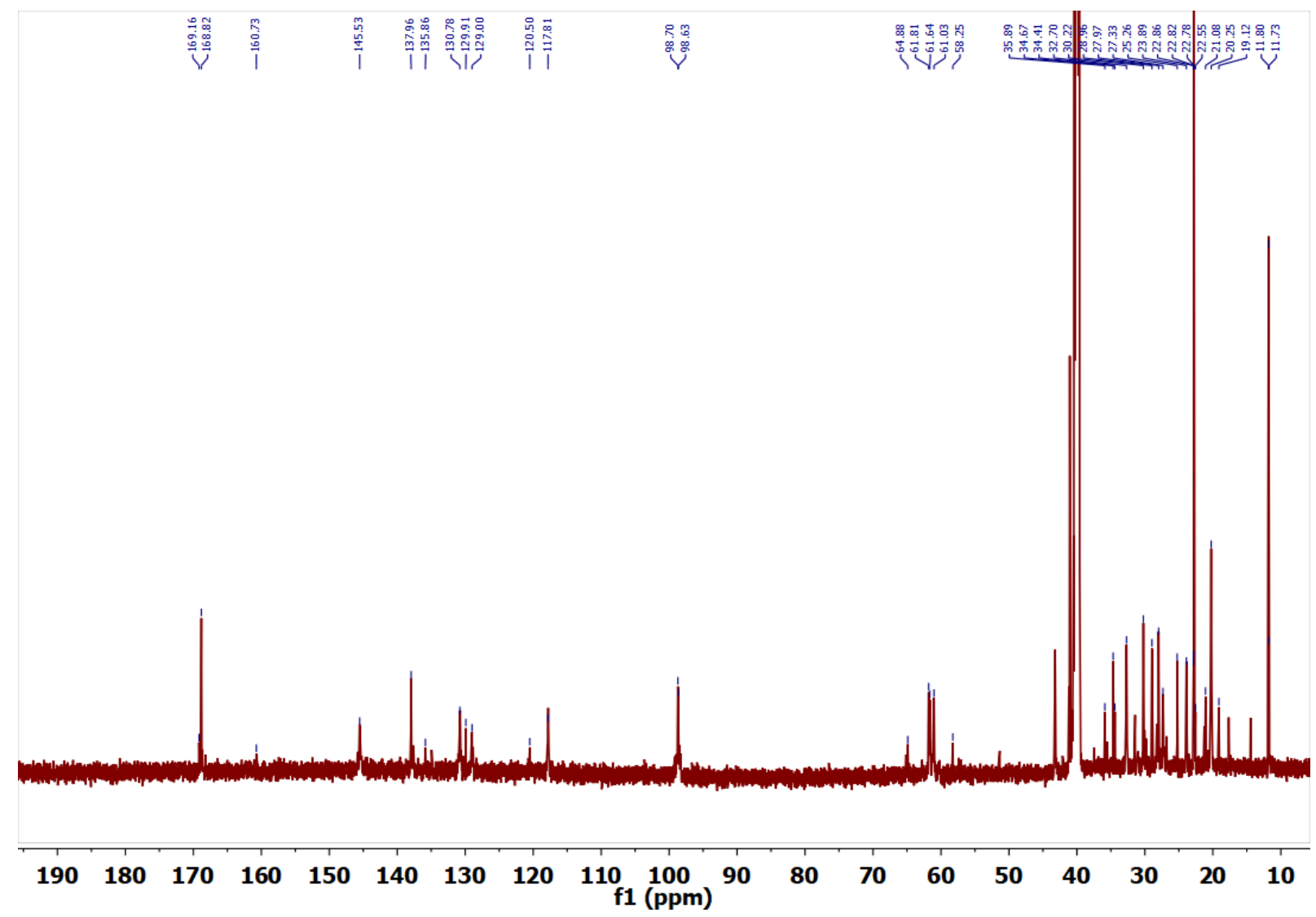

Figure S71 ${ }^{13} \mathrm{C}$ NMR $\left(700 \mathrm{MHz}, \mathrm{DMSO}-\mathrm{d}^{6}\right)$ of poly(1a-alt-3c) $)_{50}$ 


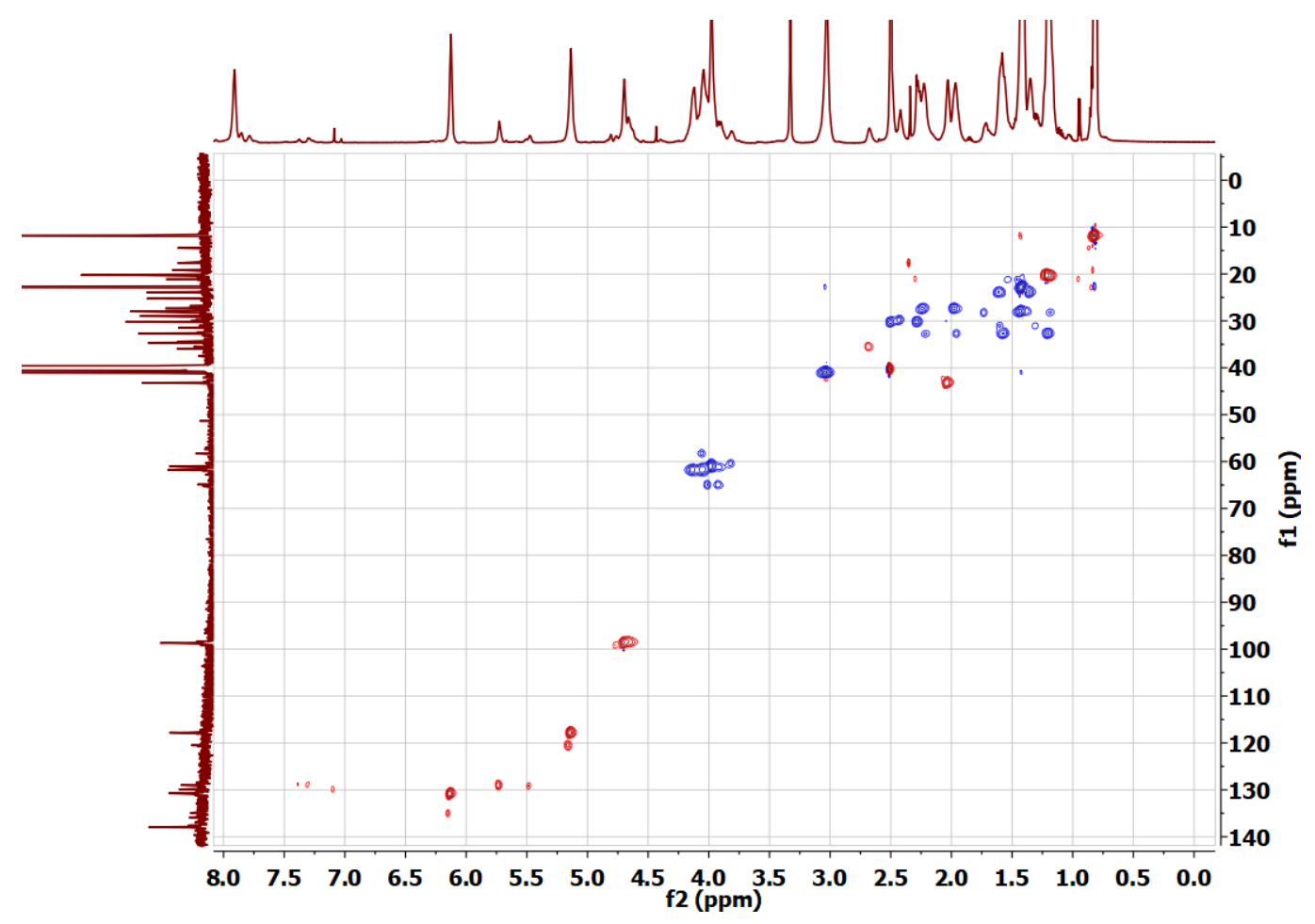

Figure S72 HSQC NMR (700 MHz, DMSO-d $)$ of poly(1a-alt-3c) $)_{50}$ 

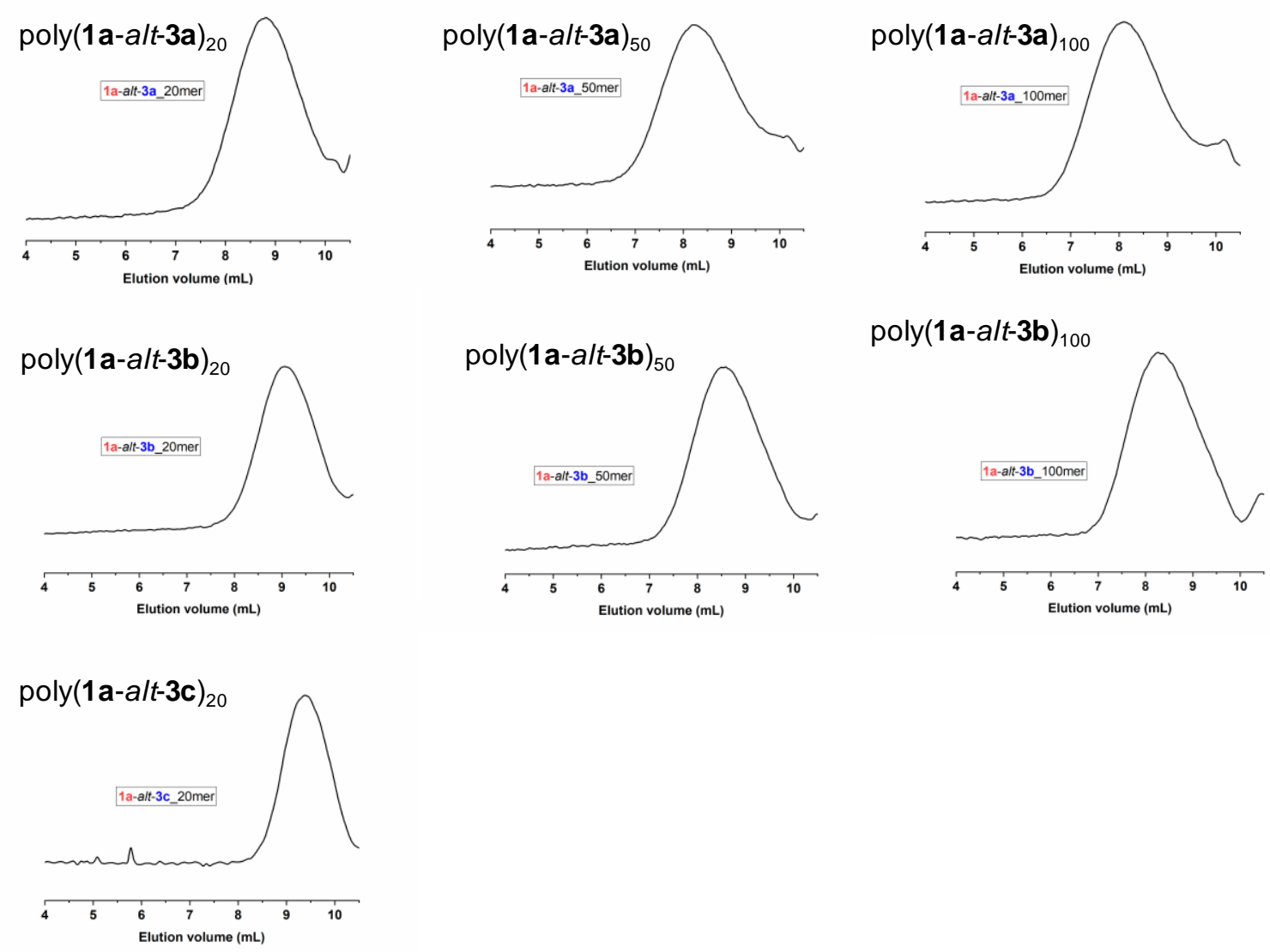

Figure S73 GPC traces of 1-alt-3 copolymers. ...). GPC was acquired on a Phenogel $5 \mu \mathrm{m} 10 \mathrm{E} 4 \mathrm{~A}$ LC column $(300 \times 7.8 \mathrm{~mm}, 5-500 \mathrm{kDa} \mathrm{MW})$ with THF as eluent at a flow rate of $0.7 \mathrm{ml} / \mathrm{min}$ at 30 ${ }^{\circ} \mathrm{C}$ 
Table S1. Copolymers, percentage of dioxepine and MW determined by end-group analysis

\begin{tabular}{|c|c|c|c|}
\hline copolymer & $\begin{array}{l}\% \mathbf{2} \text { or } \mathbf{3} \text { in } \\
\text { copolymer }\end{array}$ & $M W_{\text {Theo }}(\mathrm{kDa})^{\mathrm{b}}$ & $\begin{array}{l}\boldsymbol{M}_{\boldsymbol{n}} \text { by }{ }^{1} \mathrm{H}-\mathrm{NMR} \\
\text { endgroup (kDa) }\end{array}$ \\
\hline$\left(\mathbf{1 a}-\text { alt }_{-2 a} \mathbf{a}\right)_{10}$ & 48 & 3.50 & 4.2 \\
\hline$(\mathbf{1 a}-\text { alt-2a })_{50}$ & 49 & 17.3 & 24.0 \\
\hline$(\mathbf{1 a}-\text { alt }-\mathbf{2} \mathbf{b})_{10}$ & 48 & 3.30 & 7.4 \\
\hline$\left(\mathbf{1 a}-\text { alt }_{-2 \mathbf{2 b}}\right)_{50}$ & 46 & 16.6 & 22.6 \\
\hline$(\mathbf{1 b}-\text { alt-2a })_{10}$ & 51 & 3.90 & 5.9 \\
\hline$\left(\mathbf{1 b}-\text { alt }_{-2} \mathbf{2 b}\right)_{10}$ & 49 & 3.80 & 5.7 \\
\hline$(\mathbf{1 b}-\text { alt }-\mathbf{2 b})_{50}$ & 42 & 18.8 & 19.9 \\
\hline$(\mathbf{1 a}-\text { alt }-\mathbf{3 a})_{20}$ & 52 & 5.89 & 6.16 \\
\hline$(\mathbf{1 a}-\text { alt }-\mathbf{3 a})_{50}$ & 53 & 14.6 & 17.0 \\
\hline$\left(\mathbf{1 a}-\text { alt }^{-3 a}\right)_{100}$ & 51 & $24.9^{\mathrm{c}}$ & 29.05 \\
\hline$(\mathbf{1 a}-\text { alt }-\mathbf{3 b})_{20}$ & 47 & 8.78 & 7.39 \\
\hline$\left(\mathbf{1 a}-\text { alt }_{-} \mathbf{3 b}\right)_{50}$ & 50 & $12.0^{\mathrm{c}}$ & 12.2 \\
\hline$\left(\mathbf{1 a}-a_{l t}-\mathbf{3 b}\right)_{100}$ & 48 & $20.3^{\mathrm{c}}$ & 18.5 \\
\hline$(\mathbf{1 a}-\text { alt }-\mathbf{3 c})_{20}$ & 50 & 6.14 & 6.76 \\
\hline$(\mathbf{1 a}-a l t-\mathbf{3 c})_{50}$ & 52 & 15.4 & 18.4 \\
\hline
\end{tabular}

${ }^{a}$ percent composition of dioxepine in copolymers determined by ${ }^{1} \mathrm{H}-\mathrm{NMR}$ spectroscopy. ${ }^{\mathrm{b}}$ Theoretical molecular weight was calculated from the monomer/catalyst feed ratio. ${ }^{~}$ Theoretical molecular weight after adjustment for conversion 